Article

\title{
A Hybrid Supply Chain Risk Management Approach for Lean Green Performance Based on AHP, RCA and TRIZ: A Case Study
}

\author{
Fatima Ezzahra Essaber ${ }^{1, *}$, Rachid Benmoussa ${ }^{1} \oplus$, Roland De Guio ${ }^{2} \oplus$ and Sébastien Dubois ${ }^{2}$ \\ 1 LISA Laboratory, National School of Applied Sciences of Marrakech, Cadi Ayyad University, \\ Avenue Abdelkrim AL Khattabi, Marrakech 40000, Morocco; benmoussa.ensa@gmail.com \\ 2 ICube Laboratory, National Institute of Applied Sciences of Strasbourg, 24 Boulevard de la Victoire, \\ 67084 Strasbourg, France; roland.deguio@insa-strasbourg.fr (R.D.G.); \\ sebastien.dubois@insa-strasbourg.fr (S.D.) \\ * Correspondence: essaberfatimaezzahra@gmail.com
}

Citation: Essaber, F.E.; Benmoussa, R.; De Guio, R.; Dubois, S. A Hybrid Supply Chain Risk Management Approach for Lean Green Performance Based on AHP, RCA and TRIZ: A Case Study. Sustainability 2021, 13, 8492. https://doi.org/ $10.3390 /$ su13158492

Academic Editor: Nicholas Chileshe

Received: 28 May 2021

Accepted: 21 July 2021

Published: 29 July 2021

Publisher's Note: MDPI stays neutral with regard to jurisdictional claims in published maps and institutional affiliations.

Copyright: (c) 2021 by the authors Licensee MDPI, Basel, Switzerland. This article is an open access article distributed under the terms and conditions of the Creative Commons Attribution (CC BY) license (https:// creativecommons.org/licenses/by/ $4.0 /)$.

\begin{abstract}
The purpose of this research work is to provide supply chain managers with a formal and generalizable approach that furnishes accurate guidelines to achieve a $2 \mathrm{D}$ performance integrating both Lean and Green. Despite the fact that several research works have been conducted in the framework of Lean and Green, at a conceptual level, the relationship between both paradigms is still ambiguous. Furthermore, the literature revealed a lack of relevant and generalizable approaches that explicitly demonstrate how to successfully implement Lean and Green in a relevant and integrated way. Since risks are the main obstacles disrupting performance, this research work addresses the identified gap by proposing a risk management approach (RMA) for Lean Green performance in a supply-chain context. Risk cannot be managed if not well-identified; hence, a rigorous literature investigation was conducted to define this concept in a supply-chain context. Later, risk was introduced into Lean and Green aspects. Subsequently, through a comprehensive review of previous risk identification studies, a novel classification of supply chain risks in a Lean Green context was provided. At a corporate level, risks often include several sources that cannot be treated at once. Therefore, a risk assessment analysis was performed, employing an analytic hierarchy process for its ease of use and broad adaptability. The output of this analysis provides visibility for an organization's position toward performance goals and underlines crucial risks to be addressed. The risk treatment process was upgraded in this approach to a detailed analysis that aims at investigating the root causes behind the prioritized risks. Deployment of the approach on a corporate level revealed that treating a risk may negatively affect treating another. Indeed, thinking Lean is not necessarily Green, which stands with the fact that Lean Green supply chain challenges may outstrip classic optimization methods and techniques; therefore, its management requires innovative approaches. Thereby, our findings support the applicability and efficiency of the Theory of Inventive Problem Solving (TRIZ) in this setting. Although the case study focused on a specific company, the developed framework can be customized to fit different cases.
\end{abstract}

Keywords: Lean; Green; supply chain risk management; AHP; RCA; TRIZ

\section{Introduction}

Several businesses are reluctant to implement Lean Green because they either see it as challenging or have already failed to achieve it. This failure generally results from the misunderstanding of the philosophy behind both paradigms and the lack of a structured and comprehensive framework for Lean and Green [1]. Not only businesses but also some researchers show reticence toward the combination of Lean Green approaches since Lean can have different objectives from Green, which questions the profitability of Lean practices when implementing Green practices [2]. With the growing pressure of society, 
government, and customers regarding the environmental footprint caused by the growing industrialization and associated operations, Lean supply chain managers have been seeking a successful Green implementation in a way that maintains harmony. It is no longer a choice but an obligation to guarantee their sustainability.

Lean can be a significant mainstay to achieve Green goals in terms of cost and waste minimization, carbon footprint reduction, and enhancement of brand image, cost saving, and environmental responsibility with respect to transportation [3]. Lean production contributes to emissions reduction and pollution prevention as it is associated with greater reduction of resources [4]. The use of Lean manufacturing improves environmental impacts [5]. Coordinating Lean and Green can bring up several benefits such as improving the process flow, reducing lead times, costs, and regulatory non-compliance risk, improving environmental quality and employee morale and commitment, and also meeting customer expectations [6]. The results of the study conducted in [7] revealed a high correlation of Lean and Green, proving that bi-dimensional performance (integrating Lean and Green) outcome is greater than the sole one (integrating only Lean). Outcomes of the case studies conducted in [8,9] support that Lean and Green supply chain practices are positively associated.

Lean leads to Green, but Green thinking is not necessarily thinking Lean [10]. Lean management can act as a positive catalyzer for environmental performance; nevertheless, at a higher level, its implementation requires a significant commitment of resources, which can divert attention from environmental initiatives [11]. Some Lean aspects and practices are environmentally benign while others are not. Lean practices like respect for people and jidoka help to improve environmental performance while just-in-time (JIT) tools and practices are not necessarily eco-friendly [12]. Just-in-time practice promotes pollution, congestion, and increasing energy and space consumption [13], as well as generation of emissions [14]. Additionally, supply chain variables (plant size, sector, distances) influence how Lean practices will be in line with Green practices. For instance, inventories reduction abets emissions reduction, but when the distance increases in the supply chain, the frequency of replenishment (transportation) increases, which promotes generating carbon dioxide emissions; hence, Lean and Green can be in conflict [15].

The relationship between Lean and Green aspects and practices switches from convergence to antagonism, which highlights the need for an approach that combines both paradigms in a successful way. In the framework of the lean-green combination, the literature emphasizes two categories: autonomous and Lean-based approaches [2]. Within the first category, researchers suggest combining both paradigms in a stand-alone approach. In this context, several Lean-Green parallel/simultaneous models had been developed. These models are generally based on waste management techniques such as waste-reducing techniques (WRT) [16], six sigma and DMAIC [17], and advanced 3R (reduction, reuse, recovery) [18]. Within the second category, researchers proposed to use Lean as a catalyst for the implementation of Green practices through benefiting from the flexibility and adaptability of Lean practices [2]. In this frame, several Lean-Green sequential models had been developed that are generally based on the Value Stream Mapping (VSM) tool [19,20]. Lean approaches such as Kaizen have also been used in this framework [21].

Lean-based approaches require mastery of Lean tools and techniques for high efficiency. Thereby, these methods are not convenient for environments that are not adopting or at least familiar enough with Lean philosophy. On the other hand, both categories of Lean-Green combining approaches utilize generic problem solving as well as performance improvement methods. These methods are effective when seeking a 1D performance but not suitable for a 2D performance. This comes down to the fact that the tools used by these methods are difficult to apply when it comes to a multi-dimensional performance, which seeks to find solutions to potential contradictions instead of tradeoffs. Furthermore, there is a lack of conceptual approaches that combine Lean and Green in the literature since the existing ones are customized in order to complete companies' needs and variables (policies, local culture, and regulations) [2]. 
The gaps above spotlight the fact that despite the existing attempts, "how to successfully implement Lean and Green in the supply chain in a relevant and integrated way" remains unclear. Hence, the main goal of this research work is to provide supply chain managers with a formal and generalizable approach that provides guidelines that allow achieving a 2D performance regardless of the level of adoption of both Lean and Green philosophies.

As risks are often responsible for performance failure, we hypothesize that a risk management approach (RMA) could be a relevant solution to disclose ambiguity and address the research gaps above. Risk management is defined by the coordination of activities with a view to control and direct an organization regarding risk. This process takes part in leadership and governance and contributes to management systems' improvement. Furthermore, managing risk takes into consideration the internal and external context of an organization, including cultural factors and human behaviors, and it takes part in all associated activities. Risk management also includes the interaction with stakeholders [22]. These aspects are absent for the proposed approaches in the literature. Supply chain risk management aims at recognizing and preventing (with appropriate actions) SC's potential uncertainties. Four basic categories construct SCRM: risk sources, risk drivers, risk consequences, and risk mitigation strategies [23].

The aim of this study is to verify the previous hypothesis. In this context, secondary research questions will be addressed:

$\checkmark \quad$ How to introduce the concept of risk into Lean and Green aspects?

$\checkmark$ How to identify, assess, prioritize, and treat these risks in the context of the Lean Green supply chain?

$\checkmark \quad$ How TRIZ can be applied to deal with potential conflicts that may arise in the context of risk treatment?

The remainder of this article is designed as follows. In the first section (Introduction), we presented a brief review of Lean and Green as well as the investigated relationships between both paradigms. In this section, we underlined the major gaps in previous attempts at a Lean-Green combination. By the end of the section, we presented the research problem we are going to tackle in the present work. In the second section (Supply Chain Risk in a Lean Green context), we define risk in the supply-chain context; then, we introduce this concept into Lean and Green aspects. In the third section (Materials and Methods), we exhibit in detail the steps and methods used to answer the research questions of the previous section. The fourth section of this paper (case study) shows in detail the deployment of the approach we propose at a corporate level. The last sections (Discussion and Conclusion) discuss findings, sum up the main results and contributions of the study, and underline its limitations.

\section{Supply Chain Risk in a Lean Green Context}

\subsection{Risk in the Context of a Supply Chain}

Risk is the effect (deviation from what is expected) of uncertainty on objectives, and it is expressed usually in terms of risk sources, potential events, their likelihood, and consequences [22]. In other words, risk is defined as the expected outcome of uncertain events [24]. The severity and probability of failing to achieve the desired results (outputs) of a process define risk [25]. In the supply-chain context, risks are unexpected and adverse events that may directly or indirectly cause disruption of the supply chain [26]. Probability, frequency, impact of losses, and speed are the most-discussed supply chain risk dimensions [24]. The literature provides different classifications of supply chain risks based on several criteria. From our review analysis, we were able to define the main risk categories that can cover all risk types that should be considered by any company in Figure 1. 


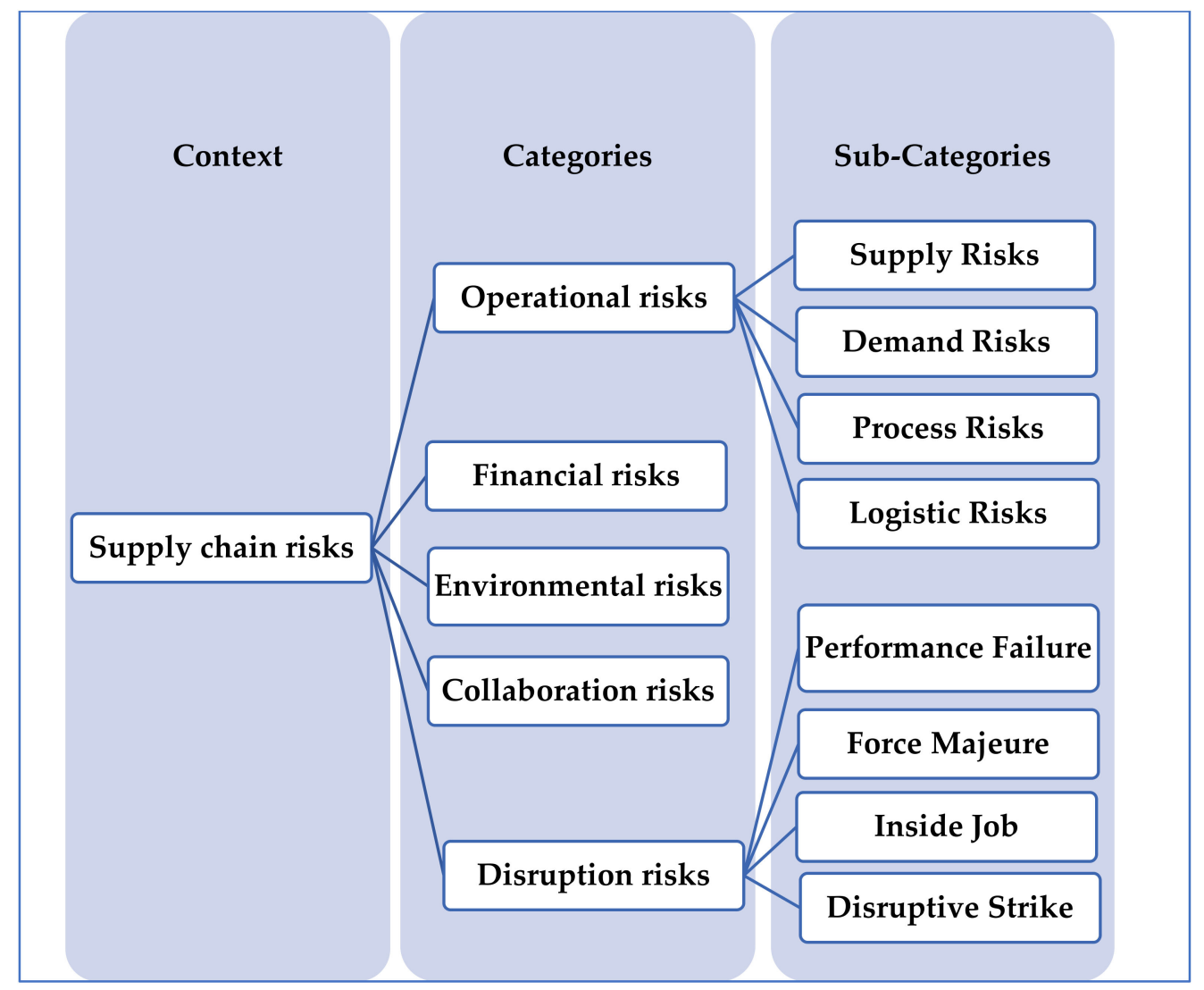

Figure 1. Supply chain risks' classification.

\subsubsection{Operational risks}

a. Supply risk

Supply risk is defined by disappointing and or significant failures associated with inbound services and goods [27]. Supply risk is the likelihood that an incident occurs that leads to a firm's inability to meet customer requirements or threatening customer life and safety. These outcomes can arise from individual supplier failures or market characteristics [28].

\section{b. Demand risk}

Adverse events related to outbound flow that affects customer requirements (desired assortment and volume) and/or the probability of customers placing orders describe demand risk [29]. Demand risks can arise from poor supply chains, coordination and information sharing, forecasting errors, demand volatility, rationing and shortage rumors, and long-term horizons [30].

c. Process risks

Results of adverse events affecting the firm's profitability and ability to produce services and goods as well timeliness and quality of production [24].

\section{d. Logistic risks}

According to a review in [31], material flow creates logistic side risks that can emit from delivery delay, transportation complexity, a wrong choice of transportation mode, transportation infrastructure failure, supply-side constrictions or warehouse problems, improper packaging, cargo damage, natural disasters, labor disputes, and terrorist activities. 


\subsubsection{Financial Risks}

Financial risks are threats that are likely to affect a financial firm's performance. These threats are associated with flows of cash among organizations, embedded costs, the incurrence of expenses and the use of investments for the entire network, accounts payable, settlements and accounts receivable, differing costs of capital and rates of expense incurrence, cash movements and settlements from one firm to the next, changes in currency exchange rates, and changes in accounting and tax laws [31].

\subsubsection{Environmental Risks}

Environmental risks are environmental potential impacts [32]. Environmental risks arise from supply chain disruption that may result from the changes in political environment and regulations, modification and renewal of laws, natural disasters, disease, epidemics, or international terror attacks, according to the investigation in [31].

\subsubsection{Collaboration Risks}

Collaboration risks are associated with the degree of cooperation of supply chain partners, which may give rise to several challenges such as decision-making complexity due to the variety of interests, cultures, and preferences of these partners [31].

\subsubsection{Disruption risks}

Disruption risks come from unexpected events that create changes in a system and disrupt normal activities. These risks can be classified into four major sections: Performance failure (sup-plier bankruptcy, accidents, poor quality controls, scheduling and routing failures, etc.), Force majeure (natural disasters, terrorism, economic disruptions, port closures, political instability, etc.), Inside job (contract breaches, fraudulent quality failures, equipment or product theft, worker strikes, intellectual property theft, etc.) and Disruptive strike (government bans and seizures, competitor litigations, targeted terrorism, piracy, hackers, theft, etc.) [33].

\subsection{Supply Chain Risk Identification in Lean Green Context}

As a risk expresses the deviation from what is expected, risks to be identified are aspects leading to Lean Green performance failure. These aspects are targets that both paradigms aim at reducing/eliminating. Lean aims at reducing wastes [34,35], classified in Table 1, reducing space and improving flexibility [36], avoiding talent waste and underutilization of skills [37], improving staff safety [34], and embracing a continuous improvement mentality [35]. Green seeks efficient energy [38] use, water use [39,40], and raw material use [6,37], reduction of emissions (to air, water, etc.) [41], reduction of solid wastes, scrap, rubbish, and others, as well as the reduction of hazardous wastes and process [41,42].

Table 1. Classification of Lean Japanese wastes [43].

\begin{tabular}{|c|c|}
\hline Waste Type & Definition \\
\hline Muda & $\begin{array}{l}\text { Unsuitable processes and methods, unnecessary motion, } \\
\text { unnecessary transport, overproduction, unnecessary stocks, } \\
\text { waiting, non-quality }\end{array}$ \\
\hline Mura & Variability, unevenness, inconsistency \\
\hline Muri & Overburden \\
\hline
\end{tabular}

At a high level (strategic), Lean seeks performance (optimize cost and quality and maximize value) while Green searches for compliance with the regulations in force, improving the image of the company and distinguishing it from competitors. Both paradigms aim at responding to consumers' and stakeholders' desires. By adapting Lean Green (LG) performance goals into the classification in Figure 1, we could identify supply chain risks for LG performance in Table 2. 
Table 2. Lean Green supply chain risks.

\begin{tabular}{|c|c|c|}
\hline Risk Categories & $\begin{array}{c}\text { Sub- } \\
\text { Categories }\end{array}$ & Risks Associated with Lean Green Performance \\
\hline \multirow{4}{*}{ Operational } & Supply Risks & $\begin{array}{l}\text { Delays, defects, inflexibility, variability, unethical practices, increased environmental } \\
\text { footprint. }\end{array}$ \\
\hline & Demand Risks & Delays, defects. \\
\hline & Process Risks & Over-production, over-processing, defects, delays, inflexibility, variability. \\
\hline & Logistic Risks & $\begin{array}{l}\text { Useless transportation and displacements, useless motion, over-stocking, high space } \\
\text { consumption (for storage and warehousing). }\end{array}$ \\
\hline Financial & Financial Risks & $\begin{array}{l}\text { All wastes can have a direct and or indirect impact on the financial situation through } \\
\text { costs enhancement. }\end{array}$ \\
\hline Environmental & Environmental risks & $\begin{array}{l}\text { Excessive energy use, misuse of water, misuse of raw materials, emissions (to air, } \\
\text { water, etc.), solid wastes, scrap, rubbish, and others, hazardous wastes, and process. }\end{array}$ \\
\hline Collaboration & Collaboration risks & $\begin{array}{c}\text { Overburden, talent waste and underutilization of skills, useless motion, resistance to } \\
\text { changes. }\end{array}$ \\
\hline Disruption & Disruption risks & $\begin{array}{l}\text { Failed customers' and or shareholders' satisfaction, noncompliance with the } \\
\text { regulations, being overtaken by competitiveness, accidents. }\end{array}$ \\
\hline
\end{tabular}

\section{Materials and Methods}

\subsection{Methodology}

With a view to fulfilling the research objectives and building a relevant supply chain risk management approach for Lean Green performance, we adopted steps in Figure 2 inspired from the RMA proposed by the British Standards ISO 31000 version 2018 [22]. The research method consisted of customizing these steps according to a Lean Green performance framework then conducting a real case study with an organization in order to assess the applicability of the developed approach.

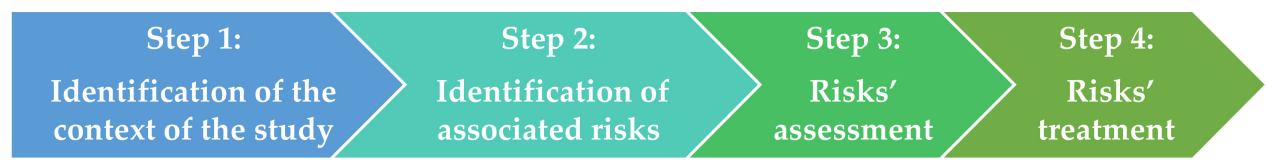

Figure 2. Supply chain risk management process.

\subsubsection{Step 1: Identification of the Context of the Study}

In any risk management approach, decision makers/managers should be clear about the scope and relevant objectives to be considered. Then, risk types that align with the scope and objectives of the organization should be specified in order to customize the context of the study. In this step, we conducted a rigorous literature investigation on supply chain risks in order to provide a classification that aligns with the aim of this research work.

\subsubsection{Step 2: Identification of Associated Risks}

After defining the scope, risks that are likely to prevent the organization from achieving its objectives should be identified. The quality of each step of the supply chain risk management process affects the quality of the subsequent steps. Then, a poor identification of supply chain risks results in an inferior output of the SCRM process [30]. In this step, we identified and then classified risks associated with Lean Green performance according to the classification of the previous step.

\subsubsection{Step 3: Risk Assessment}

The aim behind this analysis is to reveal the nature of risks and their characteristics in order to help decision making about the urgency of treating them. The details and 
complexity of this analysis depend highly on the availability and reliability of information about these risks [22]. In the framework of risk management, the literature provides several methods for risk assessment such as Pareto analysis, failure mode analysis, the likelihoodimpact matrix, and others. The choice of an adequate method relies on risk criteria that decision makers/managers decide to include in the study. Since we took more than three criteria into consideration in our case study, we used the analytic hierarchy process (AHP), which is a multiple-criteria decision-making (MCDM) method. Risk scores obtained using the AHP allow target relevant risks to be prioritized.

\subsubsection{Step 4: Risk Treatment}

This step consists of proposing feasible solutions/strategies for addressing selected risks in the bottom of the step above. Virtually, the likelihood of these solutions beingconflicting is never zero, especially in the framework of Lean Green. Some statements in the introduction section highlight many cases where Lean and Green aspects can be antagonistic. Treating one risk may negatively influence another [44]; hence, in the present work, we managed to conduct a root causes analysis (RCA) to investigate at a micro-level common causes that may unfold the nature of relationships that may exist between risks. Then, we managed to extract action parameters associated with these causes with a view to investigating the impact of their values' variation on desired performance. This led us to the extraction of existing systems of contradictions and the use of the theory of inventive problem solving (TRIZ).

\subsection{Analytic Hierarchy Process}

Relative measurement is a theory in which decision makers are less interested in the exact measurement of quantities than the measurement of proportions between them [45]. This theory is well-suited when it comes to problems of choosing the best alternative. The analytic hierarchy process (AHP) is a methodology for relative measurement; its scope consists of rating alternatives through a pairwise comparison between them, compatible with relative measurement theory [45]. Thomas L. Saaty developed AHP theory from the lack of an easily understood, easy-to-implement, and common methodology that enables making complex decisions [46]. The analytic hierarchy process has found use in several domains due to its simplicity and proven power. AHP makes it easy to understand and subjectively analyze a problem through its hierarchical decomposition into sub-problems [46]. AHP is split into the steps below that we explain in detail according to $[45,46]$.

\subsubsection{Step 1: Building a Hierarchic Structure}

Driving the decision-making process should include criteria that make an alternative preferable to others according to a specific goal. Then, at least a graphical formalism should be afforded in order to combine goals, criteria, and alternatives associated with the decision-making problem. A hierarchy serves this purpose in the AHP as it points out the relationship between elements of one level with others of the next lower level. This relationship permeates down to the lowest levels of the hierarchy, which makes each element connected to all the others, at least indirectly. Figure 3 exhibits a generic hierarchic structure $\forall \mathrm{p}, \mathrm{k} \in \mathbb{N}^{*} \backslash(1,2)$.

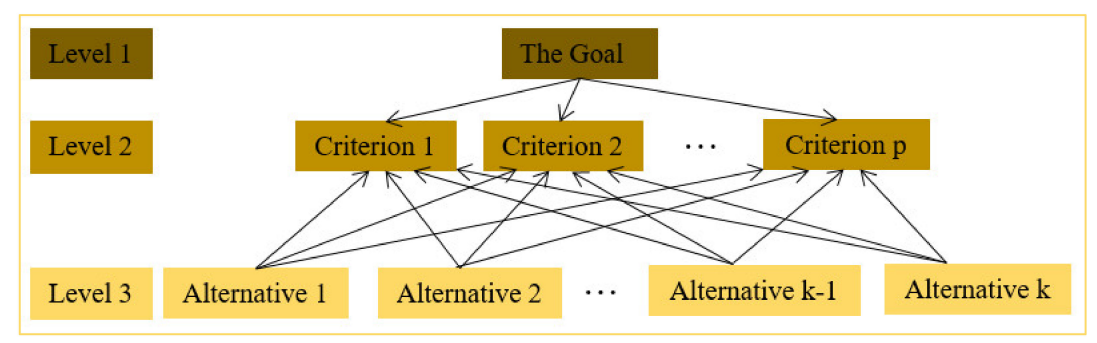

Figure 3. Generic hierarchic structure [46]. 


\subsubsection{Step 2: Driving Pairwise Comparison Matrix}

Experts or decision makers in general assign preferences to all levels of the hierarchical structure in a pairwise comparison of elements on a qualitative scale (see Table 3). The process starts with assigning preferences between criteria first, then between alternatives according to each criterion. Results of the comparison should be organized on a square matrix $\mathrm{A}=\left(\mathrm{a}_{\mathrm{ij}}\right)_{\mathrm{n} \times \mathrm{n}}$ whose diagonal elements are equal to 1 . With aij $=$ the degree of preference of one element $X i$ to another $X_{j}$ such that aij $>0$ and $i$ express columns when $\mathrm{j}$ express rows $\left(\mathrm{i}, \mathrm{j} \in \mathbb{N}^{*}\right)$. Each entry is supposed to approximate the ratio between two weights according to Saaty's theory:

$$
\text { aij } \approx \text { Wi } / \text { Wj } \quad \forall \mathrm{i}, \mathrm{j}
$$

Note that the $(i, j)$ element of the matrix $A$ is the reciprocal of the $(j, i)$ element:

$$
\mathrm{A}=\left(\begin{array}{ccccc}
\text { aij } & =1 / \text { aji } & \forall \mathrm{i}, \mathrm{j} & \\
\vdots & \cdots & \text { aj1 } & \cdots & \text { an1 } \\
\text { a1i } & \cdots & \text { aji } & \cdots & \text { ani } \\
\vdots & \ddots & \vdots & \ddots & \vdots \\
\text { a1n } & \cdots & \text { ajn } & \cdots & \text { ann }
\end{array}\right)
$$

Table 3. Saaty's scale [45,46].

\begin{tabular}{cc}
\hline Definition of Importance & Associated Intensity \\
\hline Equal importance & 1 \\
Weak importance of one over another & 3 \\
Essential or strong importance & 5 \\
Demonstrated importance & 7 \\
Absolute importance & 9 \\
Intermediate values between the two adjacent judgements & $2,4,6,8$ \\
\hline
\end{tabular}

\subsubsection{Step 3: Examining Consistency}

The subjective nature of answers about comparisons may drive inconsistency that is tolerated by AHP at a certain level. Otherwise, if the consistency ratio CR fails, these answers should be revised.

$$
\mathrm{CR}=\frac{\mathrm{CI}(\mathrm{A})}{\mathrm{RIn}}
$$

with:

$$
\mathrm{CI}(\mathrm{A})=\frac{\lambda \max (\mathrm{A})-\mathrm{n}}{\mathrm{n}-1}
$$

such that:

- CR: consistency ratio;

- $\quad$ CI: consistency index;

- $\quad$ RIn: random index (see values in Table 4);

- $\lambda$ max: the maximum eigenvalue of the matrix;

- $\mathrm{n}$ : matrix's order.

Table 4. Random index values for $n=(1,2, \ldots, 10)[45]$.

\begin{tabular}{ccccccccc}
\hline Matrix Order (n) & 3 & 4 & 5 & 6 & 7 & 8 & 9 & 10 \\
\hline Value of RIn & 0.5247 & 0.8816 & 1.1086 & 1.2479 & 1.3417 & 1.4057 & 1.4499 & 1.4854 \\
\hline
\end{tabular}


The consistency ratio CR should be less than 0.1 to claim that the matrix is consistent.

When $n>10$, the random index can be calculated according to the following Equation (5) proposed in [47] such that $\lambda$ is the least-square adjustment straight line.

$$
\operatorname{RIn}=\frac{\lambda \max (\mathrm{n})-\mathrm{n}}{\mathrm{n}-1}
$$

with

$$
\rtimes \max (n)=2.7699 n-4.3513
$$

\subsubsection{Step 4: Calculating weight vectors}

From each pairwise matrix, the decision maker should extract the associated weight vector $\mathrm{W}$, which will serve to calculate the final score of each alternative. Several methods had been proposed to calculate the weight vector; in the present work, we choose the sum method, which is very common. Let $A=(\text { aij })_{n \times n}$ be the judgment matrix of order $n$, weight vector $\mathrm{W}=(\mathrm{W} 1, \mathrm{~W} 2, \ldots, \mathrm{Wi}, \ldots, \mathrm{Wn})^{\mathrm{T}}$, such that:

$$
\mathrm{Wi}=\frac{1}{\mathrm{n}} \sum_{\mathrm{j}=1}^{\mathrm{n}} \frac{\mathrm{aij}}{\sum_{\mathrm{k}=1}^{\mathrm{n}} \mathrm{akj}^{\prime}}, \quad \mathrm{i}=(1,2, \ldots, \mathrm{n})
$$

\subsubsection{Step 5: Scoring}

Alternatives are classified according to their scores that are calculated using the following formula:

$$
\text { Salti }=\sum_{\mathrm{k}=1}^{\mathrm{m}} \mathrm{WCk} * \mathrm{~W} \text { alti/ck, } \quad\left(\mathrm{i}, \mathrm{m} \in \mathbb{N}^{*}\right)
$$

such that:

- $\mathrm{S}_{\text {alti }}$ : the score of an alternative $\mathrm{i}$;

- $\mathrm{W}_{\mathrm{Ck}}$ : the weight of a criteria $\mathrm{Ck}$;

- $\mathrm{W}_{\mathrm{alti} / \mathrm{Ck}}$ : the weight of an alternative alti according to a criteria $\mathrm{Ck}$.

\subsection{TRIZ and the Concept of Contradictions}

TRIZ (Teorija Reshenija Izobretateliskih Zadatch), the Russian acronym for the theory of inventive problem solving, is a combination of methods and tools that is based on several assumptions that are derived from dialectics and analysis regarding the evolution of technical systems. TRIZ does not impart solutions, yet it provides guidelines for that [48]. According to one of the TRIZ axioms, the evolution of technical systems can be through the identification and resolution of contradictions [49]. TRIZ defines two types of contradictions: physical contradictions (the direct opposition of two parameters formulated by one and the same system) and technical contradictions (a situation in which the improvement of a parameter A leads to the deterioration of a parameter B) [48]. Both parameters characterizing technical contradictions are labeled evaluation parameters, as they describe the problem to be solved, while the parameter describing the physical contradiction is labeled the action parameter, as it defines a way to act on the problematic situation [50]. TRIZ classical contradiction's system (Figure 4) is limited with more complex problems integrating several evaluation parameters [51]. A generalization of the model (Figure 5) has been defined to overcome this limitation [52]. The generalized model proposes generalized contradiction, whose structure is analogous to the classical TRIZ contradiction by replacing the parameters with concepts that define the logical combinations of values and variables. For the generalized physical contradiction, an action parameter turns into a set of action parameters, and values turn into concepts, while for the generalized technical contradiction, an evaluation parameter turns into a set of evaluation parameters.

- TC: Technical contradiction;

- GTC: Generalized technical contradiction. 


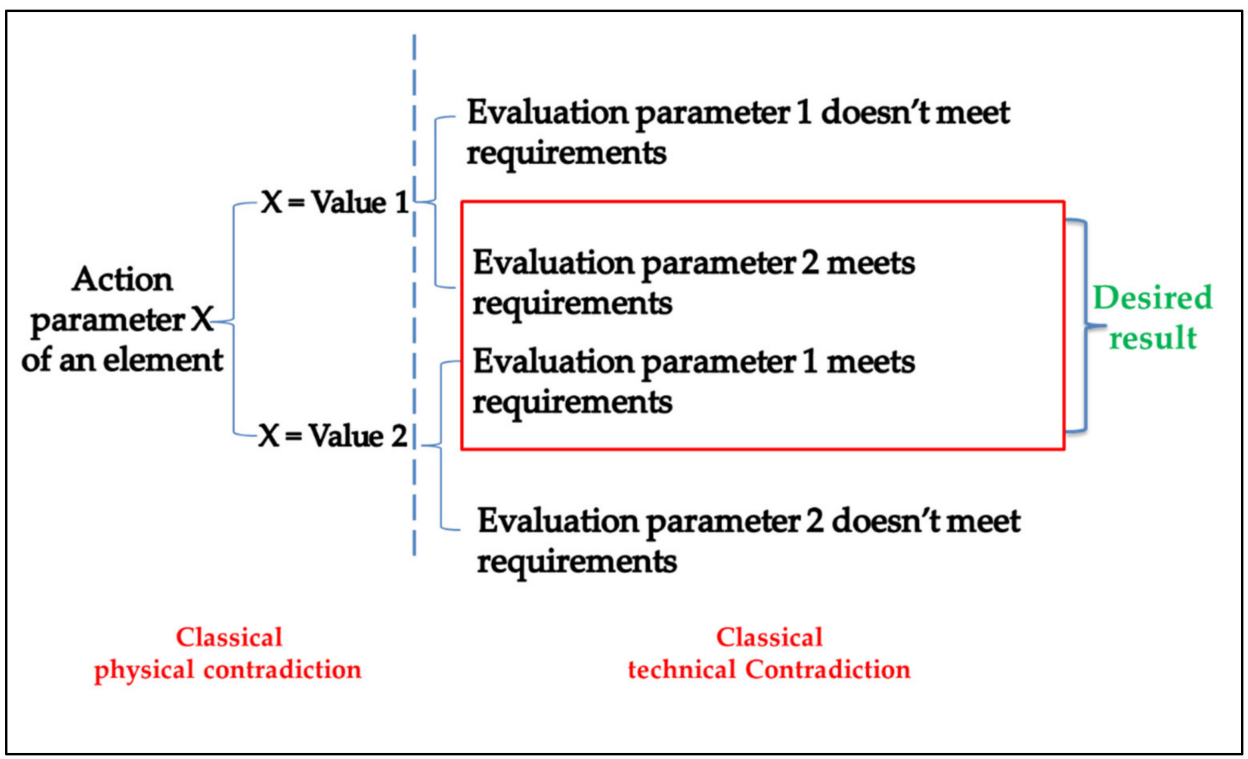

Figure 4. Classical TRIZ system of contradiction [51].

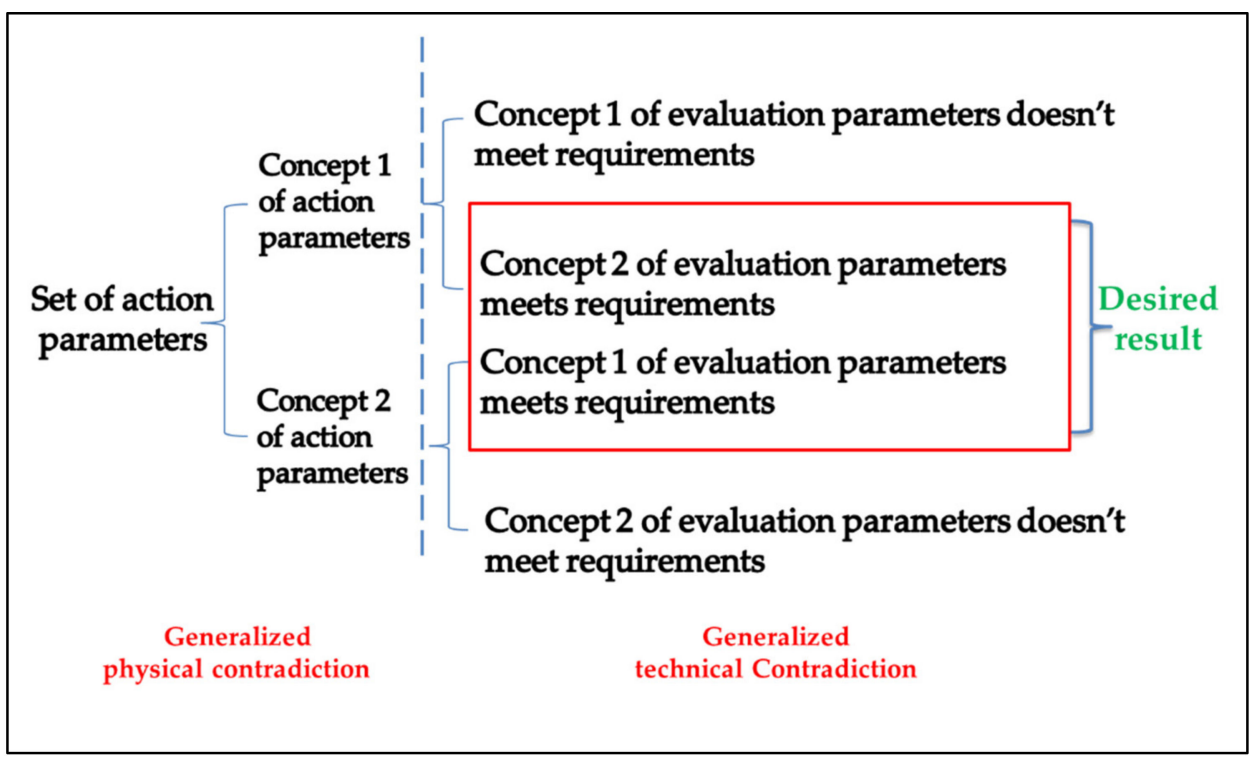

Figure 5. Generalized TRIZ system of contradiction [51].

The resolution of classical physical contradictions can be performed through using separation principles, while the resolution of classical technical contradictions can be performed through using the matrix of 40 principles developed by Genrich Altshuller [53].

\section{Case Study and Results}

\subsection{General Context (Presentation of the Case Study)}

A food company based in Morocco produces a variety of products: de-bitter red and green olives, candied black olives, candied apricots, etc., and it is known for the good quality of its products. With the growing pressure of government and stakeholders regarding environmental issues, the company decided to go Green by taking into consideration environmental impacts in all its practices. As a first step of Green implementation, the managers decided to focus on the olives' supply chain. Since the investigation encompasses the whole process from supply to delivery, the scope fits with the classification in Figure 1. 


\subsection{Risk Identification}

We identified risks in the Table 5; associated with the scope above, in accordance with the classification of Lean Green supply chain risks in Table 2.

Table 5. Risk sources associated with Lean Green performance.

\begin{tabular}{|c|c|c|}
\hline Risk Categories & Risk Sources & ID \\
\hline \multirow{9}{*}{ Supply risks } & Delays in delivery & R1 \\
\hline & Poor quality of delivered products/defective products & $\mathrm{R} 2$ \\
\hline & $\begin{array}{c}\text { Variability (in terms of desired quality) of delivered } \\
\text { products }\end{array}$ & R3 \\
\hline & Obdurate supplier (flexibility issues) & $\mathrm{R} 4$ \\
\hline & Unethical supplier practices & R5 \\
\hline & Increased environmental footprint & R6 \\
\hline & Dependence on a single supplier & R7 \\
\hline & Fluctuations in suppliers' capacity & $\mathrm{R} 8$ \\
\hline & Lack of technical experience & R9 \\
\hline \multirow{2}{*}{ Demand risks } & Customer complaints about delivery times & R10 \\
\hline & Customer complaints about quality & R11 \\
\hline \multirow{14}{*}{ Process risks } & $\begin{array}{l}\text { Overproduction (produce more features than requested } \\
\text { by the customer) }\end{array}$ & R12 \\
\hline & $\begin{array}{c}\text { Over-process (waste of time due to the unnecessary } \\
\text { complexity of a process) }\end{array}$ & R13 \\
\hline & Contamination of finished products & R14 \\
\hline & Damaged packaging & $\mathrm{R} 15$ \\
\hline & Erroneous tickets & R16 \\
\hline & Presence of extraneous corps among the fruits & R17 \\
\hline & Presence of fruit particles or pits & R18 \\
\hline & Defective shape/texture & R19 \\
\hline & Defective color & $\mathrm{R} 20$ \\
\hline & Defective size & $\mathrm{R} 21$ \\
\hline & Lack of flexibility in the production chain & $\mathrm{R} 22$ \\
\hline & Variability & $\mathrm{R} 23$ \\
\hline & Bottlenecks & $\mathrm{R} 24$ \\
\hline & Low process capability & $\mathrm{R} 25$ \\
\hline \multirow{11}{*}{ Logistic risks } & Insufficient transport means & $\mathrm{R} 26$ \\
\hline & Insufficient handling means & $\mathrm{R} 27$ \\
\hline & Unnecessary movements of handling equipment & $\mathrm{R} 28$ \\
\hline & Unnecessary movements of people & $\mathrm{R} 2$ \\
\hline & Insufficient space for storage & $\mathrm{R} 30$ \\
\hline & Over-stocking & $\mathrm{R} 31$ \\
\hline & Excessive consumption of surfaces for storage & R32 \\
\hline & Being out of stock/insufficient stock & R33 \\
\hline & Breakdowns/Breakdowns of transport equipment & R34 \\
\hline & Poor performance of logistics operations & R35 \\
\hline & Accidents & R36 \\
\hline
\end{tabular}


Table 5. Cont.

\begin{tabular}{lcc}
\hline Risk Categories & Risk Sources & ID \\
\hline \multirow{2}{*}{ Financial risks } & Price fluctuations & R37 \\
& Increase in customs taxes & R38 \\
& Exchange rates fluctuations & R39 \\
& Economic changes & R40 \\
& Late payments & $\mathrm{R} 42$ \\
& Bankruptcy of clients & $\mathrm{R} 43$ \\
\hline Concurrence & $\mathrm{R} 44$ \\
& Excessive (more than expected) energy use & $\mathrm{R} 45$ \\
& Excessive water use & $\mathrm{R} 46$ \\
& Excessive use of natural resources & $\mathrm{R} 47$ \\
& Excessive waste & $\mathrm{R} 48$ \\
& Excessive emissions to air & $\mathrm{R} 49$ \\
& Excessive emissions to water & $\mathrm{R} 50$ \\
& Lack of upstream water treatment & $\mathrm{R} 51$ \\
& No downstream water treatment (water used) & $\mathrm{R} 52$ \\
\hline Non-compliance with environmental standards & $\mathrm{R} 53$ \\
& Overloading employees & $\mathrm{R} 54$ \\
& Waste of talent and underutilization of skills & $\mathrm{R} 55$
\end{tabular}

\subsection{Risk Assessment}

As described in the methodology section, we decided to use the analytic hierarchy process for risk assessment; results are deployed in the steps below.

\subsubsection{Building Hierarchic Structure}

In the present work, the main problem is risk prioritization when alternatives are associated with risks defined in Table 5. Based on the organization's available and reliable information about these risks ( $\mathrm{R} 1, \ldots, \mathrm{R} 64)$, we decided to focus on the following criteria:

- $\quad$ C1: Frequency (occurrence of a risk);

- C2: Gravity (degree of damage that a risk can cause if it occurs);

- C3: Detectability (ability to detect risk's occurrence);

- C4: Degree of importance of a risk according to organization's policy.

The formalism of our decision-making problem is built in the graphic structure in Figure 6 . 


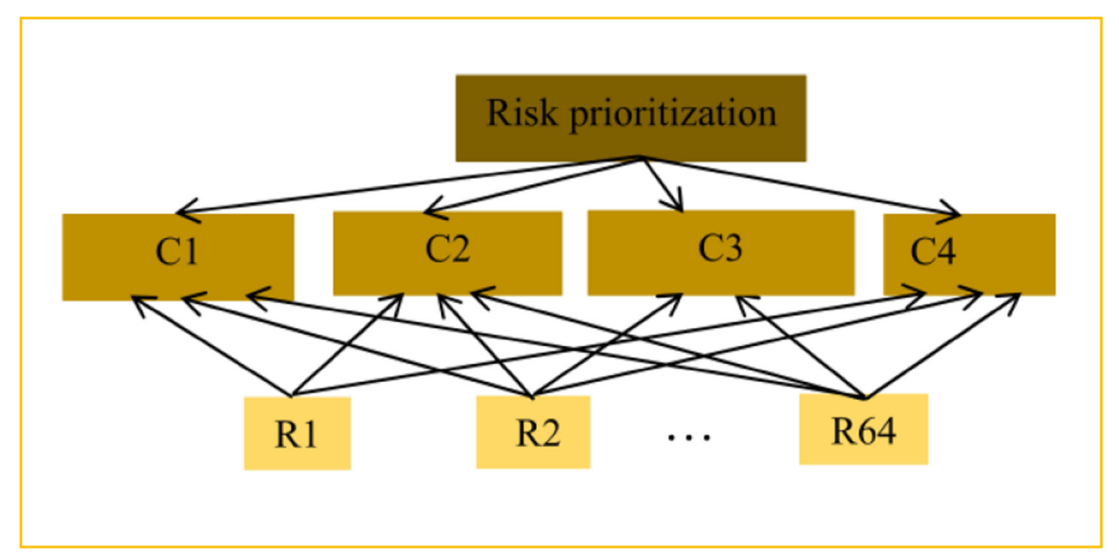

Figure 6. Hierarchic structure for the olives' supply chain.

4.3.2. Driving Pairwise Comparison Matrix

Assigning Preferences between Criteria:

The results of comparison between criteria resulted in the matrix below (A).

$$
A=\left(\begin{array}{cccc}
1 & 1 & 2 & 2 \\
1 & 1 & 2 & 2 \\
1 / 2 & 1 / 2 & 1 & 1 \\
1 / 2 & 1 / 2 & 1 & 1
\end{array}\right)
$$

Assigning Preferences between Alternatives According to Each Criterion:

After assigning preferences between criteria, in this section, we assign preferences between alternatives (risks (R1, . . R64)) according to each criterion (C1, C2, C3, C4). Appendix A exhibits the pairwise comparison matrices of risks according to their: Frequency (C1) (see Tables A1-A3), Gravity (C2) (see Tables A4-A6), Detectability (C3) (see Tables A7-A9) and according to the Organization's policy (C4) (see Tables A10-A12).

\subsubsection{Examining Consistency}

The maximum eigenvalue $\lambda$ max of the matrix $A$ is equal to 4 , and its order $\mathrm{n}$ is equal to 4. Thus, according to Equations (3) and (4), the consistency ratio is equal to zero. The condition $\mathrm{CR}<0.1$ is verified; thus, the matrix $\mathrm{A}$ is consistent.

According to Equations (3)-(6) we calculated the consistency ratio (see Table 6). Results show that for all pairwise comparison matrixes, the $C R<0.1$ which means that all of them are consistent. Note that we calculated values of $\lambda$ max and $\chi$ max using RStudio software.

Table 6. Consistency ratio's measurement.

\begin{tabular}{cccccc}
\hline Criterion & $\lambda$ max & CI & $\lambda \max$ & RIn & CR \\
\hline Frequency & 64.01322 & 0.000209841 & 172.9223 & 1.728925 & 0.000121 \\
Gravity & 64.33781 & 0.005362063 & 172.9223 & 1.728925 & 0.003101 \\
Detectability & 64.06327 & 0.001004286 & 172.9223 & 1.728925 & 0.000581 \\
Policy & 64.19932 & 0.00316381 & 172.9223 & 1.728925 & 0.00183 \\
\hline
\end{tabular}

\subsubsection{Calculating Weight Vectors}

According to the sum method (see Equation (7)), we calculated the weight vectors of each comparison matrix.

$$
\mathrm{WA}=\left(\begin{array}{c}
1 / 3 \\
1 / 3 \\
1 / 6 \\
1 / 6
\end{array}\right)
$$


- $\mathrm{W}_{\mathrm{A}}$ : weigh vector associated with the matrix $\mathrm{A}$ of pairwise comparison between criteria;

- $\mathrm{W}_{\mathrm{C} 1}$ : weigh vector associated with the pairwise comparison matrix between risks (R1, $\ldots$, R64) according to criterion C1, see Table A13 of Appendix B;

- $\mathrm{W}_{\mathrm{C} 2}$ : weigh vector associated with the pairwise comparison matrix between risks (R1, $\ldots$, R64) according to criterion C2, see Table A13 of Appendix B;

- $\mathrm{W}_{\mathrm{C} 3}$ : weigh vector associated with the pairwise comparison matrix between risks (R1, $\ldots$, R64) according to criterion C3, see Table A13 of Appendix B;

- $\mathrm{W}_{\mathrm{C} 4}$ : weigh vector associated with the pairwise comparison matrix between risks (R1, $\ldots$, R64) according to criterion C4, see Table A13 of Appendix B.

The sum of the weights $\mathrm{Wi}$ composing each weight vector of the following: $\mathrm{W}_{\mathrm{A}}, \mathrm{W}_{\mathrm{C} 1}$, $\mathrm{W}_{\mathrm{C} 2}, \mathrm{~W}_{\mathrm{C} 3}$, and $\mathrm{W}_{\mathrm{C} 4}$ is equal to 1 .

\subsubsection{Scoring}

The score $S_{\mathrm{Ri}}$ of each risk Ri is calculated according to Equation (8) as follows. Results of these calculations are presented in Table 7.

$$
\begin{gathered}
\mathrm{S}_{\mathrm{Ri}}=\sum_{\mathrm{K}=1}^{4} \mathrm{Wck} * \mathrm{WRi} / \mathrm{ck} \mathrm{i}=(1, \ldots, 64) \\
\mathrm{S}_{\mathrm{Ri}}=(1 / 3 * \mathrm{~W} \mathrm{Ri} / \mathrm{C} 1)+(1 / 3 * \mathrm{~W} \mathrm{Ri} / \mathrm{C} 2)+(1 / 6 * \mathrm{~W} \mathrm{Ri} / \mathrm{C} 3)+(1 / 6 * \mathrm{~W} \mathrm{Ri} / \mathrm{C} 4)
\end{gathered}
$$

with:

- $\mathrm{W}_{\mathrm{Ck}}$ : the weight of a criteria $\mathrm{Ck}$;

- $\mathrm{W}_{\mathrm{Ri} / \mathrm{Ck}}$ : the weight of an alternative Ri according to a criteria Ck. 
Table 7. Risks' scores.

\begin{tabular}{|c|c|c|c|}
\hline Risks & Scores & Risks & Scores \\
\hline R18 & 0.03095 & R24 & 0.014886 \\
\hline R34 & 0.027849 & R21 & 0.013933 \\
\hline R43 & 0.025678 & R57 & 0.013843 \\
\hline R14 & 0.023385 & R59 & 0.013843 \\
\hline R44 & 0.022076 & R6 & 0.013636 \\
\hline R45 & 0.022076 & $\mathrm{R} 8$ & 0.013636 \\
\hline R36 & 0.02199 & R13 & 0.013636 \\
\hline R58 & 0.021383 & R29 & 0.013577 \\
\hline R42 & 0.021323 & R32 & 0.013577 \\
\hline R33 & 0.020842 & R16 & 0.013567 \\
\hline $\mathrm{R} 10$ & 0.020757 & R60 & 0.013519 \\
\hline R27 & 0.019801 & R62 & 0.013519 \\
\hline R30 & 0.019801 & R48 & 0.012258 \\
\hline R17 & 0.019792 & R54 & 0.011719 \\
\hline R37 & 0.019523 & R55 & 0.011719 \\
\hline R41 & 0.019523 & $\mathrm{R} 4$ & 0.011443 \\
\hline R9 & 0.019354 & $\mathrm{R} 22$ & 0.011443 \\
\hline R64 & 0.019152 & $\mathrm{R} 3$ & 0.011405 \\
\hline R49 & 0.018482 & R26 & 0.011285 \\
\hline R11 & 0.018397 & R31 & 0.011285 \\
\hline R12 & 0.018121 & $\mathrm{R} 47$ & 0.011285 \\
\hline R56 & 0.017874 & $\mathrm{R} 20$ & 0.01049 \\
\hline R7 & 0.017667 & $\mathrm{R} 50$ & 0.010133 \\
\hline R38 & 0.017329 & R52 & 0.010096 \\
\hline R39 & 0.017329 & R51 & 0.010027 \\
\hline $\mathrm{R} 40$ & 0.017329 & $\mathrm{R} 53$ & 0.009525 \\
\hline $\mathrm{R} 1$ & 0.015927 & R19 & 0.009448 \\
\hline $\mathrm{R} 25$ & 0015927 & $\mathrm{R} 2$ & 0.009212 \\
\hline R35 & 0.01577 & R15 & 0.008171 \\
\hline R61 & 0.015643 & $\mathrm{R} 28$ & 0.008139 \\
\hline R63 & 0.015643 & R5 & 0.007217 \\
\hline R23 & 0.014886 & $\mathrm{R} 46$ & 0.006949 \\
\hline
\end{tabular}

According to the distribution of risks presented in the graph above (Figure 7), we can see clearly that the difference between the majority of risks is small enough to consider that they are almost of equivalent importance excepting the outliers (R18-R34-R43). By examining the scores associated with each risk (Table 7) and looking at the graph, we can classify risks as follows in Table 8. 


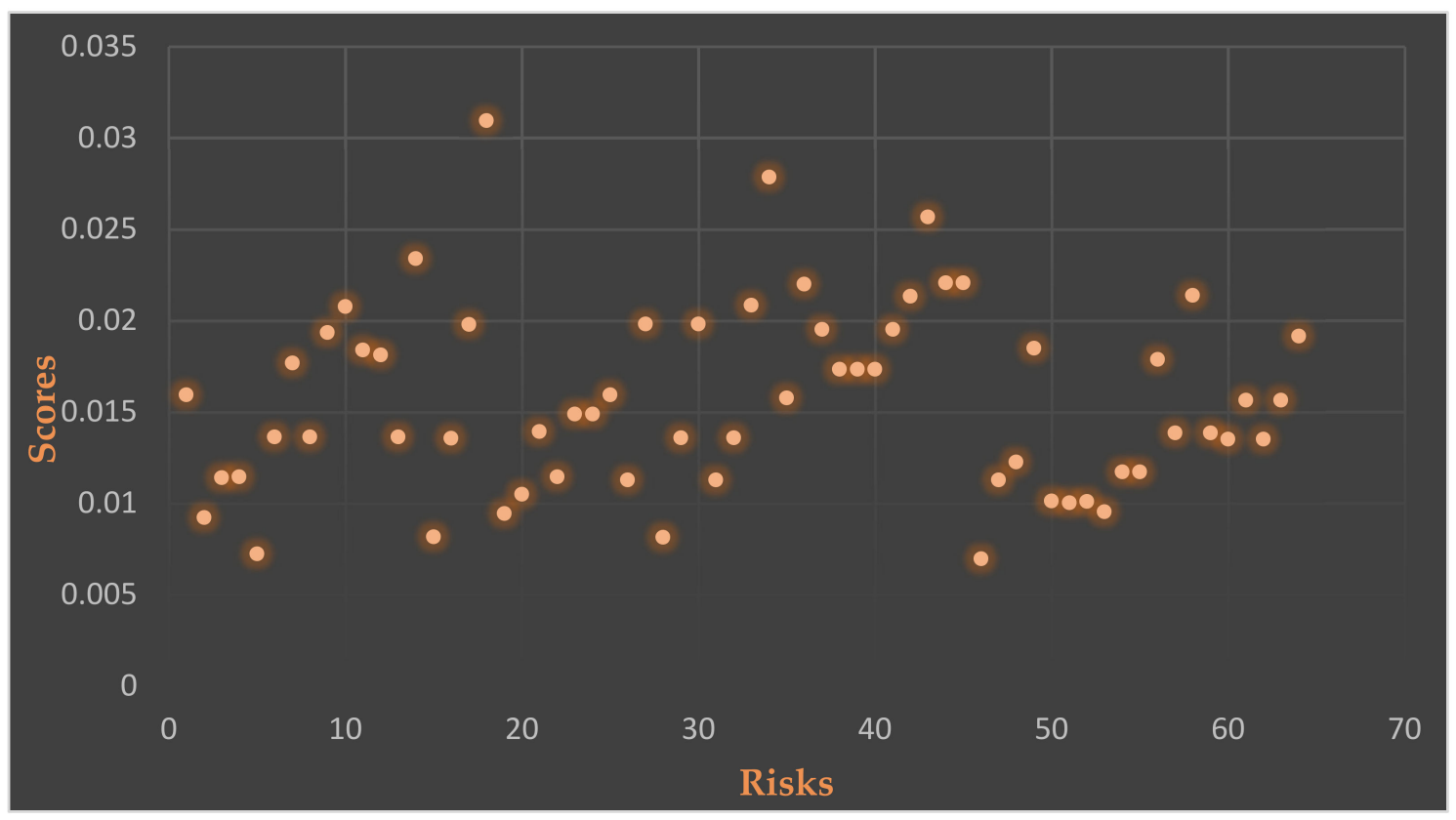

Figure 7. Risks' distribution according to their scores.

Table 8. Risks' classification.

\begin{tabular}{ccc}
\hline Risks & Importance \\
\hline R18-R34-R43 & High \\
\hline R14-R44-R45-R36-R58-R42-R33-R10-R27-R30-R17-R37-R41-R9-R64-R49-R11-R12- \\
R56-R7-R38-R39-R40-R1-R25-R35-R61-R63-R23-R24-R21-R57-R59-R6-R8-R13- \\
$\mathrm{R} 29-\mathrm{R} 32-\mathrm{R} 16-\mathrm{R} 60-\mathrm{R} 62-\mathrm{R} 48$ \\
$\mathrm{R}$
\end{tabular}

\subsection{Risk Treatment}

This step is dedicated to proposing strategies/solutions for risks to be prioritized. Thereby, we are going to focus on the risk with the highest score, R18. Behind every problem lies causes that must be identified first and then eliminated. The solutions to be proposed for these causes should be able to prevent their redundancy [54]. Usually, several causes affecting each other at different levels are at the origin of the visible problem and can be classified according to [54] as follows:

- Symptoms (are signs of the problem that may seem as actual causes but are not);

- First-level causes (they directly lead to the problem);

- Higher-level causes (they lead to first-level causes and contribute indirectly to the problem through the cause-effect chain. Higher-level causes in the bottom of this chain are root causes).

Looking at what is hidden beneath the surface of problems by looking for root causes improves profitability and efficiency, as relying on quick fixes provokes the recurrence of tasks, which is time-, energy-, and resource-consuming. Root cause analysis (RCA) involves applying a series of common-sense techniques (5 Whys, cause and effect diagrams, also known as Fishbone diagrams, fault trees, check sheets) that are able to produce a documented, quantified, and systematic approach to identifying, understanding, and resolving underlying causes [55]. Figure 8 exhibits the results of our RCA on the risk R18. 


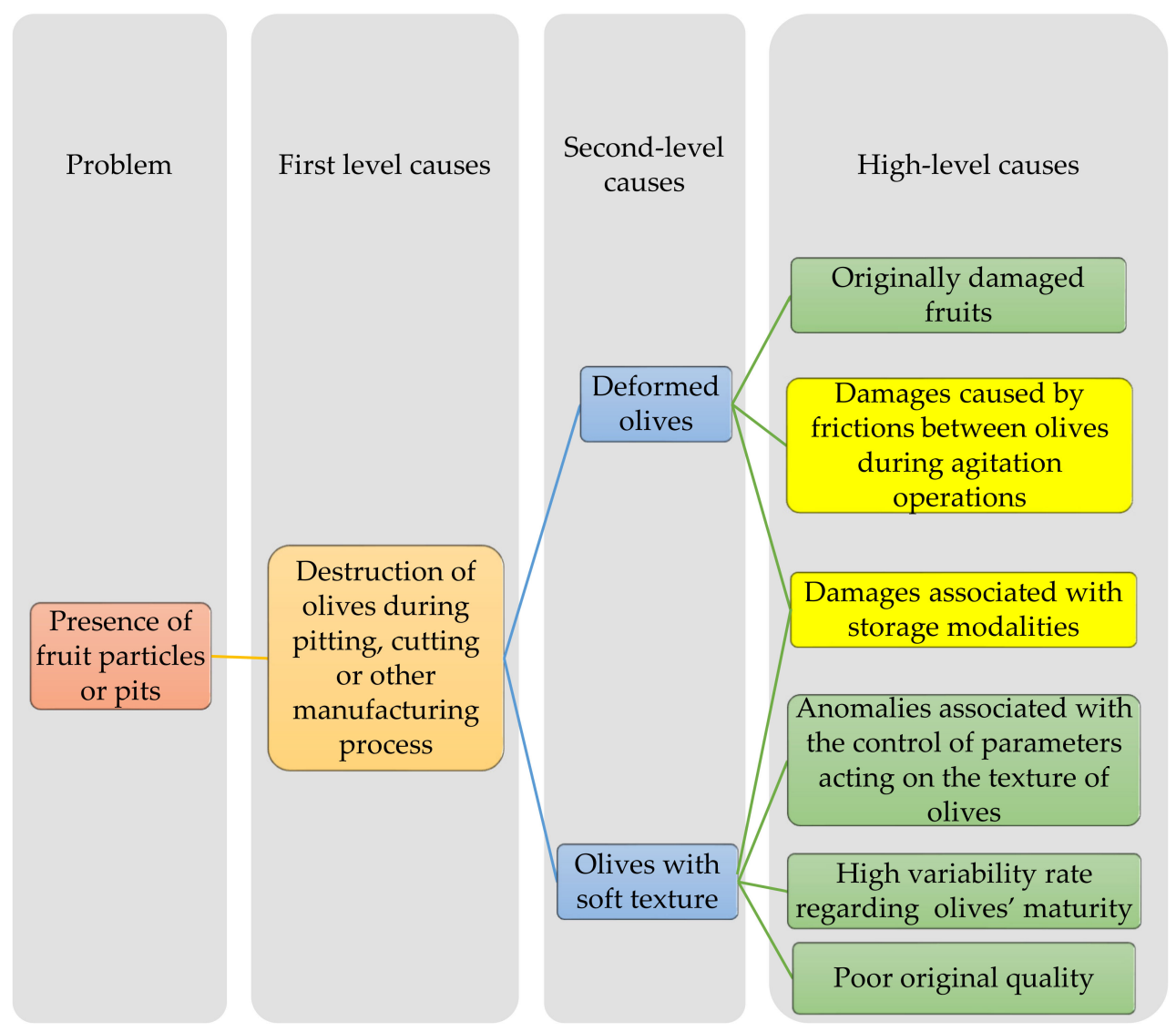

Figure 8. Root causes analysis of R18.

We examined the importance of each of the root causes of R18 according to the company's data; details of this analysis are beyond the scope of this paper. It turned out that damages associated with storage modalities as well as damages caused by frictions are the most frequent causes to be taken into consideration.

\subsubsection{Damages associated with storage modalities}

Upstream storing has two types; the first one is handled in underground tanks where olives prepared for processing are stocked, while the second type concerns semi-processed olives that are stored in barrels.

For the First Type: Underground Tanks

Since storing volume and capacity are fixed, the bigger the order batch size, the more stress will be applied to the olives due to the increased number of fruits in each tank, which decreases their stability. This phenomenon gives rise to the system of contradiction below (Figure 9).

\section{For the Second Type: Barrels}

The number of barrels and available surface for storage are fixed; the bigger the semi-processed stock size, the more stress will be applied to the olives due to the increased number of fruits in each barrel, which decreases the olives' stability. This phenomenon gives rise to the system of contradiction below (Figure 10). 


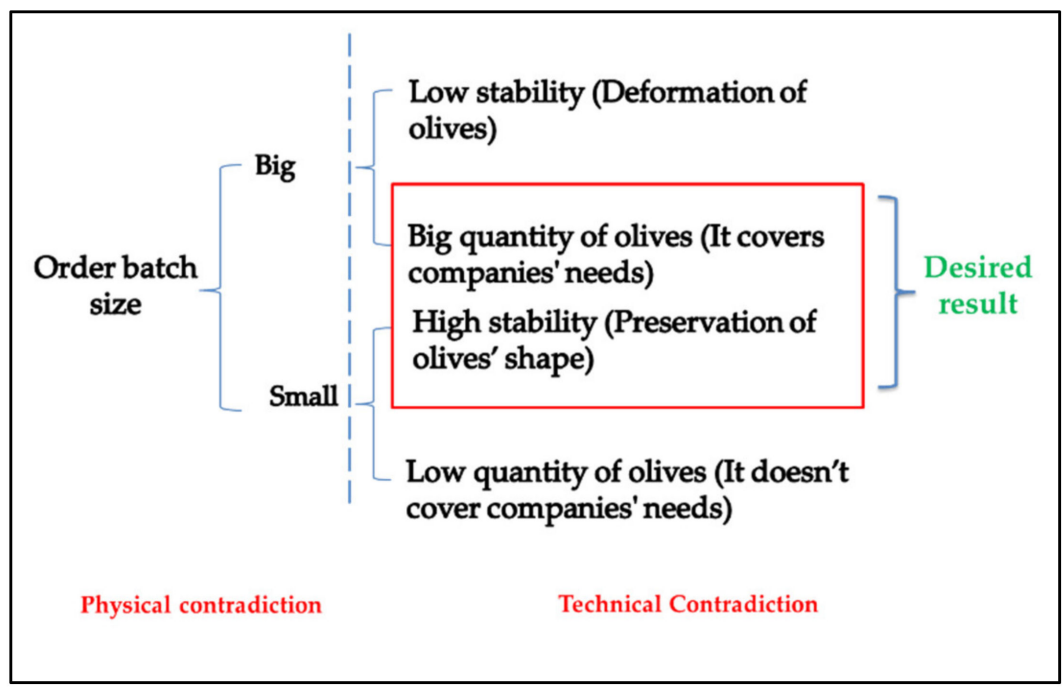

Figure 9. System of contradiction associated with the first storing type.

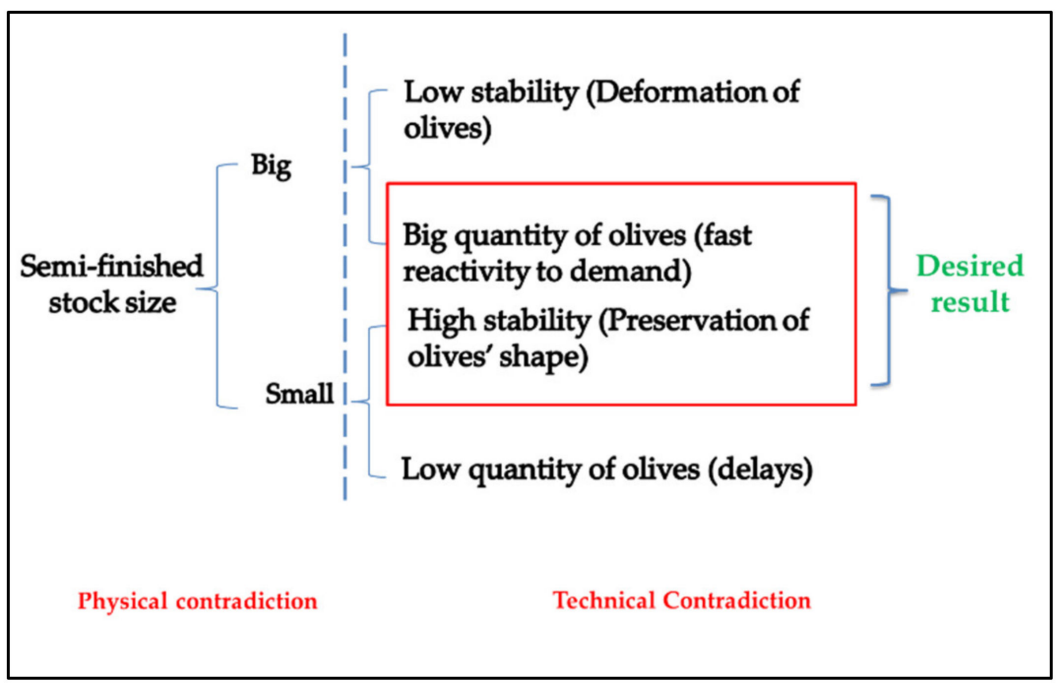

Figure 10. System of contradiction associated with the second storing type.

Resolution of Technical Contradictions

For both types, the parameter to improve is "stability" (parameter number 26 according to the table of generic engineering parameters), while the parameter that must not be degraded is "the quantity" (parameter number 13 according to the table of generic engineering parameters). According to the matrix for resolving technical contradictions developed by Altshuller, the following principles are proposed for resolution:

- TRIZ Principle 2: extraction-separation;

- TRIZ Principle 15: Dynamization-optimization;

- TRIZ Principle 17: Other dimension — change of dimension;

- $\quad$ TRIZ Principle 40: Composite materials or structures.

For the first type, we choose Principle 15 for the resolution of the technical contradiction of System 1. As a conceptual solution, we suggest integrating agitators or infiltrating compressed air into the tanks in order to avoid the settling of the olives, which will reduce the stress undergone by the olives' weight (see Figure 11). Note that by red arrows we mean the stress applied to olives on the bottom of the tank, while black round arrows design olives' movement due to agitation. 


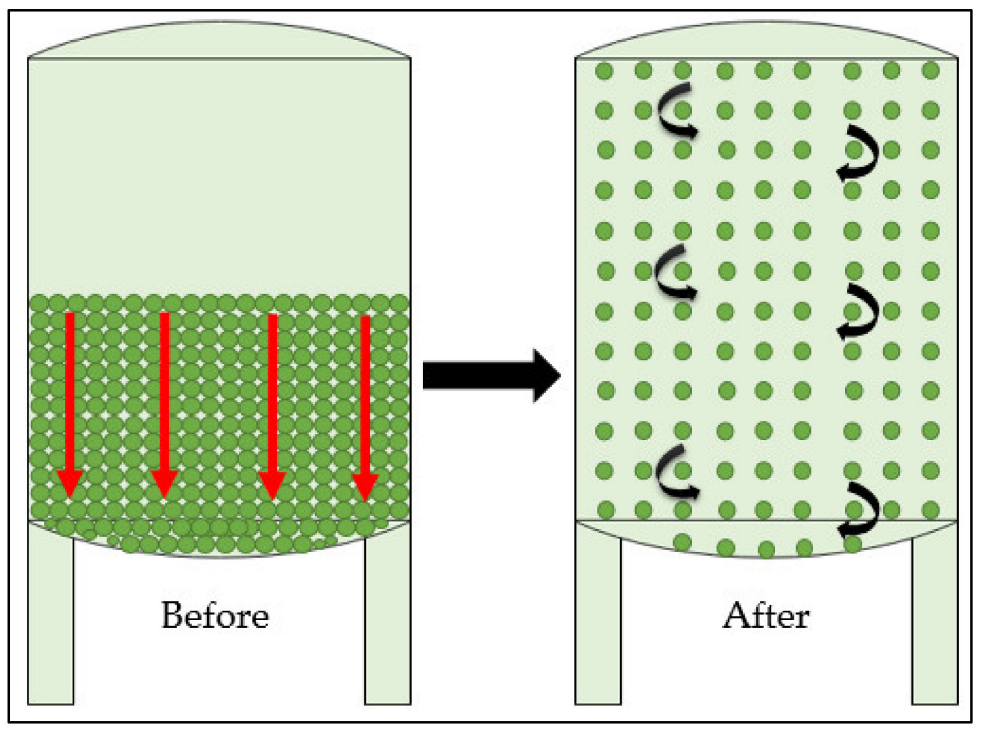

Figure 11. Solution 1.

While for the second type, we choose Principle 17 for the resolution of the technical contradiction of System 2. As a conceptual solution, we suggest overturning barrels with a view to reducing the stress exerted by the olives' weight (see Figure 12). Indeed, overturning barrels decreases stacked olives, which reduces the stress applied on fruits at the bottom. The spherical shape of the base also allows stress reduction.

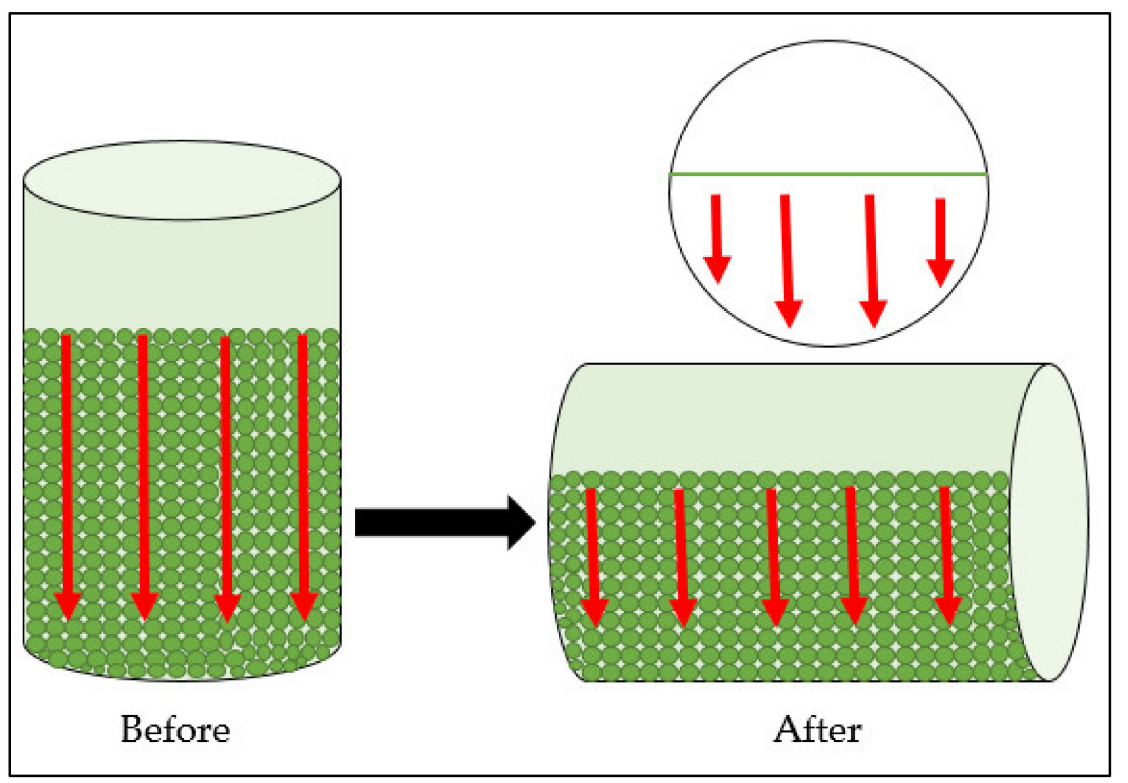

Figure 12. Solution 2.

\subsubsection{Damages caused by frictions between olives during agitation operations}

Agitation is carried out in fixed volume basins for all types of treatment. Frictions occur when the distance is small between rotating olives in these basins. The action parameters responsible for this phenomenon are the number of olives in each basin and the air pressure that supplies it. The variability of these parameters influences not only the shape of the olive but also the homogeneity of the products at the end of the process as well as energy consumption and water consumption. The bigger the number of olives in a basin, the less space olives have to move in, which favors frictions and prevents chemicals from coating all fruits, which increases variability. In contrast, the lower quantities we have in a 
basin, the more treatment cycles we will need, which increases delays. On the other hand, a high pressure of compressed air with a small number of olives allows spacing between fruits, which reduces variability and friction but increases energy consumption. According to these conclusions, which resulted from several experiments carried out by the company, we were able to extract the system of contradiction in Figure 13.

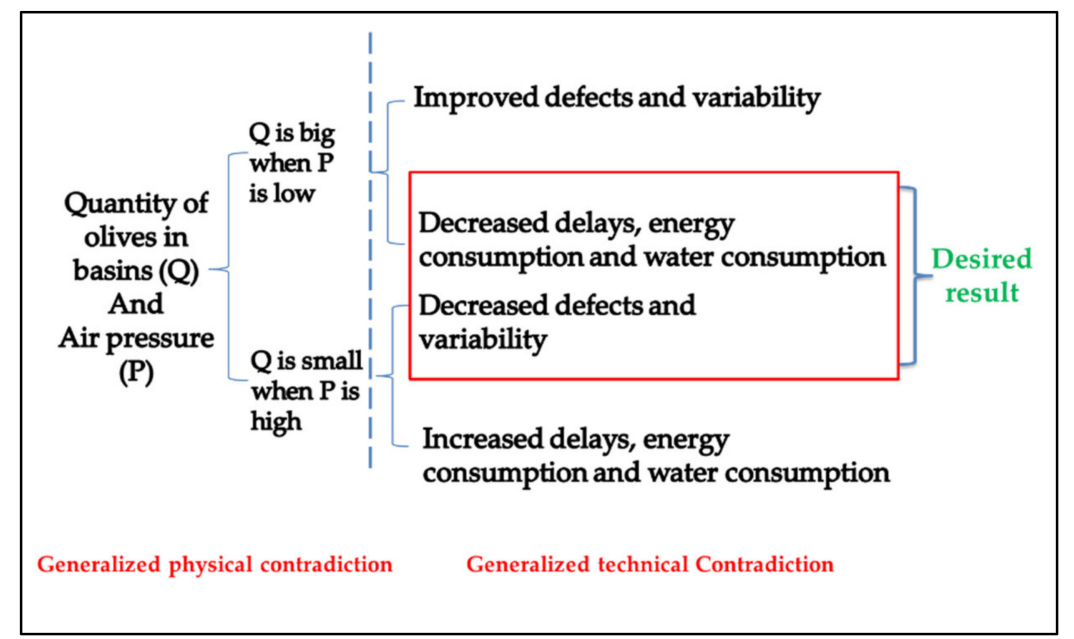

Figure 13. System of contradiction associated with damages caused by frictions.

\section{Discussion}

This research work develops a risk management approach (RMA) for Lean Green performance, responding to the lack of relevant approaches that combine both paradigms in a supply-chain context. A case study was introduced to demonstrate the applicability and relevance of the developed framework at a corporate level. Foremost, in this approach, we have driven a rigorous review analysis so as to define risks in the context of a supply chain. Later, we introduced this concept into Lean and Green aspects; then, we conducted a comprehensive literature review of risk identification studies. Thereby, we provided a novel supply chain risks' classification in which risk sources are associated with Lean Green performance goals. Subsequently, we introduced the analytic hierarchical process (AHP) for risk assessment with a view to detecting crucial risks to be prioritized. Indeed, at a corporate level, managers are often not able to treat all risk sources at once. Thus, criteria defining risks' importance should be identified to assist the decision-making process, which highlights the relevance of this step.

AHP provides a clear vision of the decision-making problem as it affords a hierarchic graphical formalism that combines the main goal with associated criteria and alternatives. These elements can be related to a tangible or intangible problem or even to an aspect of a decision. Additionally, the assessment of each element can be based on qualitative as well as quantitative data or even on judgments of the decision makers. Furthermore, AHP can include several criteria, which makes the assessment process more accurate. This flexibility provided by AHP is behind its applicability in several domains and ability to analyze complex decision-making problems. Our case study highlights these aspects as our problem criteria are inequivalent, and pairwise comparison was made according to different types of data. Deployment of AHP embodies its power and proves its applicability in a supply chain risk management framework.

In the case study, the results of the pairwise comparison revealed that the majority of risks are classified as moderate-to-low importance. At a macro-level, the situation seems stable and manageable, yet these risks can migrate in droves to a higher category (high importance risks) at any time, especially when risk scores are close. This migration will lead to performance failure; we therefore recommend that the company works on shortto medium-term strategies to mitigate these risks. As an output of this risk assessment 
process, we could classify risks according to their importance, which provides visibility to the organization's position regarding its performance goals.

Proceeding to risk treatment, analyzing the root causes of the prioritized risk R18 led to the extraction of several systems of contradiction, which allowed us to describe all conflictual situations that may arise from it. Thereby, this analysis revealed the existence of correlations between some risks, which amounts to the existence of correlations between Lean and Green aspects. A big order batch size/a big semi-finished stock size covers companies' needs and increases their capability to respond to demand fluctuations; in return, it abets the degradation of olives' stability, which increases defects (see Figures 9 and 10). On the other hand, decreasing defects and variability requires reducing quantities of olives to be treated in each basin and providing high compressed air pressure, which induce increased delays, increased energy consumption, and increased water consumption (see Figure 13). This confirms that treating a risk may negatively influence the treatment of another.

In a summarized discussion of our findings, this study revealed that Lean thinking may indeed be antagonistic to Green thinking, which supports the fact that Lean Green supply chain challenges are more complex and outweigh classic optimization methods and techniques. Hence, LGSC management requires effective and innovative management approaches, which highlights the relevance of the theory of inventive problem solving's (TRIZ) integration. TRIZ helps to avoid psychological inertia and provides strong tools for guiding problem solving, which made the risk-treatment process time-saving and costsaving. By integrating the theory of inventive problem solving, we proved its applicability to a supply chain risk management framework, especially in the context of Lean Green performance. Instead of looking for tradeoffs through classic optimization methods, we were able to propose innovative and adequate solutions that are able to resolve contradictions using TRIZ tools and techniques.

The literature distinguished two types of Lean-Green combination approaches: autonomous and Lean-based. The framework we developed in the present work aligns with the first category as it proposes a stand-alone approach. In contrast with Lean-based approaches, it affords necessary guidelines for managers that are not familiar with Lean techniques and practices. Unlike the other approaches, we utilized risk management philosophy instead of generic problem-solving and performance-improvement methods.

The first and second step of the risk management approach consist of framing the vision and defining risks associated with a specific context to be taken into consideration. These steps drive supply chain managers away from distractions that are likely to divert them from the project's main goal, as they provide necessary knowledge about the problem. Apart from a lack of expertise and poor culture about some specific techniques and concepts, performance failure generally comes from a poor identification of the real problem. Alongside this, risk identification can include aspects related to a multi-dimensional performance that outstrip the Lean-Green vision, which surpass the limitation highlighted in the introduction section about the previous attempts at a Lean-Green combination.

Subsequently to risk identification, risk assessment provides knowledge about the organization's position regarding its desired performance. Risk prioritization marks the starting point of the way to performance improvement as it gives prominence to risks with a high level of criticality. Thereby, the classification of risks supplies SC managers with a basis for improvement. The last step of this RMA was dedicated to providing suitable solutions for critical risk treatment. At a corporate level, the outputs of this step indirectly revealed the existing relationships between Lean aspects and Green aspects through examining the root causes of the prioritized risk. These results contribute to Lean Green map building and promote a better understanding of both paradigms' coexistence. Alongside this, these results underline that supply chain challenges require inventive solutions. By integrating the theory of inventive problem solving, our approach is able to outperform this challenge. 


\section{Conclusions}

In the present work, we propose a hybrid risk management approach, which provides supply chain managers with guidelines for a successful Lean Green implementation. This approach stands out for its clarity, feasibility, and simplicity as it does not require mastery of practices and techniques related to Lean and Green. It is also cost-saving, timesaving, and labor-saving as it provides appropriate guidance, which minimizes the risk of performance failure. The approach also sticks out for its adaptability and flexibility, since the framework was conceptually developed independently of any corporate- or industriallevel specifications. Furthermore, this research work is the first to propose integrating risk management philosophy into Lean-Green combination projects.

The framework we developed responds to the gaps mentioned regarding previous attempts at a Lean-Green combination, However, some limitations remain. Our proposal lacks insights into risk monitoring guidelines for continuous improvement. From this perspective, we aim to lead further researches. Alongside this, the deployment of the approach was only tested at a corporate level. In this optic, we are aiming at assessing its applicability to an industrial level for different sectors of activity and more complex cases. Additionally, we are seeking as well to proceed to the resolution of the generalized system of contradiction in Figure 13.

Author Contributions: F.E.E.: conceptualization, data curation, formal analysis, investigation, methodology, resources, validation, visualization, writing —original draft, and writing - review and editing, R.B.: conceptualization, methodology, project administration, supervision, validation, and writing-review and editing, R.D.G.: conceptualization, methodology, supervision, validation, and writing-review and editing, S.D.: conceptualization, methodology, supervision, validation, and writing-review and editing. All authors have read and agreed to the published version of the manuscript.

Funding: This research received no external funding.

Institutional Review Board Statement: The study did not involve humans or animals.

Acknowledgments: I wish to show my appreciation and thanks to Aicha El Hanine And Mohamed Chiny for their assistance and guidance.

Conflicts of Interest: The authors declare no conflict of interest.
Abbreviations
TRIZ Theory of inventive problem solving
LGSC Lean Green Supply Chain
RMA Risk management approach
SC Supply Chain
TC Technical Contradiction
GTC Generalized Technical Contradiction

\section{Appendix A}

The following Appendixes (Appendices A and B) exhibit the pairwise comparison matrices we built in our case study and associated weight vectors. These data remain crucial to the research's reproduction.

Table A1. Pairwise comparison matrix between risks according to frequency, Part 1.

\begin{tabular}{|c|c|c|c|c|c|c|c|c|c|c|c|c|c|c|c|c|c|c|c|c|c|}
\hline & R1 & R2 & R3 & R4 & R5 & R6 & R7 & R8 & R9 & R10 & R11 & R12 & R13 & R14 & R15 & R16 & R17 & R18 & R19 & R20 & R21 \\
\hline R1 & 1 & 4 & 4 & 2 & 4 & 2 & 2 & 2 & 2 & 1 & 2 & 1 & 2 & 2 & 4 & 2 & 2 & 1 & 2 & 2 & 1 \\
\hline R2 & $1 / 4$ & 1 & 1 & $1 / 2$ & 1 & $1 / 2$ & $1 / 2$ & $1 / 2$ & $1 / 2$ & $1 / 4$ & $1 / 2$ & $1 / 4$ & $1 / 2$ & $1 / 2$ & 1 & $1 / 2$ & $1 / 2$ & $1 / 4$ & $1 / 2$ & $1 / 2$ & $1 / 4$ \\
\hline R3 & $1 / 4$ & 1 & 1 & $1 / 2$ & 1 & $1 / 2$ & $1 / 2$ & $1 / 2$ & $1 / 2$ & $1 / 4$ & $1 / 2$ & $1 / 4$ & $1 / 2$ & $1 / 2$ & 1 & $1 / 2$ & $1 / 2$ & $1 / 4$ & $1 / 2$ & $1 / 2$ & $1 / 4$ \\
\hline R4 & $1 / 2$ & 2 & 2 & 1 & 2 & 1 & 1 & 1 & 1 & $1 / 2$ & 1 & $1 / 2$ & 1 & 1 & 2 & 1 & 1 & $1 / 2$ & 1 & 1 & $1 / 2$ \\
\hline R5 & $1 / 4$ & 1 & 1 & $1 / 2$ & 1 & $1 / 2$ & $1 / 2$ & $1 / 2$ & $1 / 2$ & $1 / 4$ & $1 / 2$ & $1 / 4$ & $1 / 2$ & $1 / 2$ & 1 & $1 / 2$ & $1 / 2$ & $1 / 4$ & $1 / 2$ & $1 / 2$ & $1 / 4$ \\
\hline
\end{tabular}


Table A1. Cont.

\begin{tabular}{|c|c|c|c|c|c|c|c|c|c|c|c|c|c|c|c|c|c|c|c|c|c|}
\hline & R1 & R2 & R3 & R4 & R5 & R6 & R7 & R8 & R9 & R10 & R11 & R12 & R13 & R14 & R15 & R16 & R17 & R18 & R19 & R20 & R21 \\
\hline R6 & $1 / 2$ & 2 & 2 & 1 & 2 & 1 & 1 & 1 & 1 & $1 / 2$ & 1 & $1 / 2$ & 1 & 1 & 2 & 1 & 1 & $1 / 2$ & 1 & 1 & $1 / 2$ \\
\hline R7 & $1 / 2$ & 2 & 2 & 1 & 2 & 1 & 1 & 1 & 1 & $1 / 2$ & 1 & $1 / 2$ & 1 & 1 & 2 & 1 & 1 & $1 / 2$ & 1 & 1 & $1 / 2$ \\
\hline R8 & $1 / 2$ & 2 & 2 & 1 & 2 & 1 & 1 & 1 & 1 & $1 / 2$ & 1 & $1 / 2$ & 1 & 1 & 2 & 1 & 1 & $1 / 2$ & 1 & 1 & $1 / 2$ \\
\hline R9 & $1 / 2$ & 2 & 2 & 1 & 2 & 1 & 1 & 1 & 1 & $1 / 2$ & 1 & $1 / 2$ & 1 & 1 & 2 & 1 & 1 & $1 / 2$ & 1 & 1 & $1 / 2$ \\
\hline R9 & $1 / 2$ & 2 & 2 & 1 & 2 & 1 & 1 & 1 & 1 & $1 / 2$ & 1 & $1 / 2$ & 1 & 1 & 2 & 1 & 1 & $1 / 2$ & 1 & 1 & $1 / 2$ \\
\hline R10 & 1 & 4 & 4 & 2 & 4 & 2 & 2 & 2 & 2 & 1 & 2 & 1 & 2 & 2 & 4 & 2 & 2 & 1 & 2 & 2 & 1 \\
\hline R11 & $1 / 2$ & 2 & 2 & 1 & 2 & 1 & 1 & 1 & 1 & $1 / 2$ & 1 & $1 / 2$ & 1 & 1 & 2 & 1 & 1 & $1 / 2$ & 1 & 1 & $1 / 2$ \\
\hline R12 & 1 & 4 & 4 & 2 & 4 & 2 & 2 & 2 & 2 & 1 & 2 & 1 & 2 & 2 & 4 & 2 & 2 & 1 & 2 & 2 & 1 \\
\hline R13 & $1 / 2$ & 2 & 2 & 1 & 2 & 1 & 1 & 1 & 1 & $1 / 2$ & 1 & $1 / 2$ & 1 & 1 & 2 & 1 & 1 & $1 / 2$ & 1 & 1 & $1 / 2$ \\
\hline R14 & $1 / 2$ & 2 & 2 & 1 & 2 & 1 & 1 & 1 & 1 & $1 / 2$ & 1 & $1 / 2$ & 1 & 1 & 2 & 1 & 1 & $1 / 2$ & 1 & 1 & $1 / 2$ \\
\hline R15 & $1 / 4$ & 1 & 1 & $1 / 2$ & 1 & $1 / 2$ & $1 / 2$ & $1 / 2$ & $1 / 2$ & $1 / 4$ & $1 / 2$ & $1 / 4$ & $1 / 2$ & $1 / 2$ & 1 & $1 / 2$ & $1 / 2$ & $1 / 4$ & $1 / 2$ & $1 / 2$ & $1 / 4$ \\
\hline R16 & $1 / 2$ & 2 & 2 & 1 & 2 & 1 & 1 & 1 & 1 & $1 / 2$ & 1 & $1 / 2$ & 1 & 1 & 2 & 1 & 1 & $1 / 2$ & 1 & 1 & $1 / 2$ \\
\hline R17 & $1 / 2$ & 2 & 2 & 1 & 2 & 1 & 1 & 1 & 1 & $1 / 2$ & 1 & $1 / 2$ & 1 & 1 & 2 & 1 & 1 & $1 / 2$ & 1 & 1 & $1 / 2$ \\
\hline R18 & 1 & 4 & 4 & 2 & 4 & 2 & 2 & 2 & 2 & 1 & 2 & 1 & 2 & 2 & 4 & 2 & 2 & 1 & 2 & 2 & 1 \\
\hline R19 & $1 / 2$ & 2 & 2 & 1 & 2 & 1 & 1 & 1 & 1 & $1 / 2$ & 1 & $1 / 2$ & 1 & 1 & 2 & 1 & 1 & $1 / 2$ & 1 & 1 & $1 / 2$ \\
\hline R20 & $1 / 2$ & 2 & 2 & 1 & 2 & 1 & 1 & 1 & 1 & $1 / 2$ & 1 & $1 / 2$ & 1 & 1 & 2 & 1 & 1 & $1 / 2$ & 1 & 1 & $1 / 2$ \\
\hline R21 & 1 & 4 & 4 & 2 & 4 & 2 & 2 & 2 & 2 & 1 & 2 & 1 & 2 & 2 & 4 & 2 & 2 & 1 & 2 & 2 & 1 \\
\hline R22 & $1 / 2$ & 2 & 2 & 1 & 2 & 1 & 1 & 1 & 1 & $1 / 2$ & 1 & $1 / 2$ & 1 & 1 & 2 & 1 & 1 & $1 / 2$ & 1 & 1 & $1 / 2$ \\
\hline R23 & 1 & 4 & 4 & 2 & 4 & 2 & 2 & 2 & 2 & 1 & 2 & 1 & 2 & 2 & 4 & 2 & 2 & 1 & 2 & 2 & 1 \\
\hline R24 & 1 & 4 & 4 & 2 & 4 & 2 & 2 & 2 & 2 & 1 & 2 & 1 & 2 & 2 & 4 & 2 & 2 & 1 & 2 & 2 & 1 \\
\hline R25 & 1 & 4 & 4 & 2 & 4 & 2 & 2 & 2 & 2 & 1 & 2 & 1 & 2 & 2 & 4 & 2 & 2 & 1 & 2 & 2 & 1 \\
\hline R26 & $1 / 2$ & 2 & 2 & 1 & 2 & 1 & 1 & 1 & 1 & $1 / 2$ & 1 & $1 / 2$ & 1 & 1 & 2 & 1 & 1 & $1 / 2$ & 1 & 1 & $1 / 2$ \\
\hline R27 & 1 & 4 & 4 & 2 & 4 & 2 & 2 & 2 & 2 & 1 & 2 & 1 & 2 & 2 & 4 & 2 & 2 & 1 & 2 & 2 & 1 \\
\hline R28 & $1 / 2$ & 2 & 2 & 1 & 2 & 1 & 1 & 1 & 1 & $1 / 2$ & 1 & $1 / 2$ & 1 & 1 & 2 & 1 & 1 & $1 / 2$ & 1 & 1 & $1 / 2$ \\
\hline R29 & 1 & 4 & 4 & 2 & 4 & 2 & 2 & 2 & 2 & 1 & 2 & 1 & 2 & 2 & 4 & 2 & 2 & 1 & 2 & 2 & 1 \\
\hline R30 & 1 & 4 & 4 & 2 & 4 & 2 & 2 & 2 & 2 & 1 & 2 & 1 & 2 & 2 & 4 & 2 & 2 & 1 & 2 & 2 & 1 \\
\hline R31 & $1 / 2$ & 2 & 2 & 1 & 2 & 1 & 1 & 1 & 1 & $1 / 2$ & 1 & $1 / 2$ & 1 & 1 & 2 & 1 & 1 & $1 / 2$ & 1 & 1 & $1 / 2$ \\
\hline R32 & 1 & 4 & 4 & 2 & 4 & 2 & 2 & 2 & 2 & 1 & 2 & 1 & 2 & 2 & 4 & 2 & 2 & 1 & 2 & 2 & 1 \\
\hline R33 & 1 & 4 & 4 & 2 & 4 & 2 & 2 & 2 & 2 & 1 & 2 & 1 & 2 & 2 & 4 & 2 & 2 & 1 & 2 & 2 & 1 \\
\hline R34 & 2 & 6 & 6 & 4 & 6 & 4 & 4 & 4 & 4 & 2 & 4 & 2 & 4 & 4 & 6 & 4 & 4 & 2 & 4 & 4 & 2 \\
\hline R35 & 1 & 4 & 4 & 2 & 4 & 2 & 2 & 2 & 2 & 1 & 2 & 1 & 2 & 2 & 4 & 2 & 2 & 1 & 2 & 2 & 1 \\
\hline R36 & $1 / 2$ & 2 & 2 & 1 & 2 & 1 & 1 & 1 & 1 & $1 / 2$ & 1 & $1 / 2$ & 1 & 1 & 2 & 1 & 1 & $1 / 2$ & 1 & 1 & $1 / 2$ \\
\hline R37 & $1 / 2$ & 2 & 2 & 1 & 2 & 1 & 1 & 1 & 1 & $1 / 2$ & 1 & $1 / 2$ & 1 & 1 & 2 & 1 & 1 & $1 / 2$ & 1 & 1 & $1 / 2$ \\
\hline R38 & $1 / 2$ & 2 & 2 & 1 & 2 & 1 & 1 & 1 & 1 & $1 / 2$ & 1 & $1 / 2$ & 1 & 1 & 2 & 1 & 1 & $1 / 2$ & 1 & 1 & $1 / 2$ \\
\hline R39 & $1 / 2$ & 2 & 2 & 1 & 2 & 1 & 1 & 1 & 1 & $1 / 2$ & 1 & $1 / 2$ & 1 & 1 & 2 & 1 & 1 & $1 / 2$ & 1 & 1 & $1 / 2$ \\
\hline R40 & $1 / 2$ & 2 & 2 & 1 & 2 & 1 & 1 & 1 & 1 & $1 / 2$ & 1 & $1 / 2$ & 1 & 1 & 2 & 1 & 1 & $1 / 2$ & 1 & 1 & $1 / 2$ \\
\hline R41 & $1 / 2$ & 2 & 2 & 1 & 2 & 1 & 1 & 1 & 1 & $1 / 2$ & 1 & $1 / 2$ & 1 & 1 & 2 & 1 & 1 & $1 / 2$ & 1 & 1 & $1 / 2$ \\
\hline R42 & $1 / 4$ & 1 & 1 & $1 / 2$ & 1 & $1 / 2$ & $1 / 2$ & $1 / 2$ & $1 / 2$ & $1 / 4$ & $1 / 2$ & $1 / 4$ & $1 / 2$ & $1 / 2$ & 1 & $1 / 2$ & $1 / 2$ & $1 / 4$ & $1 / 2$ & $1 / 2$ & $1 / 4$ \\
\hline R43 & $1 / 2$ & 2 & 2 & 1 & 2 & 1 & 1 & 1 & 1 & $1 / 2$ & 1 & $1 / 2$ & 1 & 1 & 2 & 1 & 1 & $1 / 2$ & 1 & 1 & $1 / 2$ \\
\hline R44 & $1 / 2$ & 2 & 2 & 1 & 2 & 1 & 1 & 1 & 1 & $1 / 2$ & 1 & $1 / 2$ & 1 & 1 & 2 & 1 & 1 & $1 / 2$ & 1 & 1 & $1 / 2$ \\
\hline R45 & $1 / 2$ & 2 & 2 & 1 & 2 & 1 & 1 & 1 & 1 & $1 / 2$ & 1 & $1 / 2$ & 1 & 1 & 2 & 1 & 1 & $1 / 2$ & 1 & 1 & $1 / 2$ \\
\hline R46 & $1 / 4$ & 1 & 1 & $1 / 2$ & 1 & $1 / 2$ & $1 / 2$ & $1 / 2$ & $1 / 2$ & $1 / 4$ & $1 / 2$ & $1 / 4$ & $1 / 2$ & $1 / 2$ & 1 & $1 / 2$ & $1 / 2$ & $1 / 4$ & $1 / 2$ & $1 / 2$ & $1 / 4$ \\
\hline R47 & $1 / 2$ & 2 & 2 & 1 & 2 & 1 & 1 & 1 & 1 & $1 / 2$ & 1 & $1 / 2$ & 1 & 1 & 2 & 1 & 1 & $1 / 2$ & 1 & 1 & $1 / 2$ \\
\hline R48 & $1 / 2$ & 2 & 2 & 1 & 2 & 1 & 1 & 1 & 1 & $1 / 2$ & 1 & $1 / 2$ & 1 & 1 & 2 & 1 & 1 & $1 / 2$ & 1 & 1 & $1 / 2$ \\
\hline $\mathbf{R} 49$ & $1 / 2$ & 2 & 2 & 1 & 2 & 1 & 1 & 1 & 1 & $1 / 2$ & 1 & $1 / 2$ & 1 & 1 & 2 & 1 & 1 & $1 / 2$ & 1 & 1 & $1 / 2$ \\
\hline R50 & $1 / 2$ & 2 & 2 & 1 & 2 & 1 & 1 & 1 & 1 & $1 / 2$ & 1 & $1 / 2$ & 1 & 1 & 2 & 1 & 1 & $1 / 2$ & 1 & 1 & $1 / 2$ \\
\hline R51 & $1 / 4$ & 1 & 1 & $1 / 2$ & 1 & $1 / 2$ & $1 / 2$ & $1 / 2$ & $1 / 2$ & $1 / 4$ & $1 / 2$ & $1 / 4$ & $1 / 2$ & $1 / 2$ & 1 & $1 / 2$ & $1 / 2$ & $1 / 4$ & $1 / 2$ & $1 / 2$ & $1 / 4$ \\
\hline R52 & $1 / 4$ & 1 & 1 & $1 / 2$ & 1 & $1 / 2$ & $1 / 2$ & $1 / 2$ & $1 / 2$ & $1 / 4$ & $1 / 2$ & $1 / 4$ & $1 / 2$ & $1 / 2$ & 1 & $1 / 2$ & $1 / 2$ & $1 / 4$ & $1 / 2$ & $1 / 2$ & $1 / 4$ \\
\hline R53 & $1 / 2$ & 2 & 2 & 1 & 2 & 1 & 1 & 1 & 1 & $1 / 2$ & 1 & $1 / 2$ & 1 & 1 & 2 & 1 & 1 & $1 / 2$ & 1 & 1 & $1 / 2$ \\
\hline R54 & $1 / 2$ & 2 & 2 & 1 & 2 & 1 & 1 & 1 & 1 & $1 / 2$ & 1 & $1 / 2$ & 1 & 1 & 2 & 1 & 1 & $1 / 2$ & 1 & 1 & $1 / 2$ \\
\hline R55 & $1 / 2$ & 2 & 2 & 1 & 2 & 1 & 1 & 1 & 1 & $1 / 2$ & 1 & $1 / 2$ & 1 & 1 & 2 & 1 & 1 & $1 / 2$ & 1 & 1 & $1 / 2$ \\
\hline R56 & $1 / 2$ & 2 & 2 & 1 & 2 & 1 & 1 & 1 & 1 & $1 / 2$ & 1 & $1 / 2$ & 1 & 1 & 2 & 1 & 1 & $1 / 2$ & 1 & 1 & $1 / 2$ \\
\hline R57 & $1 / 2$ & 2 & 2 & 1 & 2 & 1 & 1 & 1 & 1 & $1 / 2$ & 1 & $1 / 2$ & 1 & 1 & 2 & 1 & 1 & $1 / 2$ & 1 & 1 & $1 / 2$ \\
\hline R58 & $1 / 2$ & 2 & 2 & 1 & 2 & 1 & 1 & 1 & 1 & $1 / 2$ & 1 & $1 / 2$ & 1 & 1 & 2 & 1 & 1 & $1 / 2$ & 1 & 1 & $1 / 2$ \\
\hline R59 & $1 / 2$ & 2 & 2 & $\mathbf{1}$ & 2 & 1 & 1 & 1 & 1 & $1 / 2$ & 1 & $1 / 2$ & 1 & 1 & 2 & 1 & 1 & $1 / 2$ & 1 & 1 & $1 / 2$ \\
\hline R60 & $1 / 4$ & 1 & 1 & $1 / 2$ & 1 & $1 / 2$ & $1 / 2$ & $1 / 2$ & $1 / 2$ & $1 / 4$ & $1 / 2$ & $1 / 4$ & $1 / 2$ & $1 / 2$ & 1 & $1 / 2$ & $1 / 2$ & $1 / 4$ & $1 / 2$ & $1 / 2$ & $1 / 4$ \\
\hline
\end{tabular}


Table A1. Cont.

\begin{tabular}{|c|c|c|c|c|c|c|c|c|c|c|c|c|c|c|c|c|c|c|c|c|c|}
\hline & R1 & R2 & R3 & R4 & R5 & R6 & R7 & R8 & R9 & R10 & R11 & R12 & R13 & R14 & R15 & R16 & R17 & R18 & R19 & R20 & R21 \\
\hline R61 & $1 / 4$ & 1 & 1 & $1 / 2$ & 1 & $1 / 2$ & $1 / 2$ & $1 / 2$ & $1 / 2$ & $1 / 4$ & $1 / 2$ & $1 / 4$ & $1 / 2$ & $1 / 2$ & 1 & $1 / 2$ & $1 / 2$ & $1 / 4$ & $1 / 2$ & $1 / 2$ & $1 / 4$ \\
\hline R62 & $1 / 4$ & 1 & 1 & $1 / 2$ & 1 & $1 / 2$ & $1 / 2$ & $1 / 2$ & $1 / 2$ & $1 / 4$ & $1 / 2$ & $1 / 4$ & $1 / 2$ & $1 / 2$ & 1 & $1 / 2$ & $1 / 2$ & $1 / 4$ & $1 / 2$ & $1 / 2$ & $1 / 4$ \\
\hline R63 & $1 / 4$ & 1 & 1 & $1 / 2$ & 1 & $1 / 2$ & $1 / 2$ & $1 / 2$ & $1 / 2$ & $1 / 4$ & $1 / 2$ & $1 / 4$ & $1 / 2$ & $1 / 2$ & 1 & $1 / 2$ & $1 / 2$ & $1 / 4$ & $1 / 2$ & $1 / 2$ & $1 / 4$ \\
\hline R64 & $1 / 4$ & 1 & 1 & $1 / 2$ & 1 & $1 / 2$ & $1 / 2$ & $1 / 2$ & $1 / 2$ & $1 / 4$ & $1 / 2$ & $1 / 4$ & $1 / 2$ & $1 / 2$ & 1 & $1 / 2$ & $1 / 2$ & $1 / 4$ & $1 / 2$ & $1 / 2$ & $1 / 4$ \\
\hline
\end{tabular}

Table A2. Pairwise comparison matrix between risks according to frequency, Part 2.

\begin{tabular}{|c|c|c|c|c|c|c|c|c|c|c|c|c|c|c|c|c|c|c|c|c|c|}
\hline & R22 & R23 & R24 & R25 & R26 & R27 & R28 & R29 & R30 & R31 & R32 & R33 & R34 & R35 & R36 & R37 & R38 & R39 & R40 & R41 & R42 \\
\hline R1 & 2 & 1 & 1 & 1 & 2 & 1 & 2 & 1 & 1 & 2 & 1 & 1 & $1 / 2$ & 1 & 2 & 2 & 2 & 2 & 2 & 2 & 4 \\
\hline $\mathbf{R} 2$ & $1 / 2$ & $1 / 4$ & $1 / 4$ & $1 / 4$ & $1 / 2$ & $1 / 4$ & $1 / 2$ & $1 / 4$ & $1 / 4$ & $1 / 2$ & $1 / 4$ & $1 / 4$ & $1 / 6$ & $1 / 4$ & $1 / 2$ & $1 / 2$ & $1 / 2$ & $1 / 2$ & $1 / 2$ & $1 / 2$ & 1 \\
\hline R3 & $1 / 2$ & $1 / 4$ & $1 / 4$ & $1 / 4$ & $1 / 2$ & $1 / 4$ & $1 / 2$ & $1 / 4$ & $1 / 4$ & $1 / 2$ & $1 / 4$ & $1 / 4$ & $1 / 6$ & $1 / 4$ & $1 / 2$ & $1 / 2$ & $1 / 2$ & $1 / 2$ & $1 / 2$ & $1 / 2$ & 1 \\
\hline R4 & 1 & $1 / 2$ & $1 / 2$ & $1 / 2$ & 1 & $1 / 2$ & 1 & $1 / 2$ & $1 / 2$ & 1 & $1 / 2$ & $1 / 2$ & $1 / 4$ & $1 / 2$ & 1 & 1 & 1 & 1 & 1 & 1 & 2 \\
\hline R5 & $1 / 2$ & $1 / 4$ & $1 / 4$ & $1 / 4$ & $1 / 2$ & $1 / 4$ & $1 / 2$ & $1 / 4$ & $1 / 4$ & $1 / 2$ & $1 / 4$ & $1 / 4$ & $1 / 6$ & $1 / 4$ & $1 / 2$ & $1 / 2$ & $1 / 2$ & $1 / 2$ & $1 / 2$ & $1 / 2$ & 1 \\
\hline R6 & 1 & $1 / 2$ & $1 / 2$ & $1 / 2$ & 1 & $1 / 2$ & 1 & $1 / 2$ & $1 / 2$ & 1 & $1 / 2$ & $1 / 2$ & $1 / 4$ & $1 / 2$ & 1 & 1 & 1 & 1 & 1 & 1 & 2 \\
\hline R7 & 1 & $1 / 2$ & $1 / 2$ & $1 / 2$ & 1 & $1 / 2$ & 1 & $1 / 2$ & $1 / 2$ & 1 & $1 / 2$ & $1 / 2$ & $1 / 4$ & $1 / 2$ & 1 & 1 & 1 & 1 & 1 & 1 & 2 \\
\hline R8 & 1 & $1 / 2$ & $1 / 2$ & $1 / 2$ & 1 & $1 / 2$ & 1 & $1 / 2$ & $1 / 2$ & 1 & $1 / 2$ & $1 / 2$ & $1 / 4$ & $1 / 2$ & 1 & 1 & 1 & 1 & 1 & 1 & 2 \\
\hline R9 & 1 & $1 / 2$ & $1 / 2$ & $1 / 2$ & 1 & $1 / 2$ & 1 & $1 / 2$ & $1 / 2$ & 1 & $1 / 2$ & $1 / 2$ & $1 / 4$ & $1 / 2$ & 1 & 1 & 1 & 1 & 1 & 1 & 2 \\
\hline R10 & 2 & 1 & 1 & 1 & 2 & 1 & 2 & 1 & 1 & 2 & 1 & 1 & $1 / 2$ & 1 & 2 & 2 & 2 & 2 & 2 & 2 & 4 \\
\hline R11 & 1 & $1 / 2$ & $1 / 2$ & $1 / 2$ & 1 & $1 / 2$ & 1 & $1 / 2$ & $1 / 2$ & 1 & $1 / 2$ & $1 / 2$ & $1 / 4$ & $1 / 2$ & 1 & 1 & 1 & 1 & 1 & 1 & 2 \\
\hline R12 & 2 & 1 & 1 & 1 & 2 & 1 & 2 & 1 & 1 & 2 & 1 & 1 & $1 / 2$ & 1 & 2 & 2 & 2 & 2 & 2 & 2 & 4 \\
\hline R13 & 1 & $1 / 2$ & $1 / 2$ & $1 / 2$ & 1 & $1 / 2$ & 1 & $1 / 2$ & $1 / 2$ & 1 & $1 / 2$ & $1 / 2$ & $1 / 4$ & $1 / 2$ & 1 & 1 & 1 & 1 & 1 & 1 & 2 \\
\hline R14 & 1 & $1 / 2$ & $1 / 2$ & $1 / 2$ & 1 & $1 / 2$ & 1 & $1 / 2$ & $1 / 2$ & 1 & $1 / 2$ & $1 / 2$ & $1 / 4$ & $1 / 2$ & 1 & 1 & 1 & 1 & 1 & 1 & 2 \\
\hline R15 & $1 / 2$ & $1 / 4$ & $1 / 4$ & $1 / 4$ & $1 / 2$ & $1 / 4$ & $1 / 2$ & $1 / 4$ & $1 / 4$ & $1 / 2$ & $1 / 4$ & $1 / 4$ & $1 / 6$ & $1 / 4$ & $1 / 2$ & $1 / 2$ & $1 / 2$ & $1 / 2$ & $1 / 2$ & $1 / 2$ & 1 \\
\hline R16 & 1 & $1 / 2$ & $1 / 2$ & $1 / 2$ & 1 & $1 / 2$ & 1 & $1 / 2$ & $1 / 2$ & 1 & $1 / 2$ & $1 / 2$ & $1 / 4$ & $1 / 2$ & 1 & 1 & 1 & 1 & 1 & 1 & 2 \\
\hline R17 & 1 & $1 / 2$ & $1 / 2$ & $1 / 2$ & 1 & $1 / 2$ & 1 & $1 / 2$ & $1 / 2$ & 1 & $1 / 2$ & $1 / 2$ & $1 / 4$ & $1 / 2$ & 1 & 1 & 1 & 1 & 1 & 1 & 2 \\
\hline R18 & 2 & 1 & 1 & 1 & 2 & 1 & 2 & 1 & 1 & 2 & 1 & 1 & $1 / 2$ & 1 & 2 & 2 & 2 & 2 & 2 & 2 & 4 \\
\hline R19 & 1 & $1 / 2$ & $1 / 2$ & $1 / 2$ & 1 & $1 / 2$ & 1 & $1 / 2$ & $1 / 2$ & 1 & $1 / 2$ & $1 / 2$ & $1 / 4$ & $1 / 2$ & 1 & 1 & 1 & 1 & 1 & 1 & 2 \\
\hline R20 & 1 & $1 / 2$ & $1 / 2$ & $1 / 2$ & 1 & $1 / 2$ & 1 & $1 / 2$ & $1 / 2$ & 1 & $1 / 2$ & $1 / 2$ & $1 / 4$ & $1 / 2$ & 1 & 1 & 1 & 1 & 1 & 1 & 2 \\
\hline R21 & 2 & 1 & 1 & 1 & 2 & 1 & 2 & 1 & 1 & 2 & 1 & 1 & $1 / 2$ & 1 & 2 & 2 & 2 & 2 & 2 & 2 & 4 \\
\hline R22 & 1 & $1 / 2$ & $1 / 2$ & $1 / 2$ & 1 & $1 / 2$ & 1 & $1 / 2$ & $1 / 2$ & 1 & $1 / 2$ & $1 / 2$ & $1 / 4$ & $1 / 2$ & 1 & 1 & 1 & 1 & 1 & 1 & 2 \\
\hline R23 & 2 & 1 & 1 & 1 & 2 & 1 & 2 & 1 & 1 & 2 & 1 & 1 & $1 / 2$ & 1 & 2 & 2 & 2 & 2 & 2 & 2 & 4 \\
\hline R24 & 2 & 1 & 1 & 1 & 2 & 1 & 2 & 1 & 1 & 2 & 1 & 1 & $1 / 2$ & 1 & 2 & 2 & 2 & 2 & 2 & 2 & 4 \\
\hline R25 & 2 & 1 & 1 & 1 & 2 & 1 & 2 & 1 & 1 & 2 & 1 & 1 & $1 / 2$ & 1 & 2 & 2 & 2 & 2 & 2 & 2 & 4 \\
\hline R26 & 1 & $1 / 2$ & $1 / 2$ & $1 / 2$ & 1 & $1 / 2$ & 1 & $1 / 2$ & $1 / 2$ & 1 & $1 / 2$ & $1 / 2$ & $1 / 4$ & $1 / 2$ & 1 & 1 & 1 & 1 & 1 & 1 & 2 \\
\hline R27 & 2 & 1 & 1 & 1 & 2 & 1 & 2 & 1 & 1 & 2 & 1 & 1 & $1 / 2$ & 1 & 2 & 2 & 2 & 2 & 2 & 2 & 4 \\
\hline R28 & 1 & $1 / 2$ & $1 / 2$ & $1 / 2$ & 1 & $1 / 2$ & 1 & $1 / 2$ & $1 / 2$ & 1 & $1 / 2$ & $1 / 2$ & $1 / 4$ & $1 / 2$ & 1 & 1 & 1 & 1 & 1 & 1 & 2 \\
\hline R29 & 2 & 1 & 1 & 1 & 2 & 1 & 2 & 1 & 1 & 2 & 1 & 1 & $1 / 2$ & 1 & 2 & 2 & 2 & 2 & 2 & 2 & 4 \\
\hline R30 & 2 & 1 & 1 & 1 & 2 & 1 & 2 & 1 & 1 & 2 & 1 & 1 & $1 / 2$ & 1 & 2 & 2 & 2 & 2 & 2 & 2 & 4 \\
\hline R31 & 1 & $1 / 2$ & $1 / 2$ & $1 / 2$ & 1 & $1 / 2$ & 1 & $1 / 2$ & $1 / 2$ & 1 & $1 / 2$ & $1 / 2$ & $1 / 4$ & $1 / 2$ & 1 & 1 & 1 & 1 & 1 & 1 & 2 \\
\hline R32 & 2 & 1 & 1 & 1 & 2 & 1 & 2 & 1 & 1 & 2 & 1 & 1 & $1 / 2$ & 1 & 2 & 2 & 2 & 2 & 2 & 2 & 4 \\
\hline R33 & 2 & 1 & 1 & 1 & 2 & 1 & 2 & 1 & 1 & 2 & 1 & 1 & $1 / 2$ & 1 & 2 & 2 & 2 & 2 & 2 & 2 & 4 \\
\hline R34 & 4 & 2 & 2 & 2 & 4 & 2 & 4 & 2 & 2 & 4 & 2 & 2 & 1 & 2 & 4 & 4 & 4 & 4 & 4 & 4 & 6 \\
\hline R35 & 2 & 1 & 1 & 1 & 2 & 1 & 2 & 1 & 1 & 2 & 1 & 1 & $1 / 2$ & 1 & 2 & 2 & 2 & 2 & 2 & 2 & 4 \\
\hline R36 & 1 & $1 / 2$ & $1 / 2$ & $1 / 2$ & 1 & $1 / 2$ & 1 & $1 / 2$ & $1 / 2$ & 1 & $1 / 2$ & $1 / 2$ & $1 / 4$ & $1 / 2$ & 1 & 1 & 1 & 1 & 1 & 1 & 2 \\
\hline R37 & 1 & $1 / 2$ & $1 / 2$ & $1 / 2$ & 1 & $1 / 2$ & 1 & $1 / 2$ & $1 / 2$ & 1 & $1 / 2$ & $1 / 2$ & $1 / 4$ & $1 / 2$ & 1 & 1 & 1 & 1 & 1 & 1 & 2 \\
\hline R38 & 1 & $1 / 2$ & $1 / 2$ & $1 / 2$ & 1 & $1 / 2$ & 1 & $1 / 2$ & $1 / 2$ & 1 & $1 / 2$ & $1 / 2$ & $1 / 4$ & $1 / 2$ & 1 & 1 & 1 & 1 & 1 & 1 & 2 \\
\hline R39 & 1 & $1 / 2$ & $1 / 2$ & $1 / 2$ & 1 & $1 / 2$ & 1 & $1 / 2$ & $1 / 2$ & 1 & $1 / 2$ & $1 / 2$ & $1 / 4$ & $1 / 2$ & 1 & 1 & 1 & 1 & 1 & 1 & 2 \\
\hline R40 & 1 & $1 / 2$ & $1 / 2$ & $1 / 2$ & 1 & $1 / 2$ & 1 & $1 / 2$ & $1 / 2$ & 1 & $1 / 2$ & $1 / 2$ & $1 / 4$ & $1 / 2$ & 1 & 1 & 1 & 1 & 1 & 1 & 2 \\
\hline R41 & 1 & $1 / 2$ & $1 / 2$ & $1 / 2$ & 1 & $1 / 2$ & 1 & $1 / 2$ & $1 / 2$ & 1 & $1 / 2$ & $1 / 2$ & $1 / 4$ & $1 / 2$ & 1 & 1 & 1 & 1 & 1 & 1 & 2 \\
\hline R42 & $1 / 2$ & $1 / 4$ & $1 / 4$ & $1 / 4$ & $1 / 2$ & $1 / 4$ & $1 / 2$ & $1 / 4$ & $1 / 4$ & $1 / 2$ & $1 / 4$ & $1 / 4$ & $1 / 6$ & $1 / 4$ & $1 / 2$ & $1 / 2$ & $1 / 2$ & $1 / 2$ & $1 / 2$ & $1 / 2$ & 1 \\
\hline R43 & 1 & $1 / 2$ & $1 / 2$ & $1 / 2$ & 1 & $1 / 2$ & 1 & $1 / 2$ & $1 / 2$ & 1 & $1 / 2$ & $1 / 2$ & $1 / 4$ & $1 / 2$ & 1 & 1 & 1 & 1 & 1 & 1 & 2 \\
\hline R44 & 1 & $1 / 2$ & $1 / 2$ & $1 / 2$ & 1 & $1 / 2$ & 1 & $1 / 2$ & $1 / 2$ & 1 & $1 / 2$ & $1 / 2$ & $1 / 4$ & $1 / 2$ & 1 & 1 & 1 & 1 & 1 & 1 & 2 \\
\hline R45 & 1 & $1 / 2$ & $1 / 2$ & $1 / 2$ & 1 & $1 / 2$ & 1 & $1 / 2$ & $1 / 2$ & 1 & $1 / 2$ & $1 / 2$ & $1 / 4$ & $1 / 2$ & 1 & 1 & 1 & 1 & 1 & 1 & 2 \\
\hline
\end{tabular}


Table A2. Cont.

\begin{tabular}{|c|c|c|c|c|c|c|c|c|c|c|c|c|c|c|c|c|c|c|c|c|c|}
\hline & R22 & R23 & R24 & R25 & R26 & R27 & R28 & R29 & R30 & R31 & R32 & R33 & R34 & R35 & R36 & R37 & R38 & R39 & R40 & R41 & R42 \\
\hline R46 & $1 / 2$ & $1 / 4$ & $1 / 4$ & $1 / 4$ & $1 / 2$ & $1 / 4$ & $1 / 2$ & $1 / 4$ & $1 / 4$ & $1 / 2$ & $1 / 4$ & $1 / 4$ & $1 / 6$ & $1 / 4$ & $1 / 2$ & $1 / 2$ & $1 / 2$ & $1 / 2$ & $1 / 2$ & $1 / 2$ & 1 \\
\hline R47 & 1 & $1 / 2$ & $1 / 2$ & $1 / 2$ & 1 & $1 / 2$ & 1 & $1 / 2$ & $1 / 2$ & 1 & $1 / 2$ & $1 / 2$ & $1 / 4$ & $1 / 2$ & 1 & 1 & 1 & 1 & 1 & 1 & 2 \\
\hline R48 & 1 & $1 / 2$ & $1 / 2$ & $1 / 2$ & 1 & $1 / 2$ & 1 & $1 / 2$ & $1 / 2$ & 1 & $1 / 2$ & $1 / 2$ & $1 / 4$ & $1 / 2$ & 1 & 1 & 1 & 1 & 1 & 1 & 2 \\
\hline R49 & 1 & $1 / 2$ & $1 / 2$ & $1 / 2$ & 1 & $1 / 2$ & 1 & $1 / 2$ & $1 / 2$ & 1 & $1 / 2$ & $1 / 2$ & $1 / 4$ & $1 / 2$ & 1 & 1 & 1 & 1 & 1 & 1 & 2 \\
\hline R50 & 1 & $1 / 2$ & $1 / 2$ & $1 / 2$ & 1 & $1 / 2$ & 1 & $1 / 2$ & $1 / 2$ & 1 & $1 / 2$ & $1 / 2$ & $1 / 4$ & $1 / 2$ & 1 & 1 & 1 & 1 & 1 & 1 & 2 \\
\hline R51 & $1 / 2$ & $1 / 4$ & $1 / 4$ & $1 / 4$ & $1 / 2$ & $1 / 4$ & $1 / 2$ & $1 / 4$ & $1 / 4$ & $1 / 2$ & $1 / 4$ & $1 / 4$ & $1 / 6$ & $1 / 4$ & $1 / 2$ & $1 / 2$ & $1 / 2$ & $1 / 2$ & $1 / 2$ & $1 / 2$ & 1 \\
\hline R52 & $1 / 2$ & $1 / 4$ & $1 / 4$ & $1 / 4$ & $1 / 2$ & $1 / 4$ & $1 / 2$ & $1 / 4$ & $1 / 4$ & $1 / 2$ & $1 / 4$ & $1 / 4$ & $1 / 6$ & $1 / 4$ & $1 / 2$ & $1 / 2$ & $1 / 2$ & $1 / 2$ & $1 / 2$ & $1 / 2$ & 1 \\
\hline R53 & 1 & $1 / 2$ & $1 / 2$ & $1 / 2$ & 1 & $1 / 2$ & 1 & $1 / 2$ & $1 / 2$ & 1 & $1 / 2$ & $1 / 2$ & $1 / 4$ & $1 / 2$ & 1 & 1 & 1 & 1 & 1 & 1 & 2 \\
\hline R54 & 1 & $1 / 2$ & $1 / 2$ & $1 / 2$ & 1 & $1 / 2$ & 1 & $1 / 2$ & $1 / 2$ & 1 & $1 / 2$ & $1 / 2$ & $1 / 4$ & $1 / 2$ & 1 & 1 & 1 & 1 & 1 & 1 & 2 \\
\hline R55 & 1 & $1 / 2$ & $1 / 2$ & $1 / 2$ & 1 & $1 / 2$ & 1 & $1 / 2$ & $1 / 2$ & 1 & $1 / 2$ & $1 / 2$ & $1 / 4$ & $1 / 2$ & 1 & 1 & 1 & 1 & 1 & 1 & 2 \\
\hline R56 & 1 & $1 / 2$ & $1 / 2$ & $1 / 2$ & 1 & $1 / 2$ & 1 & $1 / 2$ & $1 / 2$ & 1 & $1 / 2$ & $1 / 2$ & $1 / 4$ & $1 / 2$ & 1 & 1 & 1 & 1 & 1 & 1 & 2 \\
\hline R57 & 1 & $1 / 2$ & $1 / 2$ & $1 / 2$ & 1 & $1 / 2$ & 1 & $1 / 2$ & $1 / 2$ & 1 & $1 / 2$ & $1 / 2$ & $1 / 4$ & $1 / 2$ & 1 & 1 & 1 & 1 & 1 & 1 & 2 \\
\hline R58 & 1 & $1 / 2$ & $1 / 2$ & $1 / 2$ & 1 & $1 / 2$ & 1 & $1 / 2$ & $1 / 2$ & 1 & $1 / 2$ & $1 / 2$ & $1 / 4$ & $1 / 2$ & 1 & 1 & 1 & 1 & 1 & 1 & 2 \\
\hline R59 & 1 & $1 / 2$ & $1 / 2$ & $1 / 2$ & 1 & $1 / 2$ & 1 & $1 / 2$ & $1 / 2$ & 1 & $1 / 2$ & $1 / 2$ & $1 / 4$ & $1 / 2$ & 1 & 1 & 1 & 1 & 1 & 1 & 2 \\
\hline R60 & $1 / 2$ & $1 / 4$ & $1 / 4$ & $1 / 4$ & $1 / 2$ & $1 / 4$ & $1 / 2$ & $1 / 4$ & $1 / 4$ & $1 / 2$ & $1 / 4$ & $1 / 4$ & $1 / 6$ & $1 / 4$ & $1 / 2$ & $1 / 2$ & $1 / 2$ & $1 / 2$ & $1 / 2$ & $1 / 2$ & 1 \\
\hline R61 & $1 / 2$ & $1 / 4$ & $1 / 4$ & $1 / 4$ & $1 / 2$ & $1 / 4$ & $1 / 2$ & $1 / 4$ & $1 / 4$ & $1 / 2$ & $1 / 4$ & $1 / 4$ & $1 / 6$ & $1 / 4$ & $1 / 2$ & $1 / 2$ & $1 / 2$ & $1 / 2$ & $1 / 2$ & $1 / 2$ & 1 \\
\hline R62 & $1 / 2$ & $1 / 4$ & $1 / 4$ & $1 / 4$ & $1 / 2$ & $1 / 4$ & $1 / 2$ & $1 / 4$ & $1 / 4$ & $1 / 2$ & $1 / 4$ & $1 / 4$ & $1 / 6$ & $1 / 4$ & $1 / 2$ & $1 / 2$ & $1 / 2$ & $1 / 2$ & $1 / 2$ & $1 / 2$ & 1 \\
\hline R63 & $1 / 2$ & $1 / 4$ & $1 / 4$ & $1 / 4$ & $1 / 2$ & $1 / 4$ & $1 / 2$ & $1 / 4$ & $1 / 4$ & $1 / 2$ & $1 / 4$ & $1 / 4$ & $1 / 6$ & $1 / 4$ & $1 / 2$ & $1 / 2$ & $1 / 2$ & $1 / 2$ & $1 / 2$ & $1 / 2$ & 1 \\
\hline R64 & $1 / 2$ & $1 / 4$ & $1 / 4$ & $1 / 4$ & $1 / 2$ & $1 / 4$ & $1 / 2$ & $1 / 4$ & $1 / 4$ & $1 / 2$ & $1 / 4$ & $1 / 4$ & $1 / 6$ & $1 / 4$ & $1 / 2$ & $1 / 2$ & $1 / 2$ & $1 / 2$ & $1 / 2$ & $1 / 2$ & 1 \\
\hline
\end{tabular}

Table A3. Pairwise comparison matrix between risks according to frequency, Part 3.

\begin{tabular}{|c|c|c|c|c|c|c|c|c|c|c|c|c|c|c|c|c|c|c|c|c|c|c|}
\hline & R43 & R44 & R45 & R46 & R47 & R48 & R49 & R50 & R51 & R52 & R53 & R54 & R55 & R56 & R57 & R58 & R59 & R60 & R61 & R62 & R63 & R64 \\
\hline R1 & 2 & 2 & 2 & 4 & 2 & 2 & 2 & 2 & 4 & 4 & 2 & 2 & 2 & 2 & 2 & 2 & 2 & 4 & 4 & 4 & 4 & 4 \\
\hline $\mathbf{R} 2$ & $1 / 2$ & $1 / 2$ & $1 / 2$ & 1 & $1 / 2$ & $1 / 2$ & $1 / 2$ & $1 / 2$ & 1 & 1 & $1 / 2$ & $1 / 2$ & $1 / 2$ & $1 / 2$ & $1 / 2$ & $1 / 2$ & $1 / 2$ & 1 & 1 & 1 & 1 & 1 \\
\hline R3 & $1 / 2$ & $1 / 2$ & $1 / 2$ & 1 & $1 / 2$ & $1 / 2$ & $1 / 2$ & $1 / 2$ & 1 & 1 & $1 / 2$ & $1 / 2$ & $1 / 2$ & $1 / 2$ & $1 / 2$ & $1 / 2$ & $1 / 2$ & 1 & 1 & 1 & 1 & 1 \\
\hline R4 & 1 & 1 & 1 & 2 & 1 & 1 & 1 & 1 & 2 & 2 & 1 & 1 & 1 & 1 & 1 & 1 & 1 & 2 & 2 & 2 & 2 & 2 \\
\hline R5 & $1 / 2$ & $1 / 2$ & $1 / 2$ & 1 & $1 / 2$ & $1 / 2$ & $1 / 2$ & $1 / 2$ & 1 & 1 & $1 / 2$ & $1 / 2$ & $1 / 2$ & $1 / 2$ & $1 / 2$ & $1 / 2$ & $1 / 2$ & 1 & 1 & 1 & 1 & 1 \\
\hline R6 & 1 & 1 & 1 & 2 & 1 & 1 & 1 & 1 & 2 & 2 & 1 & 1 & 1 & 1 & 1 & 1 & 1 & 2 & 2 & 2 & 2 & 2 \\
\hline R7 & 1 & 1 & 1 & 2 & 1 & 1 & 1 & 1 & 2 & 2 & 1 & 1 & 1 & 1 & 1 & 1 & 1 & 2 & 2 & 2 & 2 & 2 \\
\hline R8 & 1 & 1 & 1 & 2 & 1 & 1 & 1 & 1 & 2 & 2 & 1 & 1 & 1 & 1 & 1 & 1 & 1 & 2 & 2 & 2 & 2 & 2 \\
\hline R9 & 1 & 1 & 1 & 2 & 1 & 1 & 1 & 1 & 2 & 2 & 1 & 1 & 1 & 1 & 1 & 1 & 1 & 2 & 2 & 2 & 2 & 2 \\
\hline R10 & 2 & 2 & 2 & 4 & 2 & 2 & 2 & 2 & 4 & 4 & 2 & 2 & 2 & 2 & 2 & 2 & 2 & 4 & 4 & 4 & 4 & 4 \\
\hline R11 & 1 & 1 & 1 & 2 & 1 & 1 & 1 & 1 & 2 & 2 & 1 & 1 & 1 & 1 & 1 & 1 & 1 & 2 & 2 & 2 & 2 & 2 \\
\hline R12 & 2 & 2 & 2 & 4 & 2 & 2 & 2 & 2 & 4 & 4 & 2 & 2 & 2 & 2 & 2 & 2 & 2 & 4 & 4 & 4 & 4 & 4 \\
\hline R13 & 1 & 1 & 1 & 2 & 1 & 1 & 1 & 1 & 2 & 2 & 1 & 1 & 1 & 1 & 1 & 1 & 1 & 2 & 2 & 2 & 2 & 2 \\
\hline R14 & 1 & 1 & 1 & 2 & 1 & 1 & 1 & 1 & 2 & 2 & 1 & 1 & 1 & 1 & 1 & 1 & 1 & 2 & 2 & 2 & 2 & 2 \\
\hline R15 & $1 / 2$ & $1 / 2$ & $1 / 2$ & 1 & $1 / 2$ & $1 / 2$ & $1 / 2$ & $1 / 2$ & 1 & 1 & $1 / 2$ & $1 / 2$ & $1 / 2$ & $1 / 2$ & $1 / 2$ & $1 / 2$ & $1 / 2$ & 1 & 1 & 1 & 1 & 1 \\
\hline R16 & 1 & 1 & 1 & 2 & 1 & 1 & 1 & 1 & 2 & 2 & 1 & 1 & 1 & 1 & 1 & 1 & 1 & 2 & 2 & 2 & 2 & 2 \\
\hline R17 & 1 & 1 & 1 & 2 & 1 & 1 & 1 & 1 & 2 & 2 & 1 & 1 & 1 & 1 & 1 & 1 & 1 & 2 & 2 & 2 & 2 & 2 \\
\hline R18 & 2 & 2 & 2 & 4 & 2 & 2 & 2 & 2 & 4 & 4 & 2 & 2 & 2 & 2 & 2 & 2 & 2 & 4 & 4 & 4 & 4 & 4 \\
\hline R19 & 1 & 1 & 1 & 2 & 1 & 1 & 1 & 1 & 2 & 2 & 1 & 1 & 1 & 1 & 1 & 1 & 1 & 2 & 2 & 2 & 2 & 2 \\
\hline R20 & 1 & 1 & 1 & 2 & 1 & 1 & 1 & 1 & 2 & 2 & 1 & 1 & 1 & 1 & 1 & 1 & 1 & 2 & 2 & 2 & 2 & 2 \\
\hline R21 & 2 & 2 & 2 & 4 & 2 & 2 & 2 & 2 & 4 & 4 & 2 & 2 & 2 & 2 & 2 & 2 & 2 & 4 & 4 & 4 & 4 & 4 \\
\hline R22 & 1 & 1 & 1 & 2 & 1 & 1 & 1 & 1 & 2 & 2 & 1 & 1 & 1 & 1 & 1 & 1 & 1 & 2 & 2 & 2 & 2 & 2 \\
\hline R23 & 2 & 2 & 2 & 4 & 2 & 2 & 2 & 2 & 4 & 4 & 2 & 2 & 2 & 2 & 2 & 2 & 2 & 4 & 4 & 4 & 4 & 4 \\
\hline R24 & 2 & 2 & 2 & 4 & 2 & 2 & 2 & 2 & 4 & 4 & 2 & 2 & 2 & 2 & 2 & 2 & 2 & 4 & 4 & 4 & 4 & 4 \\
\hline R25 & 2 & 2 & 2 & 4 & 2 & 2 & 2 & 2 & 4 & 4 & 2 & 2 & 2 & 2 & 2 & 2 & 2 & 4 & 4 & 4 & 4 & 4 \\
\hline R26 & 1 & 1 & 1 & 2 & 1 & 1 & 1 & 1 & 2 & 2 & 1 & 1 & 1 & 1 & 1 & 1 & 1 & 2 & 2 & 2 & 2 & 2 \\
\hline R27 & 2 & 2 & 2 & 4 & 2 & 2 & 2 & 2 & 4 & 4 & 2 & 2 & 2 & 2 & 2 & 2 & 2 & 4 & 4 & 4 & 4 & 4 \\
\hline R28 & 1 & 1 & 1 & 2 & 1 & 1 & 1 & 1 & 2 & 2 & 1 & 1 & 1 & 1 & 1 & 1 & 1 & 2 & 2 & 2 & 2 & 2 \\
\hline R29 & 2 & 2 & 2 & 4 & 2 & 2 & 2 & 2 & 4 & 4 & 2 & 2 & 2 & 2 & 2 & 2 & 2 & 4 & 4 & 4 & 4 & 4 \\
\hline R30 & 2 & 2 & 2 & 4 & 2 & 2 & 2 & 2 & 4 & 4 & 2 & 2 & 2 & 2 & 2 & 2 & 2 & 4 & 4 & 4 & 4 & 4 \\
\hline
\end{tabular}


Table A3. Cont.

$\begin{array}{llllllllllllllllllllll}\text { R43 } & \text { R44 } & \text { R45 } & \text { R46 } & \text { R47 } & \text { R48 } & \text { R49 } & \text { R50 } & \text { R51 } & \text { R52 } & \text { R53 } & \text { R54 } & \text { R55 } & \text { R56 } & \text { R57 } & \text { R58 } & \text { R59 } & \text { R60 } & \text { R61 } & \text { R62 } & \text { R63 } & \text { R64 }\end{array}$

\begin{tabular}{|c|c|c|c|c|c|c|c|c|c|c|c|c|c|c|c|c|c|c|c|c|c|c|}
\hline R31 & 1 & 1 & 1 & 2 & 1 & 1 & 1 & 1 & 2 & 2 & $\mathbf{1}$ & 1 & 1 & 1 & 1 & 1 & 1 & 2 & 2 & 2 & 2 & 2 \\
\hline R32 & 2 & 2 & 2 & 4 & 2 & 2 & 2 & 2 & 4 & 4 & 2 & 2 & 2 & 2 & 2 & 2 & 2 & 4 & 4 & 4 & 4 & 4 \\
\hline R33 & 2 & 2 & 2 & 4 & 2 & 2 & 2 & 2 & 4 & 4 & 2 & 2 & 2 & 2 & 2 & 2 & 2 & 4 & 4 & 4 & 4 & 4 \\
\hline R34 & 4 & 4 & 4 & 6 & 4 & 4 & 4 & 4 & 6 & 6 & 4 & 4 & 4 & 4 & 4 & 4 & 4 & 6 & 6 & 6 & 6 & 6 \\
\hline R35 & 2 & 2 & 2 & 4 & 2 & 2 & 2 & 2 & 4 & 4 & 2 & 2 & 2 & 2 & 2 & 2 & 2 & 4 & 4 & 4 & 4 & 4 \\
\hline R36 & 1 & 1 & 1 & 2 & 1 & 1 & 1 & 1 & 2 & 2 & 1 & 1 & 1 & $\mathbf{1}$ & 1 & 1 & 1 & 2 & 2 & 2 & 2 & 2 \\
\hline R37 & 1 & 1 & 1 & 2 & 1 & 1 & 1 & 1 & 2 & 2 & $\mathbf{1}$ & 1 & 1 & $\mathbf{1}$ & 1 & 1 & 1 & 2 & 2 & 2 & 2 & 2 \\
\hline R38 & 1 & 1 & 1 & 2 & 1 & 1 & 1 & 1 & 2 & 2 & $\mathbf{1}$ & 1 & 1 & $\mathbf{1}$ & 1 & 1 & 1 & 2 & 2 & 2 & 2 & 2 \\
\hline R39 & 1 & 1 & 1 & 2 & 1 & 1 & 1 & 1 & 2 & 2 & 1 & 1 & 1 & 1 & 1 & 1 & 1 & 2 & 2 & 2 & 2 & 2 \\
\hline R40 & 1 & 1 & 1 & 2 & 1 & 1 & 1 & 1 & 2 & 2 & 1 & 1 & 1 & 1 & 1 & 1 & 1 & 2 & 2 & 2 & 2 & 2 \\
\hline R41 & 1 & 1 & 1 & 2 & 1 & 1 & 1 & 1 & 2 & 2 & 1 & 1 & 1 & $\mathbf{1}$ & 1 & 1 & 1 & 2 & 2 & 2 & 2 & 2 \\
\hline R42 & $1 / 2$ & $1 / 2$ & $1 / 2$ & 1 & $1 / 2$ & $1 / 2$ & $1 / 2$ & $1 / 2$ & 1 & 1 & $1 / 2$ & $1 / 2$ & $1 / 2$ & $1 / 2$ & $1 / 2$ & $1 / 2$ & $1 / 2$ & 1 & 1 & 1 & 1 & 1 \\
\hline R43 & 1 & 1 & 1 & 2 & 1 & 1 & 1 & 1 & 2 & 2 & 1 & 1 & 1 & 1 & 1 & 1 & 1 & 2 & 2 & 2 & 2 & 2 \\
\hline R44 & 1 & 1 & 1 & 2 & 1 & 1 & 1 & 1 & 2 & 2 & 1 & 1 & 1 & 1 & 1 & 1 & 1 & 2 & 2 & 2 & 2 & 2 \\
\hline $\mathbf{R} 45$ & 1 & 1 & 1 & 2 & 1 & 1 & 1 & 1 & 2 & 2 & 1 & 1 & 1 & 1 & 1 & 1 & 1 & 2 & 2 & 2 & 2 & 2 \\
\hline R46 & $1 / 2$ & $1 / 2$ & $1 / 2$ & 1 & $1 / 2$ & $1 / 2$ & $1 / 2$ & $1 / 2$ & 1 & 1 & $1 / 2$ & $1 / 2$ & $1 / 2$ & $1 / 2$ & $1 / 2$ & $1 / 2$ & $1 / 2$ & 1 & 1 & 1 & 1 & 1 \\
\hline R47 & 1 & 1 & 1 & 2 & 1 & 1 & 1 & 1 & 2 & 2 & 1 & 1 & 1 & 1 & 1 & 1 & 1 & 2 & 2 & 2 & 2 & 2 \\
\hline R48 & 1 & 1 & 1 & 2 & 1 & 1 & 1 & 1 & 2 & 2 & 1 & 1 & 1 & 1 & 1 & 1 & 1 & 2 & 2 & 2 & 2 & 2 \\
\hline R49 & 1 & 1 & 1 & 2 & 1 & 1 & 1 & 1 & 2 & 2 & 1 & 1 & 1 & 1 & 1 & 1 & 1 & 2 & 2 & 2 & 2 & 2 \\
\hline R50 & 1 & 1 & 1 & 2 & 1 & 1 & 1 & 1 & 2 & 2 & 1 & 1 & 1 & 1 & 1 & 1 & 1 & 2 & 2 & 2 & 2 & 2 \\
\hline R51 & $1 / 2$ & $1 / 2$ & $1 / 2$ & 1 & $1 / 2$ & $1 / 2$ & $1 / 2$ & $1 / 2$ & 1 & 1 & $1 / 2$ & $1 / 2$ & $1 / 2$ & $1 / 2$ & $1 / 2$ & $1 / 2$ & $1 / 2$ & 1 & 1 & 1 & 1 & 1 \\
\hline R52 & $1 / 2$ & $1 / 2$ & $1 / 2$ & 1 & $1 / 2$ & $1 / 2$ & $1 / 2$ & $1 / 2$ & 1 & 1 & $1 / 2$ & $1 / 2$ & $1 / 2$ & $1 / 2$ & $1 / 2$ & $1 / 2$ & $1 / 2$ & 1 & 1 & 1 & 1 & 1 \\
\hline R53 & 1 & 1 & 1 & 2 & 1 & 1 & 1 & 1 & 2 & 2 & 1 & 1 & 1 & 1 & 1 & 1 & 1 & 2 & 2 & 2 & 2 & 2 \\
\hline R54 & 1 & 1 & 1 & 2 & 1 & 1 & 1 & 1 & 2 & 2 & 1 & 1 & 1 & 1 & 1 & 1 & 1 & 2 & 2 & 2 & 2 & 2 \\
\hline R55 & 1 & 1 & 1 & 2 & 1 & 1 & 1 & 1 & 2 & 2 & 1 & 1 & 1 & 1 & 1 & 1 & 1 & 2 & 2 & 2 & 2 & 2 \\
\hline R56 & 1 & 1 & 1 & 2 & 1 & 1 & 1 & 1 & 2 & 2 & 1 & 1 & 1 & 1 & 1 & 1 & 1 & 2 & 2 & 2 & 2 & 2 \\
\hline R57 & 1 & 1 & 1 & 2 & 1 & 1 & 1 & 1 & 2 & 2 & 1 & 1 & 1 & 1 & 1 & 1 & 1 & 2 & 2 & 2 & 2 & 2 \\
\hline R58 & 1 & 1 & 1 & 2 & 1 & 1 & 1 & 1 & 2 & 2 & 1 & 1 & 1 & 1 & 1 & 1 & 1 & 2 & 2 & 2 & 2 & 2 \\
\hline R59 & 1 & 1 & 1 & 2 & 1 & 1 & 1 & 1 & 2 & 2 & 1 & 1 & 1 & 1 & 1 & 1 & 1 & 2 & 2 & 2 & 2 & 2 \\
\hline R60 & $1 / 2$ & $1 / 2$ & $1 / 2$ & 1 & $1 / 2$ & $1 / 2$ & $1 / 2$ & $1 / 2$ & 1 & 1 & $1 / 2$ & $1 / 2$ & $1 / 2$ & $1 / 2$ & $1 / 2$ & $1 / 2$ & $1 / 2$ & 1 & 1 & 1 & 1 & 1 \\
\hline R61 & $1 / 2$ & $1 / 2$ & $1 / 2$ & 1 & $1 / 2$ & $1 / 2$ & $1 / 2$ & $1 / 2$ & 1 & 1 & $1 / 2$ & $1 / 2$ & $1 / 2$ & $1 / 2$ & $1 / 2$ & $1 / 2$ & $1 / 2$ & 1 & 1 & 1 & 1 & 1 \\
\hline R62 & $1 / 2$ & $1 / 2$ & $1 / 2$ & 1 & $1 / 2$ & $1 / 2$ & $1 / 2$ & $1 / 2$ & 1 & 1 & $1 / 2$ & $1 / 2$ & $1 / 2$ & $1 / 2$ & $1 / 2$ & $1 / 2$ & $1 / 2$ & 1 & 1 & 1 & 1 & 1 \\
\hline R63 & $1 / 2$ & $1 / 2$ & $1 / 2$ & 1 & $1 / 2$ & $1 / 2$ & $1 / 2$ & $1 / 2$ & 1 & 1 & $1 / 2$ & $1 / 2$ & $1 / 2$ & $1 / 2$ & $1 / 2$ & $1 / 2$ & $1 / 2$ & 1 & 1 & 1 & 1 & 1 \\
\hline R64 & $1 / 2$ & $1 / 2$ & $1 / 2$ & 1 & $1 / 2$ & $1 / 2$ & $1 / 2$ & $1 / 2$ & 1 & 1 & $1 / 2$ & $1 / 2$ & $1 / 2$ & $1 / 2$ & $1 / 2$ & $1 / 2$ & $1 / 2$ & 1 & 1 & 1 & 1 & 1 \\
\hline
\end{tabular}

Table A4. Pairwise comparison matrix between risks according to risks' gravity, Part 1.

\begin{tabular}{|c|c|c|c|c|c|c|c|c|c|c|c|c|c|c|c|c|c|c|c|c|c|}
\hline & R1 & R2 & R3 & R4 & R5 & R6 & R7 & R8 & R9 & R10 & R11 & R12 & R13 & R14 & R15 & R16 & R17 & R18 & R19 & R20 & R21 \\
\hline R1 & 1 & 1 & $1 / 2$ & 1 & 2 & $1 / 2$ & $1 / 4$ & $1 / 2$ & $1 / 2$ & $1 / 2$ & $1 / 2$ & $1 / 2$ & $1 / 2$ & $1 / 4$ & 1 & 1 & $1 / 4$ & $1 / 6$ & 2 & 2 & 2 \\
\hline R2 & 1 & 1 & $1 / 2$ & 1 & 2 & $1 / 2$ & $1 / 4$ & $1 / 2$ & $1 / 2$ & $1 / 2$ & $1 / 2$ & $1 / 2$ & $1 / 2$ & $1 / 4$ & 1 & 1 & $1 / 4$ & $1 / 6$ & 2 & 2 & 2 \\
\hline R3 & 2 & 2 & 1 & 2 & 4 & 1 & $1 / 2$ & 1 & 1 & 1 & 1 & 1 & 1 & $1 / 2$ & 2 & 2 & $1 / 2$ & $1 / 4$ & 4 & 4 & 4 \\
\hline R4 & 1 & 1 & $1 / 2$ & 1 & 2 & $1 / 2$ & $1 / 4$ & $1 / 2$ & $1 / 2$ & $1 / 2$ & $1 / 2$ & $1 / 2$ & $1 / 2$ & $1 / 4$ & 1 & 1 & $1 / 4$ & $1 / 6$ & 2 & 2 & 2 \\
\hline R5 & $1 / 2$ & $1 / 2$ & $1 / 4$ & $1 / 2$ & 1 & $1 / 4$ & $1 / 6$ & $1 / 4$ & $1 / 4$ & $1 / 4$ & $1 / 4$ & $1 / 4$ & $1 / 4$ & $1 / 6$ & $1 / 2$ & $1 / 2$ & $1 / 6$ & $1 / 8$ & 1 & 1 & 1 \\
\hline R6 & 2 & 2 & 1 & 2 & 4 & 1 & $1 / 2$ & 1 & 1 & 1 & 1 & 1 & 1 & $1 / 2$ & 2 & 2 & $1 / 2$ & $1 / 4$ & 4 & 4 & 4 \\
\hline R7 & 4 & 4 & 2 & 4 & 6 & 2 & 1 & 2 & 2 & 2 & 2 & 2 & 2 & 1 & 4 & 4 & 1 & $1 / 2$ & 6 & 6 & 6 \\
\hline R8 & 2 & 2 & 1 & 2 & 4 & 1 & $1 / 2$ & 1 & 1 & 1 & 1 & 1 & 1 & $1 / 2$ & 2 & 2 & $1 / 2$ & $1 / 4$ & 4 & 4 & 4 \\
\hline R9 & 2 & 2 & 1 & 2 & 4 & 1 & $1 / 2$ & 1 & 1 & 1 & 1 & 1 & 1 & $1 / 2$ & 2 & 2 & $1 / 2$ & $1 / 4$ & 4 & 4 & 4 \\
\hline R10 & 2 & 2 & 1 & 2 & 4 & 1 & $1 / 2$ & 1 & 1 & 1 & 1 & 1 & 1 & $1 / 2$ & 2 & 2 & $1 / 2$ & $1 / 4$ & 4 & 4 & 4 \\
\hline R11 & 2 & 2 & 1 & 2 & 4 & 1 & $1 / 2$ & 1 & 1 & 1 & 1 & 1 & 1 & $1 / 2$ & 2 & 2 & $1 / 2$ & $1 / 4$ & 4 & 4 & 4 \\
\hline R12 & 2 & 2 & 1 & 2 & 4 & 1 & $1 / 2$ & 1 & 1 & 1 & 1 & 1 & 1 & $1 / 2$ & 2 & 2 & $1 / 2$ & $1 / 4$ & 4 & 4 & 4 \\
\hline R13 & 2 & 2 & 1 & 2 & 4 & 1 & $1 / 2$ & 1 & 1 & 1 & 1 & 1 & 1 & $1 / 2$ & 2 & 2 & $1 / 2$ & $1 / 4$ & 4 & 4 & 4 \\
\hline R14 & 4 & 4 & 2 & 4 & 6 & 2 & 1 & 2 & 2 & 2 & 2 & 2 & 2 & 1 & 4 & 4 & 1 & $1 / 2$ & 6 & 6 & 6 \\
\hline R15 & 1 & 1 & $1 / 2$ & 1 & 2 & $1 / 2$ & $1 / 4$ & $1 / 2$ & $1 / 2$ & $1 / 2$ & $1 / 2$ & $1 / 2$ & $1 / 2$ & $1 / 4$ & 1 & 1 & $1 / 4$ & $1 / 6$ & 2 & 2 & 2 \\
\hline
\end{tabular}


Table A4. Cont.

\begin{tabular}{|c|c|c|c|c|c|c|c|c|c|c|c|c|c|c|c|c|c|c|c|c|c|}
\hline & R1 & R2 & R3 & R4 & R5 & R6 & R7 & R8 & R9 & R10 & R11 & R12 & R13 & R14 & R15 & R16 & R17 & R18 & R19 & R20 & R21 \\
\hline R16 & 1 & 1 & $1 / 2$ & 1 & 2 & $1 / 2$ & $1 / 4$ & $1 / 2$ & $1 / 2$ & $1 / 2$ & $1 / 2$ & $1 / 2$ & $1 / 2$ & $1 / 4$ & 1 & 1 & $1 / 4$ & $1 / 6$ & 2 & 2 & 2 \\
\hline R17 & 4 & 4 & 2 & 4 & 6 & 2 & 1 & 2 & 2 & 2 & 2 & 2 & 2 & 1 & 4 & 4 & 1 & $1 / 2$ & 6 & 6 & 6 \\
\hline R18 & 6 & 6 & 4 & 6 & 8 & 4 & 2 & 4 & 4 & 4 & 4 & 4 & 4 & 2 & 6 & 6 & 2 & 1 & 8 & 8 & 8 \\
\hline R19 & $1 / 2$ & $1 / 2$ & $1 / 4$ & $1 / 2$ & 1 & $1 / 4$ & $1 / 6$ & $1 / 4$ & $1 / 4$ & $1 / 4$ & $1 / 4$ & $1 / 4$ & $1 / 4$ & $1 / 6$ & $1 / 2$ & $1 / 2$ & $1 / 6$ & $1 / 8$ & 1 & 1 & 1 \\
\hline R20 & $1 / 2$ & $1 / 2$ & $1 / 4$ & $1 / 2$ & 1 & $1 / 4$ & $1 / 6$ & $1 / 4$ & $1 / 4$ & $1 / 4$ & $1 / 4$ & $1 / 4$ & $1 / 4$ & $1 / 6$ & $1 / 2$ & $1 / 2$ & $1 / 6$ & $1 / 8$ & 1 & 1 & 1 \\
\hline R21 & $1 / 2$ & $1 / 2$ & $1 / 4$ & $1 / 2$ & 1 & $1 / 4$ & $1 / 6$ & $1 / 4$ & $1 / 4$ & $1 / 4$ & $1 / 4$ & $1 / 4$ & $1 / 4$ & $1 / 6$ & $1 / 2$ & $1 / 2$ & $1 / 6$ & $1 / 8$ & 1 & 1 & 1 \\
\hline R22 & 1 & 1 & $1 / 2$ & 1 & 2 & $1 / 2$ & $1 / 4$ & $1 / 2$ & $1 / 2$ & $1 / 2$ & $1 / 2$ & $1 / 2$ & $1 / 2$ & $1 / 4$ & 1 & 1 & $1 / 4$ & $1 / 6$ & 2 & 2 & 2 \\
\hline R23 & 1 & 1 & $1 / 2$ & 1 & 2 & $1 / 2$ & $1 / 4$ & $1 / 2$ & $1 / 2$ & $1 / 2$ & $1 / 2$ & $1 / 2$ & $1 / 2$ & $1 / 4$ & 1 & 1 & $1 / 4$ & $1 / 6$ & 2 & 2 & 2 \\
\hline R24 & 1 & 1 & $1 / 2$ & 1 & 2 & $1 / 2$ & $1 / 4$ & $1 / 2$ & $1 / 2$ & $1 / 2$ & $1 / 2$ & $1 / 2$ & $1 / 2$ & $1 / 4$ & 1 & 1 & $1 / 4$ & $1 / 6$ & 2 & 2 & 2 \\
\hline R25 & 1 & 1 & $1 / 2$ & 1 & 2 & $1 / 2$ & $1 / 4$ & $1 / 2$ & $1 / 2$ & $1 / 2$ & $1 / 2$ & $1 / 2$ & $1 / 2$ & $1 / 4$ & 1 & 1 & $1 / 4$ & $1 / 6$ & 2 & 2 & 2 \\
\hline R26 & 2 & 2 & 1 & 2 & 4 & 1 & $1 / 2$ & 1 & 1 & 1 & 1 & 1 & 1 & $1 / 2$ & 2 & 2 & $1 / 2$ & $1 / 4$ & 4 & 4 & 4 \\
\hline R27 & 4 & 4 & 2 & 4 & 6 & 2 & 1 & 2 & 2 & 2 & 2 & 2 & 2 & 1 & 4 & 4 & 1 & $1 / 2$ & 6 & 6 & 6 \\
\hline R28 & $1 / 2$ & $1 / 2$ & $1 / 4$ & $1 / 2$ & 1 & $1 / 4$ & $1 / 6$ & $1 / 4$ & $1 / 4$ & $1 / 4$ & $1 / 4$ & $1 / 4$ & $1 / 4$ & $1 / 6$ & $1 / 2$ & $1 / 2$ & $1 / 6$ & $1 / 8$ & 1 & 1 & 1 \\
\hline R29 & 1 & 1 & $1 / 2$ & 1 & 2 & $1 / 2$ & $1 / 4$ & $1 / 2$ & $1 / 2$ & $1 / 2$ & $1 / 2$ & $1 / 2$ & $1 / 2$ & $1 / 4$ & 1 & 1 & $1 / 4$ & $1 / 6$ & 2 & 2 & 2 \\
\hline R30 & 4 & 4 & 2 & 4 & 6 & 2 & 1 & 2 & 2 & 2 & 2 & 2 & 2 & 1 & 4 & 4 & 1 & $1 / 2$ & 6 & 6 & 6 \\
\hline R31 & 2 & 2 & 1 & 2 & 4 & 1 & $1 / 2$ & 1 & 1 & 1 & 1 & 1 & 1 & $1 / 2$ & 2 & 2 & $1 / 2$ & $1 / 4$ & 4 & 4 & 4 \\
\hline R32 & 1 & 1 & $1 / 2$ & 1 & 2 & $1 / 2$ & $1 / 4$ & $1 / 2$ & $1 / 2$ & $1 / 2$ & $1 / 2$ & $1 / 2$ & $1 / 2$ & $1 / 4$ & 1 & 1 & $1 / 4$ & $1 / 6$ & 2 & 2 & 2 \\
\hline R33 & 4 & 4 & 2 & 4 & 6 & 2 & 1 & 2 & 2 & 2 & 2 & 2 & 2 & 1 & 4 & 4 & 1 & $1 / 2$ & 6 & 6 & 6 \\
\hline R34 & 4 & 4 & 2 & 4 & 6 & 2 & 1 & 2 & 2 & 2 & 2 & 2 & 2 & 1 & 4 & 4 & 1 & $1 / 2$ & 6 & 6 & 6 \\
\hline R35 & 2 & 2 & 1 & 2 & 4 & 1 & $1 / 2$ & 1 & 1 & 1 & 1 & 1 & 1 & $1 / 2$ & 2 & 2 & $1 / 2$ & $1 / 4$ & 4 & 4 & 4 \\
\hline R36 & 6 & 6 & 4 & 6 & 8 & 4 & 2 & 4 & 4 & 4 & 4 & 4 & 4 & 2 & 6 & 6 & 2 & 1 & 8 & 8 & 8 \\
\hline R37 & 2 & 2 & 1 & 2 & 4 & 1 & $1 / 2$ & 1 & 1 & 1 & 1 & 1 & 1 & $1 / 2$ & 2 & 2 & $1 / 2$ & $1 / 4$ & 4 & 4 & 4 \\
\hline R38 & 1 & 1 & $1 / 2$ & 1 & 2 & $1 / 2$ & $1 / 4$ & $1 / 2$ & $1 / 2$ & $1 / 2$ & $1 / 2$ & $1 / 2$ & $1 / 2$ & $1 / 4$ & 1 & 1 & $1 / 4$ & $1 / 6$ & 2 & 2 & 2 \\
\hline R39 & 1 & 1 & $1 / 2$ & 1 & 2 & $1 / 2$ & $1 / 4$ & $1 / 2$ & $1 / 2$ & $1 / 2$ & $1 / 2$ & $1 / 2$ & $1 / 2$ & $1 / 4$ & 1 & 1 & $1 / 4$ & $1 / 6$ & 2 & 2 & 2 \\
\hline R40 & 1 & 1 & $1 / 2$ & 1 & 2 & $1 / 2$ & $1 / 4$ & $1 / 2$ & $1 / 2$ & $1 / 2$ & $1 / 2$ & $1 / 2$ & $1 / 2$ & $1 / 4$ & 1 & 1 & $1 / 4$ & $1 / 6$ & 2 & 2 & 2 \\
\hline R41 & 2 & 2 & 1 & 2 & 4 & 1 & $1 / 2$ & 1 & 1 & 1 & 1 & 1 & 1 & $1 / 2$ & 2 & 2 & $1 / 2$ & $1 / 4$ & 4 & 4 & 4 \\
\hline R42 & 4 & 4 & 2 & 4 & 6 & 2 & 1 & 2 & 2 & 2 & 2 & 2 & 2 & 1 & 4 & 4 & 1 & $1 / 2$ & 6 & 6 & 6 \\
\hline R43 & 4 & 4 & 2 & 4 & 6 & 2 & 1 & 2 & 2 & 2 & 2 & 2 & 2 & 1 & 4 & 4 & 1 & $1 / 2$ & 6 & 6 & 6 \\
\hline R44 & 4 & 4 & 2 & 4 & 6 & 2 & 1 & 2 & 2 & 2 & 2 & 2 & 2 & 1 & 4 & 4 & 1 & $1 / 2$ & 6 & 6 & 6 \\
\hline R45 & 4 & 4 & 2 & 4 & 6 & 2 & 1 & 2 & 2 & 2 & 2 & 2 & 2 & 1 & 4 & 4 & 1 & $1 / 2$ & 6 & 6 & 6 \\
\hline R46 & $1 / 2$ & $1 / 2$ & $1 / 4$ & $1 / 2$ & 1 & $1 / 4$ & $1 / 6$ & $1 / 4$ & $1 / 4$ & $1 / 4$ & $1 / 4$ & $1 / 4$ & $1 / 4$ & $1 / 6$ & $1 / 2$ & $1 / 2$ & $1 / 6$ & $1 / 8$ & 1 & 1 & 1 \\
\hline R47 & 2 & 2 & 1 & 2 & 4 & 1 & $1 / 2$ & 1 & 1 & 1 & 1 & 1 & 1 & $1 / 2$ & 2 & 2 & $1 / 2$ & $1 / 4$ & 4 & 4 & 4 \\
\hline R48 & 1 & 1 & $1 / 2$ & 1 & 2 & $1 / 2$ & $1 / 4$ & $1 / 2$ & $1 / 2$ & $1 / 2$ & $1 / 2$ & $1 / 2$ & $1 / 2$ & $1 / 4$ & 1 & 1 & $1 / 4$ & $1 / 6$ & 2 & 2 & 2 \\
\hline R49 & 4 & 4 & 2 & 4 & 6 & 2 & 1 & 2 & 2 & 2 & 2 & 2 & 2 & 1 & 4 & 4 & 1 & $1 / 2$ & 6 & 6 & 6 \\
\hline R50 & 1 & 1 & $1 / 2$ & 1 & 2 & $1 / 2$ & $1 / 4$ & $1 / 2$ & $1 / 2$ & $1 / 2$ & $1 / 2$ & $1 / 2$ & $1 / 2$ & $1 / 4$ & 1 & 1 & $1 / 4$ & $1 / 6$ & 2 & 2 & 2 \\
\hline R51 & 1 & 1 & $1 / 2$ & 1 & 2 & $1 / 2$ & $1 / 4$ & $1 / 2$ & $1 / 2$ & $1 / 2$ & $1 / 2$ & $1 / 2$ & $1 / 2$ & $1 / 4$ & 1 & 1 & $1 / 4$ & $1 / 6$ & 2 & 2 & 2 \\
\hline R52 & 2 & 2 & 1 & 2 & 4 & 1 & $1 / 2$ & 1 & 1 & 1 & 1 & 1 & 1 & $1 / 2$ & 2 & 2 & $1 / 2$ & $1 / 4$ & 4 & 4 & 4 \\
\hline R53 & 1 & 1 & $1 / 2$ & 1 & 2 & $1 / 2$ & $1 / 4$ & $1 / 2$ & $1 / 2$ & $1 / 2$ & $1 / 2$ & $1 / 2$ & $1 / 2$ & $1 / 4$ & 1 & 1 & $1 / 4$ & $1 / 6$ & 2 & 2 & 2 \\
\hline R54 & 2 & 2 & 1 & 2 & 4 & 1 & $1 / 2$ & 1 & 1 & 1 & 1 & 1 & 1 & $1 / 2$ & 2 & 2 & $1 / 2$ & $1 / 4$ & 4 & 4 & 4 \\
\hline R55 & 2 & 2 & 1 & 2 & 4 & 1 & $1 / 2$ & 1 & 1 & 1 & 1 & 1 & 1 & $1 / 2$ & 2 & 2 & $1 / 2$ & $1 / 4$ & 4 & 4 & 4 \\
\hline R56 & 4 & 4 & 2 & 4 & 6 & 2 & 1 & 2 & 2 & 2 & 2 & 2 & 2 & 1 & 4 & 4 & 1 & $1 / 2$ & 6 & 6 & 6 \\
\hline R57 & 2 & 2 & 1 & 2 & 4 & 1 & $1 / 2$ & 1 & 1 & 1 & 1 & 1 & 1 & $1 / 2$ & 2 & 2 & $1 / 2$ & $1 / 4$ & 4 & 4 & 4 \\
\hline R58 & 6 & 6 & 4 & 6 & 8 & 4 & 2 & 4 & 4 & 4 & 4 & 4 & 4 & 2 & 6 & 6 & 2 & 1 & 8 & 8 & 8 \\
\hline R59 & 2 & 2 & 1 & 2 & 4 & 1 & $1 / 2$ & 1 & 1 & 1 & 1 & 1 & 1 & $1 / 2$ & 2 & 2 & $1 / 2$ & $1 / 4$ & 4 & 4 & 4 \\
\hline R60 & 4 & 4 & 2 & 4 & 6 & 2 & 1 & 2 & 2 & 2 & 2 & 2 & 2 & 1 & 4 & 4 & 1 & $1 / 2$ & 6 & 6 & 6 \\
\hline R61 & 4 & 4 & 2 & 4 & 6 & 2 & 1 & 2 & 2 & 2 & 2 & 2 & 2 & 1 & 4 & 4 & 1 & $1 / 2$ & 6 & 6 & 6 \\
\hline R62 & 4 & 4 & 2 & 4 & 6 & 2 & 1 & 2 & 2 & 2 & 2 & 2 & 2 & 1 & 4 & 4 & 1 & $1 / 2$ & 6 & 6 & 6 \\
\hline R63 & 4 & 4 & 2 & 4 & 6 & 2 & 1 & 2 & 2 & 2 & 2 & 2 & 2 & 1 & 4 & 4 & 1 & $1 / 2$ & 6 & 6 & 6 \\
\hline R64 & 6 & 6 & 4 & 6 & 8 & 4 & 2 & 4 & 4 & 4 & 4 & 4 & 4 & 2 & 6 & 6 & 2 & 1 & 8 & 8 & 8 \\
\hline
\end{tabular}

Table A5. Pairwise comparison matrix between risks according to risks' gravity, Part 2.

\begin{tabular}{|c|c|c|c|c|c|c|c|c|c|c|c|c|c|c|c|c|c|c|c|c|c|}
\hline & R22 & R23 & R24 & R25 & R26 & R27 & R28 & R29 & R30 & R31 & R32 & R33 & R34 & R35 & R36 & R37 & R38 & R39 & R40 & R41 & R42 \\
\hline 21 & 1 & 1 & 1 & 1 & $1 / 2$ & $1 / 4$ & 2 & 1 & $1 / 4$ & $1 / 2$ & 1 & $1 / 4$ & $1 / 4$ & $1 / 4$ & $1 / 6$ & $1 / 2$ & 1 & 1 & 1 & $1 / 2$ & $1 / 4$ \\
\hline R2 & 1 & 1 & 1 & 1 & $1 / 2$ & $1 / 4$ & 2 & 1 & $1 / 4$ & $1 / 2$ & 1 & $1 / 4$ & $1 / 4$ & $1 / 4$ & $1 / 6$ & $1 / 2$ & 1 & 1 & 1 & $1 / 2$ & $1 / 4$ \\
\hline R3 & 2 & 2 & 2 & 2 & 1 & $1 / 2$ & 4 & 2 & $1 / 2$ & 1 & 2 & $1 / 2$ & $1 / 2$ & 1 & $1 / 4$ & 1 & 2 & 2 & 2 & 1 & $1 / 2$ \\
\hline
\end{tabular}


Table A5. Cont.

\begin{tabular}{|c|c|c|c|c|c|c|c|c|c|c|c|c|c|c|c|c|c|c|c|c|c|}
\hline & R22 & R23 & R24 & R25 & R26 & R27 & R28 & R29 & R30 & R31 & R32 & R33 & R34 & R35 & R36 & R37 & R38 & R39 & R40 & R41 & R42 \\
\hline R4 & 1 & 1 & 1 & 1 & $1 / 2$ & $1 / 4$ & 2 & 1 & $1 / 4$ & $1 / 2$ & 1 & $1 / 4$ & $1 / 4$ & $1 / 4$ & $1 / 6$ & $1 / 2$ & 1 & 1 & 1 & $1 / 2$ & $1 / 4$ \\
\hline R5 & $1 / 2$ & $1 / 2$ & $1 / 2$ & $1 / 2$ & $1 / 4$ & $1 / 6$ & 1 & $1 / 2$ & $1 / 6$ & $1 / 4$ & $1 / 2$ & $1 / 6$ & $1 / 6$ & $1 / 4$ & $1 / 8$ & $1 / 4$ & $1 / 2$ & $1 / 2$ & $1 / 2$ & $1 / 4$ & $1 / 6$ \\
\hline R6 & 2 & 2 & 2 & 2 & 1 & $1 / 2$ & 4 & 2 & $1 / 2$ & 1 & 2 & $1 / 2$ & $1 / 2$ & 1 & $1 / 4$ & 1 & 2 & 2 & 2 & 1 & $1 / 2$ \\
\hline R7 & 4 & 4 & 4 & 4 & 2 & 1 & 6 & 4 & 1 & 2 & 4 & 1 & 1 & 2 & $1 / 2$ & 2 & 4 & 4 & 4 & 2 & 1 \\
\hline R8 & 2 & 2 & 2 & 2 & 1 & $1 / 2$ & 4 & 2 & $1 / 2$ & 1 & 2 & $1 / 2$ & $1 / 2$ & 1 & $1 / 4$ & 1 & 2 & 2 & 2 & 1 & $1 / 2$ \\
\hline R9 & 2 & 2 & 2 & 2 & 1 & $1 / 2$ & 4 & 2 & $1 / 2$ & 1 & 2 & $1 / 2$ & $1 / 2$ & 1 & $1 / 4$ & 1 & 2 & 2 & 2 & 1 & $1 / 2$ \\
\hline R10 & 2 & 2 & 2 & 2 & 1 & $1 / 2$ & 4 & 2 & $1 / 2$ & 1 & 2 & $1 / 2$ & $1 / 2$ & 1 & $1 / 4$ & 1 & 2 & 2 & 2 & 1 & $1 / 2$ \\
\hline R11 & 2 & 2 & 2 & 2 & 1 & $1 / 2$ & 4 & 2 & $1 / 2$ & 1 & 2 & $1 / 2$ & $1 / 2$ & 1 & $1 / 4$ & 1 & 2 & 2 & 2 & 1 & $1 / 2$ \\
\hline R12 & 2 & 2 & 2 & 2 & 1 & $1 / 2$ & 4 & 2 & $1 / 2$ & 1 & 2 & $1 / 2$ & $1 / 2$ & 1 & $1 / 4$ & 1 & 2 & 2 & 2 & 1 & $1 / 2$ \\
\hline R13 & 2 & 2 & 2 & 2 & 1 & $1 / 2$ & 4 & 2 & $1 / 2$ & 1 & 2 & $1 / 2$ & $1 / 2$ & $\mathbf{1}$ & $1 / 4$ & 1 & 2 & 2 & 2 & 1 & $1 / 2$ \\
\hline R14 & 4 & 4 & 4 & 4 & 2 & 1 & 6 & 4 & 1 & 2 & 4 & 1 & 1 & 2 & $1 / 2$ & 2 & 4 & 4 & 4 & 2 & 1 \\
\hline R15 & 1 & 1 & 1 & 1 & $1 / 2$ & $1 / 4$ & 2 & 1 & $1 / 4$ & $1 / 2$ & 1 & $1 / 4$ & $1 / 4$ & $1 / 4$ & $1 / 6$ & $1 / 2$ & 1 & 1 & 1 & $1 / 2$ & $1 / 4$ \\
\hline R16 & 1 & 1 & 1 & 1 & $1 / 2$ & $1 / 4$ & 2 & $\mathbf{1}$ & $1 / 4$ & $1 / 2$ & $\overline{1}$ & $1 / 4$ & $1 / 4$ & $1 / 4$ & $1 / 6$ & $1 / 2$ & $\mathbf{1}$ & 1 & 1 & $1 / 2$ & $1 / 4$ \\
\hline R17 & 4 & 4 & 4 & 4 & 2 & 1 & 6 & 4 & 1 & 2 & 4 & 1 & 1 & 2 & $1 / 2$ & 2 & 4 & 4 & 4 & 2 & 1 \\
\hline R18 & 6 & 6 & 6 & 6 & 4 & 2 & 8 & 6 & 2 & 4 & 6 & 2 & 2 & 4 & 1 & 4 & 6 & 6 & 6 & 4 & 2 \\
\hline R19 & $1 / 2$ & $1 / 2$ & $1 / 2$ & $1 / 2$ & $1 / 4$ & $1 / 6$ & 1 & $1 / 2$ & $1 / 6$ & $1 / 4$ & $1 / 2$ & $1 / 6$ & $1 / 6$ & $1 / 4$ & $1 / 8$ & $1 / 4$ & $1 / 2$ & $1 / 2$ & $1 / 2$ & $1 / 4$ & $1 / 6$ \\
\hline R20 & $1 / 2$ & $1 / 2$ & $1 / 2$ & $1 / 2$ & $1 / 4$ & $1 / 6$ & 1 & $1 / 2$ & $1 / 6$ & $1 / 4$ & $1 / 2$ & $1 / 6$ & $1 / 6$ & $1 / 4$ & $1 / 8$ & $1 / 4$ & $1 / 2$ & $1 / 2$ & $1 / 2$ & $1 / 4$ & $1 / 6$ \\
\hline R21 & $1 / 2$ & $1 / 2$ & $1 / 2$ & $1 / 2$ & $1 / 4$ & $1 / 6$ & 1 & $1 / 2$ & $1 / 6$ & $1 / 4$ & $1 / 2$ & $1 / 6$ & $1 / 6$ & $1 / 4$ & $1 / 8$ & $1 / 4$ & $1 / 2$ & $1 / 2$ & $1 / 2$ & $1 / 4$ & $1 / 6$ \\
\hline R22 & 1 & 1 & 1 & 1 & $1 / 2$ & $1 / 4$ & 2 & 1 & $1 / 4$ & $1 / 2$ & 1 & $1 / 4$ & $1 / 4$ & $1 / 4$ & $1 / 6$ & $1 / 2$ & 1 & 1 & 1 & $1 / 2$ & $1 / 4$ \\
\hline R23 & 1 & 1 & 1 & 1 & $1 / 2$ & $1 / 4$ & 2 & 1 & $1 / 4$ & $1 / 2$ & 1 & $1 / 4$ & $1 / 4$ & $1 / 4$ & $1 / 6$ & $1 / 2$ & 1 & 1 & 1 & $1 / 2$ & $1 / 4$ \\
\hline R24 & 1 & 1 & 1 & 1 & $1 / 2$ & $1 / 4$ & 2 & 1 & $1 / 4$ & $1 / 2$ & 1 & $1 / 4$ & $1 / 4$ & $1 / 4$ & $1 / 6$ & $1 / 2$ & 1 & 1 & 1 & $1 / 2$ & $1 / 4$ \\
\hline$\overline{\text { R25 }}$ & 1 & 1 & 1 & 1 & $1 / 2$ & $1 / 4$ & 2 & $\mathbf{1}$ & $1 / 4$ & $1 / 2$ & 1 & $1 / 4$ & $1 / 4$ & $1 / 4$ & $1 / 6$ & $1 / 2$ & 1 & 1 & 1 & $1 / 2$ & $1 / 4$ \\
\hline R26 & 2 & 2 & 2 & 2 & 1 & $1 / 2$ & 4 & 2 & $1 / 2$ & 1 & 2 & $1 / 2$ & $1 / 2$ & 1 & $1 / 4$ & 1 & 2 & 2 & 2 & 1 & $1 / 2$ \\
\hline R27 & 4 & 4 & 4 & 4 & 2 & 1 & 6 & 4 & 1 & 2 & 4 & 1 & 1 & 2 & $1 / 2$ & 2 & 4 & 4 & 4 & 2 & 1 \\
\hline R28 & $1 / 2$ & $1 / 2$ & $1 / 2$ & $1 / 2$ & $1 / 4$ & $1 / 6$ & 1 & $1 / 2$ & $1 / 6$ & $1 / 4$ & $1 / 2$ & $1 / 6$ & $1 / 6$ & $1 / 4$ & $1 / 8$ & $1 / 4$ & $1 / 2$ & $1 / 2$ & $1 / 2$ & $1 / 4$ & $1 / 6$ \\
\hline R29 & 1 & 1 & 1 & 1 & $1 / 2$ & $1 / 4$ & 2 & 1 & $1 / 4$ & $1 / 2$ & 1 & $1 / 4$ & $1 / 4$ & $1 / 4$ & $1 / 6$ & $1 / 2$ & 1 & 1 & 1 & $1 / 2$ & $1 / 4$ \\
\hline R30 & 4 & 4 & 4 & 4 & 2 & 1 & 6 & 4 & 1 & 2 & 4 & 1 & 1 & 2 & $1 / 2$ & 2 & 4 & 4 & 4 & 2 & 1 \\
\hline R31 & 2 & 2 & 2 & 2 & 1 & $1 / 2$ & 4 & 2 & $1 / 2$ & 1 & 2 & $1 / 2$ & $1 / 2$ & 1 & $1 / 4$ & 1 & 2 & 2 & 2 & 1 & $1 / 2$ \\
\hline R32 & 1 & 1 & 1 & 1 & $1 / 2$ & $1 / 4$ & 2 & 1 & $1 / 4$ & $1 / 2$ & 1 & $1 / 4$ & $1 / 4$ & $1 / 4$ & $1 / 6$ & $1 / 2$ & 1 & 1 & 1 & $1 / 2$ & $1 / 4$ \\
\hline R33 & 4 & 4 & 4 & 4 & 2 & 1 & 6 & 4 & 1 & 2 & 4 & 1 & 1 & 2 & $1 / 2$ & 2 & 4 & 4 & 4 & 2 & 1 \\
\hline R34 & 4 & 4 & 4 & 4 & 2 & 1 & 6 & 4 & 1 & 2 & 4 & 1 & 1 & 2 & $1 / 2$ & 2 & 4 & 4 & 4 & 2 & 1 \\
\hline R35 & 2 & 2 & 2 & 2 & 1 & $1 / 2$ & 4 & 2 & $1 / 2$ & 1 & 2 & $1 / 2$ & $1 / 2$ & 1 & $1 / 4$ & 1 & 2 & 2 & 2 & 1 & $1 / 2$ \\
\hline R36 & 6 & 6 & 6 & 6 & 4 & 2 & 8 & 6 & 2 & 4 & 6 & 2 & 2 & 4 & 1 & 4 & 6 & 6 & 6 & 4 & 2 \\
\hline R37 & 2 & 2 & 2 & 2 & 1 & $1 / 2$ & 4 & 2 & $1 / 2$ & 1 & 2 & $1 / 2$ & $1 / 2$ & 1 & $1 / 4$ & 1 & 2 & 2 & 2 & 1 & $1 / 2$ \\
\hline R38 & 1 & 1 & 1 & 1 & $1 / 2$ & $1 / 4$ & 2 & 1 & $1 / 4$ & $1 / 2$ & 1 & $1 / 4$ & $1 / 4$ & $1 / 4$ & $1 / 6$ & $1 / 2$ & 1 & 1 & 1 & $1 / 2$ & $1 / 4$ \\
\hline R39 & 1 & 1 & 1 & 1 & $1 / 2$ & $1 / 4$ & 2 & 1 & $1 / 4$ & $1 / 2$ & 1 & $1 / 4$ & $1 / 4$ & $1 / 4$ & $1 / 6$ & $1 / 2$ & 1 & 1 & 1 & $1 / 2$ & $1 / 4$ \\
\hline R40 & 1 & 1 & 1 & 1 & $1 / 2$ & $1 / 4$ & 2 & 1 & $1 / 4$ & $1 / 2$ & 1 & $1 / 4$ & $1 / 4$ & $1 / 4$ & $1 / 6$ & $1 / 2$ & 1 & 1 & 1 & $1 / 2$ & $1 / 4$ \\
\hline R41 & 2 & 2 & 2 & 2 & 1 & $1 / 2$ & 4 & 2 & $1 / 2$ & 1 & 2 & $1 / 2$ & $1 / 2$ & 1 & $1 / 4$ & 1 & 2 & 2 & 2 & 1 & $1 / 2$ \\
\hline R42 & 4 & 4 & 4 & 4 & 2 & 1 & 6 & 4 & 1 & 2 & 4 & 1 & 1 & 2 & $1 / 2$ & 2 & 4 & 4 & 4 & 2 & 1 \\
\hline R43 & 4 & 4 & 4 & 4 & 2 & 1 & 6 & 4 & 1 & 2 & 4 & 1 & 1 & 2 & $1 / 2$ & 2 & 4 & 4 & 4 & 2 & 1 \\
\hline R44 & 4 & 4 & 4 & 4 & 2 & 1 & 6 & 4 & 1 & 2 & 4 & 1 & 1 & 2 & $1 / 2$ & 2 & 4 & 4 & 4 & 2 & 1 \\
\hline R45 & 4 & 4 & 4 & 4 & 2 & 1 & 6 & 4 & 1 & 2 & 4 & 1 & 1 & 2 & $1 / 2$ & 2 & 4 & 4 & 4 & 2 & 1 \\
\hline R46 & $1 / 2$ & $1 / 2$ & $1 / 2$ & $1 / 2$ & $1 / 4$ & $1 / 6$ & 1 & $1 / 2$ & $1 / 6$ & $1 / 4$ & $1 / 2$ & $1 / 6$ & $1 / 6$ & $1 / 4$ & $1 / 8$ & $1 / 4$ & $1 / 2$ & $1 / 2$ & $1 / 2$ & $1 / 4$ & $1 / 6$ \\
\hline R47 & 2 & 2 & 2 & 2 & 1 & $1 / 2$ & 4 & 2 & $1 / 2$ & 1 & 2 & $1 / 2$ & $1 / 2$ & 1 & $1 / 4$ & 1 & 2 & 2 & 2 & 1 & $1 / 2$ \\
\hline R48 & 1 & 1 & 1 & 1 & $1 / 2$ & $1 / 4$ & 2 & 1 & $1 / 4$ & $1 / 2$ & 1 & $1 / 4$ & $1 / 4$ & $1 / 4$ & $1 / 6$ & $1 / 2$ & 1 & 1 & 1 & $1 / 2$ & $1 / 4$ \\
\hline R49 & 4 & 4 & 4 & 4 & 2 & 1 & 6 & 4 & 1 & 2 & 4 & 1 & 1 & 2 & $1 / 2$ & 2 & 4 & 4 & 4 & 2 & 1 \\
\hline R50 & 1 & 1 & 1 & 1 & $1 / 2$ & $1 / 4$ & 2 & 1 & $1 / 4$ & $1 / 2$ & 1 & $1 / 4$ & $1 / 4$ & $1 / 4$ & $1 / 6$ & $1 / 2$ & 1 & 1 & 1 & $1 / 2$ & $1 / 4$ \\
\hline R51 & 1 & 1 & 1 & 1 & $1 / 2$ & $1 / 4$ & 2 & 1 & $1 / 4$ & $1 / 2$ & 1 & $1 / 4$ & $1 / 4$ & $1 / 4$ & $1 / 6$ & $1 / 2$ & 1 & 1 & 1 & $1 / 2$ & $1 / 4$ \\
\hline R52 & 2 & 2 & 2 & 2 & 1 & $1 / 2$ & 4 & 2 & $1 / 2$ & 1 & 2 & $1 / 2$ & $1 / 2$ & 1 & $1 / 4$ & 1 & 2 & 2 & 2 & 1 & $1 / 2$ \\
\hline R53 & 1 & 1 & 1 & 1 & $1 / 2$ & $1 / 4$ & 2 & 1 & $1 / 4$ & $1 / 2$ & 1 & $1 / 4$ & $1 / 4$ & $1 / 4$ & $1 / 6$ & $1 / 2$ & 1 & 1 & 1 & $1 / 2$ & $1 / 4$ \\
\hline R54 & 2 & 2 & 2 & 2 & 1 & $1 / 2$ & 4 & 2 & $1 / 2$ & 1 & 2 & $1 / 2$ & $1 / 2$ & 1 & $1 / 4$ & 1 & 2 & 2 & 2 & 1 & $1 / 2$ \\
\hline R55 & 2 & 2 & 2 & 2 & 1 & $1 / 2$ & 4 & 2 & $1 / 2$ & 1 & 2 & $1 / 2$ & $1 / 2$ & 1 & $1 / 4$ & 1 & 2 & 2 & 2 & 1 & $1 / 2$ \\
\hline R56 & 4 & 4 & 4 & 4 & 2 & 1 & 6 & 4 & 1 & 2 & 4 & 1 & 1 & 2 & $1 / 2$ & 2 & 4 & 4 & 4 & 2 & 1 \\
\hline R57 & 2 & 2 & 2 & 2 & 1 & $1 / 2$ & 4 & 2 & $1 / 2$ & 1 & 2 & $1 / 2$ & $1 / 2$ & 1 & $1 / 4$ & 1 & 2 & 2 & 2 & 1 & $1 / 2$ \\
\hline R58 & 6 & 6 & 6 & 6 & 4 & 2 & 8 & 6 & 2 & 4 & 6 & 2 & 2 & 4 & 1 & 4 & 6 & 6 & 6 & 4 & 2 \\
\hline
\end{tabular}


Table A5. Cont.

$\begin{array}{llllllllllllllllllllll}\text { R22 } & \text { R23 } & \text { R24 } & \text { R25 } & \text { R26 } & \text { R27 } & \text { R28 } & \text { R29 } & \text { R30 } & \text { R31 } & \text { R32 } & \text { R33 } & \text { R34 } & \text { R35 } & \text { R36 } & \text { R37 } & \text { R38 } & \text { R39 } & \text { R40 } & \text { R41 } & \text { R42 }\end{array}$

\begin{tabular}{llllllllllllllllllllll} 
R59 & 2 & 2 & 2 & 2 & 1 & $1 / 2$ & 4 & 2 & $1 / 2$ & 1 & 2 & $1 / 2$ & $1 / 2$ & 1 & $1 / 4$ & 1 & 2 & 2 & 2 & 1 & $1 / 2$ \\
\hline R60 & 4 & 4 & 4 & 4 & 2 & 1 & 6 & 4 & 1 & 2 & 4 & 1 & 1 & 2 & $1 / 2$ & 2 & 4 & 4 & 4 & 2 & 1 \\
\hline R61 & 4 & 4 & 4 & 4 & 2 & 1 & 6 & 4 & 1 & 2 & 4 & 1 & 1 & 2 & $1 / 2$ & 2 & 4 & 4 & 4 & 2 & 1 \\
\hline R62 & 4 & 4 & 4 & 4 & 2 & 1 & 6 & 4 & 1 & 2 & 4 & 1 & 1 & 2 & $1 / 2$ & 2 & 4 & 4 & 4 & 2 & 1 \\
\hline R63 & 4 & 4 & 4 & 4 & 2 & 1 & 6 & 4 & 1 & 2 & 4 & 1 & 1 & 2 & $1 / 2$ & 2 & 4 & 4 & 4 & 2 & 1 \\
\hline R64 & 6 & 6 & 6 & 6 & 4 & 2 & 8 & 6 & 2 & 4 & 6 & 2 & 2 & 4 & 1 & 4 & 6 & 6 & 6 & 4 & 2 \\
\hline
\end{tabular}

Table A6. Pairwise comparison matrix between risks according to risks' gravity, Part 3.

\begin{tabular}{|c|c|c|c|c|c|c|c|c|c|c|c|c|c|c|c|c|c|c|c|c|c|c|}
\hline & & 44 & 45 & R46 & 47 & 248 & 49 & R50 & R51 & R52 & R53 & R54 & R55 & R56 & R57 & R58 & R59 & R60 & R61 & R62 & R63 & R64 \\
\hline R1 & $1 / 4$ & $1 / 4$ & $1 / 4$ & 2 & $1 / 2$ & 1 & $1 / 4$ & 1 & 1 & $1 / 2$ & 1 & $1 / 2$ & $1 / 2$ & $1 / 4$ & $1 / 2$ & $1 / 6$ & $1 / 2$ & $1 / 4$ & $1 / 4$ & $1 / 4$ & $1 / 4$ & $1 / 6$ \\
\hline $\mathbf{R} 2$ & $1 / 4$ & $1 / 4$ & $1 / 4$ & 2 & $1 / 2$ & 1 & $1 / 4$ & 1 & 1 & $1 / 2$ & 1 & $1 / 2$ & $1 / 2$ & $1 / 4$ & $1 / 2$ & $1 / 6$ & $1 / 2$ & $1 / 4$ & $1 / 4$ & $1 / 4$ & $1 / 4$ & $1 / 6$ \\
\hline$\overline{\mathrm{R} 3}$ & $1 / 2$ & $1 / 2$ & $1 / 2$ & 4 & $\mathbf{1}$ & 2 & $1 / 2$ & 2 & 2 & 1 & 2 & 1 & $\mathbf{1}$ & $1 / 2$ & 1 & $1 / 4$ & 1 & $1 / 2$ & $1 / 2$ & $1 / 2$ & $1 / 2$ & $1 / 2$ \\
\hline R4 & $1 / 4$ & $1 / 4$ & $1 / 4$ & 2 & $1 / 2$ & 1 & $1 / 4$ & 1 & 1 & $1 / 2$ & 1 & $1 / 2$ & $1 / 2$ & $1 / 4$ & $1 / 2$ & $1 / 6$ & $1 / 2$ & $1 / 4$ & $1 / 4$ & $1 / 4$ & $1 / 4$ & $1 / 6$ \\
\hline R5 & $1 / 6$ & $1 / 6$ & $1 / 6$ & 1 & $1 / 4$ & $1 / 2$ & $1 / 6$ & $1 / 2$ & $1 / 2$ & $1 / 4$ & $1 / 2$ & $1 / 4$ & $1 / 4$ & $1 / 6$ & $1 / 4$ & $1 / 8$ & $1 / 4$ & $1 / 6$ & $1 / 6$ & $1 / 6$ & $1 / 6$ & $1 / 8$ \\
\hline R6 & $1 / 2$ & $1 / 2$ & $1 / 2$ & 4 & 1 & 2 & $1 / 2$ & 2 & 2 & 1 & 2 & 1 & 1 & $1 / 2$ & 1 & $1 / 4$ & 1 & $1 / 2$ & $1 / 2$ & $1 / 2$ & $1 / 2$ & $1 / 2$ \\
\hline R7 & 1 & 1 & 1 & 6 & 2 & 4 & 1 & 4 & 4 & 2 & 4 & 2 & 2 & 1 & 2 & $1 / 2$ & 2 & 1 & 1 & 1 & 1 & $1 / 2$ \\
\hline R8 & $1 / 2$ & $1 / 2$ & $1 / 2$ & 4 & 1 & 2 & $1 / 2$ & 2 & 2 & 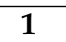 & 2 & 1 & 1 & $1 / 2$ & 1 & $1 / 4$ & 1 & $1 / 2$ & $1 / 2$ & $1 / 2$ & $1 / 2$ & $1 / 2$ \\
\hline R9 & $1 / 2$ & $1 / 2$ & $1 / 2$ & 4 & 1 & 2 & $1 / 2$ & 2 & 2 & 1 & 2 & 1 & 1 & $1 / 2$ & 4 & $1 / 4$ & 1 & $1 / 2$ & $1 / 2$ & $1 / 2$ & $1 / 2$ & $1 / 2$ \\
\hline R10 & $1 / 2$ & $1 / 2$ & $1 / 2$ & 4 & 1 & 2 & $1 / 2$ & 2 & 2 & 1 & 2 & 1 & 1 & $1 / 2$ & 1 & $1 / 4$ & 1 & $1 / 2$ & $1 / 2$ & $1 / 2$ & $1 / 2$ & $1 / 2$ \\
\hline R11 & $1 / 2$ & $1 / 2$ & $1 / 2$ & 4 & 1 & 2 & $1 / 2$ & 2 & 2 & 1 & 2 & 1 & 1 & $1 / 2$ & 1 & $1 / 4$ & 1 & $1 / 2$ & $1 / 2$ & $1 / 2$ & $1 / 2$ & $1 / 2$ \\
\hline R12 & $1 / 2$ & $1 / 2$ & $1 / 2$ & 4 & 1 & 2 & $1 / 2$ & 2 & 2 & 1 & 2 & 1 & 1 & $1 / 2$ & 1 & $1 / 4$ & 1 & $1 / 2$ & $1 / 2$ & $1 / 2$ & $1 / 2$ & $1 / 2$ \\
\hline R13 & $1 / 2$ & $1 / 2$ & $1 / 2$ & 4 & 1 & 2 & $1 / 2$ & 2 & 2 & 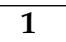 & 2 & 1 & 1 & $1 / 2$ & 1 & $1 / 4$ & 1 & $1 / 2$ & $1 / 2$ & $1 / 2$ & $1 / 2$ & $1 / 2$ \\
\hline R14 & 1 & 1 & 1 & 6 & 2 & 4 & 1 & 4 & 4 & 2 & 4 & 2 & 2 & 1 & 2 & $1 / 2$ & 2 & 1 & 1 & 1 & 1 & $1 / 2$ \\
\hline R15 & $1 / 4$ & $1 / 4$ & $1 / 4$ & 2 & $1 / 2$ & 1 & $1 / 4$ & 1 & 1 & $1 / 2$ & 1 & $1 / 2$ & $1 / 2$ & $1 / 4$ & $1 / 2$ & $1 / 6$ & $1 / 2$ & $1 / 4$ & $1 / 4$ & $1 / 4$ & $1 / 4$ & $1 / 6$ \\
\hline R16 & $1 / 4$ & $1 / 4$ & $1 / 4$ & 2 & $1 / 2$ & 1 & $1 / 4$ & 1 & 1 & $1 / 2$ & 1 & $1 / 2$ & $1 / 2$ & $1 / 4$ & $1 / 2$ & $1 / 6$ & $1 / 2$ & $1 / 4$ & $1 / 4$ & $1 / 4$ & $1 / 4$ & $1 / 6$ \\
\hline R17 & 1 & 1 & 1 & 6 & 2 & 4 & 1 & 4 & 4 & 2 & 4 & 2 & 2 & 1 & 2 & $1 / 2$ & 2 & 1 & 1 & 1 & 1 & $1 / 2$ \\
\hline R18 & 2 & 2 & 2 & 8 & 4 & 6 & 2 & 6 & 6 & 4 & 6 & 4 & 4 & 2 & 4 & 1 & 4 & 2 & 2 & 2 & 2 & 1 \\
\hline R19 & $1 / 6$ & $1 / 6$ & $1 / 6$ & 1 & $1 / 4$ & $1 / 2$ & $1 / 6$ & $1 / 2$ & $1 / 2$ & $1 / 4$ & $1 / 2$ & $1 / 4$ & $1 / 4$ & $1 / 6$ & $1 / 4$ & $1 / 8$ & $1 / 4$ & $1 / 6$ & $1 / 6$ & $1 / 6$ & $1 / 6$ & $1 / 8$ \\
\hline R20 & $1 / 6$ & $1 / 6$ & $1 / 6$ & 1 & $1 / 4$ & $1 / 2$ & $1 / 6$ & $1 / 2$ & $1 / 2$ & $1 / 4$ & $1 / 2$ & $1 / 4$ & $1 / 4$ & $1 / 6$ & $1 / 4$ & $1 / 8$ & $1 / 4$ & $1 / 6$ & $1 / 6$ & $1 / 6$ & $1 / 6$ & $1 / 8$ \\
\hline R21 & $/ 6$ & $1 / 6$ & $1 / 6$ & 1 & $1 / 4$ & $1 / 2$ & $1 / 6$ & $1 / 2$ & $1 / 2$ & $1 / 4$ & $1 / 2$ & $1 / 4$ & $1 / 4$ & $1 / 6$ & $1 / 4$ & $1 / 8$ & $1 / 4$ & $1 / 6$ & $1 / 6$ & $1 / 6$ & $1 / 6$ & $1 / 8$ \\
\hline R22 & $1 / 4$ & $1 / 4$ & $1 / 4$ & 2 & $1 / 2$ & 1 & $1 / 4$ & 1 & 1 & $1 / 2$ & 1 & $1 / 2$ & $1 / 2$ & $1 / 4$ & $1 / 2$ & $1 / 6$ & $1 / 2$ & $1 / 4$ & $1 / 4$ & $1 / 4$ & $1 / 4$ & $1 / 6$ \\
\hline R23 & $/ 4$ & $1 / 4$ & $1 / 4$ & 2 & $1 / 2$ & 1 & $1 / 4$ & 1 & 1 & $1 / 2$ & 1 & $1 / 2$ & $1 / 2$ & $1 / 4$ & $1 / 2$ & $1 / 6$ & $1 / 2$ & $1 / 4$ & $1 / 4$ & $1 / 4$ & $1 / 4$ & $1 / 6$ \\
\hline R24 & $/ 4$ & $1 / 4$ & $1 / 4$ & 2 & $1 / 2$ & 1 & $1 / 4$ & 1 & 1 & $1 / 2$ & 1 & $1 / 2$ & $1 / 2$ & $1 / 4$ & $1 / 2$ & $1 / 6$ & $1 / 2$ & $1 / 4$ & $1 / 4$ & $1 / 4$ & $1 / 4$ & $1 / 6$ \\
\hline R25 & $1 / 4$ & $1 / 4$ & $1 / 4$ & 2 & $1 / 2$ & 1 & $1 / 4$ & 1 & 1 & $1 / 2$ & 1 & $1 / 2$ & $1 / 2$ & $1 / 4$ & $1 / 2$ & $1 / 6$ & $1 / 2$ & $1 / 4$ & $1 / 4$ & $1 / 4$ & $1 / 4$ & $1 / 6$ \\
\hline R26 & $1 / 2$ & $1 / 2$ & $1 / 2$ & 4 & 1 & 2 & $1 / 2$ & 2 & 2 & 1 & 2 & $\mathbf{1}$ & 1 & $1 / 2$ & 7 & $1 / 4$ & 1 & $1 / 2$ & $1 / 2$ & $1 / 2$ & $1 / 2$ & $1 / 2$ \\
\hline R27 & 1 & 1 & 1 & 6 & 2 & 4 & $\mathbf{1}$ & 4 & 4 & 2 & 4 & 2 & 2 & 1 & 2 & $1 / 2$ & 2 & 1 & 1 & 1 & 1 & $1 / 2$ \\
\hline R28 & $1 / 6$ & $1 / 6$ & $1 / 6$ & 1 & $1 / 4$ & $1 / 2$ & $1 / 6$ & $1 / 2$ & $1 / 2$ & $1 / 4$ & $1 / 2$ & $1 / 4$ & $1 / 4$ & $1 / 6$ & $1 / 4$ & $1 / 8$ & $1 / 4$ & $1 / 6$ & $1 / 6$ & $1 / 6$ & $1 / 6$ & $1 / 8$ \\
\hline R29 & $1 / 4$ & $1 / 4$ & $1 / 4$ & 2 & $1 / 2$ & 1 & $1 / 4$ & 1 & 1 & $1 / 2$ & 1 & $1 / 2$ & $1 / 2$ & $1 / 4$ & $1 / 2$ & $1 / 6$ & $1 / 2$ & $1 / 4$ & $1 / 4$ & $1 / 4$ & $1 / 4$ & $1 / 6$ \\
\hline R30 & 1 & 1 & 1 & 6 & 2 & 4 & 1 & 4 & 4 & 2 & 4 & 2 & 2 & 1 & 2 & $1 / 2$ & 2 & 1 & 1 & 1 & 1 & $1 / 2$ \\
\hline R31 & $1 / 2$ & $1 / 2$ & $1 / 2$ & 4 & 1 & 2 & $1 / 2$ & 2 & 2 & 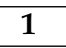 & 2 & 1 & 1 & $1 / 2$ & 1 & $1 / 4$ & 1 & $1 / 2$ & $1 / 2$ & $1 / 2$ & $1 / 2$ & $1 / 2$ \\
\hline R32 & $1 / 4$ & $1 / 4$ & $1 / 4$ & 2 & $1 / 2$ & 1 & $1 / 4$ & 1 & 1 & $1 / 2$ & 1 & $1 / 2$ & $1 / 2$ & $1 / 4$ & $1 / 2$ & $1 / 6$ & $1 / 2$ & $1 / 4$ & $1 / 4$ & $1 / 4$ & $1 / 4$ & $1 / 6$ \\
\hline R33 & 1 & 1 & 1 & 6 & 2 & 4 & 1 & $\overline{4}$ & 4 & 2 & 4 & 2 & 2 & 1 & 2 & $1 / 2$ & 2 & 1 & 1 & 1 & 1 & $1 / 2$ \\
\hline R34 & 1 & 1 & 1 & 6 & 2 & 4 & 1 & 4 & 4 & 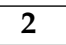 & 4 & 2 & 2 & 1 & 2 & $1 / 2$ & 2 & 1 & 1 & 1 & 1 & $1 / 2$ \\
\hline R35 & $1 / 2$ & $1 / 2$ & $1 / 2$ & 4 & 1 & 2 & $1 / 2$ & 2 & 2 & 1 & 2 & 1 & 1 & $1 / 2$ & 1 & $1 / 4$ & 1 & $1 / 2$ & $1 / 2$ & $1 / 2$ & $1 / 2$ & $1 / 2$ \\
\hline R36 & 2 & 2 & 2 & 8 & 4 & 6 & 2 & 6 & 6 & 4 & 6 & 4 & 4 & 2 & 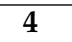 & 1 & 4 & 2 & 2 & 2 & 2 & 1 \\
\hline R37 & $1 / 2$ & $1 / 2$ & $1 / 2$ & 4 & 1 & 2 & $1 / 2$ & 2 & 2 & 1 & 2 & 1 & 1 & $1 / 2$ & 1 & $1 / 4$ & 1 & $1 / 2$ & $1 / 2$ & $1 / 2$ & $1 / 2$ & $1 / 2$ \\
\hline R38 & $1 / 4$ & $1 / 4$ & $1 / 4$ & 2 & $1 / 2$ & 1 & $1 / 4$ & 1 & 1 & $1 / 2$ & 1 & $1 / 2$ & $1 / 2$ & $1 / 4$ & $1 / 2$ & $1 / 6$ & $1 / 2$ & $1 / 4$ & $1 / 4$ & $1 / 4$ & $1 / 4$ & $1 / 6$ \\
\hline R39 & $1 / 4$ & $1 / 4$ & $1 / 4$ & 2 & $1 / 2$ & 1 & $1 / 4$ & 1 & 1 & $1 / 2$ & 1 & $1 / 2$ & $1 / 2$ & $1 / 4$ & $1 / 2$ & $1 / 6$ & $1 / 2$ & $1 / 4$ & $1 / 4$ & $1 / 4$ & $1 / 4$ & $1 / 6$ \\
\hline R40 & $1 / 4$ & $1 / 4$ & $1 / 4$ & 2 & $1 / 2$ & 1 & $1 / 4$ & 1 & 1 & $1 / 2$ & 1 & $1 / 2$ & $1 / 2$ & $1 / 4$ & $1 / 2$ & $1 / 6$ & $1 / 2$ & $1 / 4$ & $1 / 4$ & $1 / 4$ & $1 / 4$ & $1 / 6$ \\
\hline R41 & $1 / 2$ & $1 / 2$ & $1 / 2$ & 4 & 1 & 2 & $1 / 2$ & 2 & 2 & 1 & 2 & 1 & 1 & $1 / 2$ & 1 & $1 / 4$ & 1 & $1 / 2$ & $1 / 2$ & $1 / 2$ & $1 / 2$ & $1 / 2$ \\
\hline R42 & 1 & 1 & 1 & 6 & 2 & 4 & 1 & 4 & 4 & 2 & 4 & 2 & 2 & 1 & 2 & $1 / 2$ & 2 & 1 & 1 & 1 & 1 & $1 / 2$ \\
\hline R43 & 1 & 1 & 1 & 6 & 2 & 4 & 1 & 4 & 4 & 2 & 4 & 2 & 2 & 1 & 2 & $1 / 2$ & 2 & 1 & 1 & 1 & 1 & $1 / 2$ \\
\hline R44 & 1 & 1 & 1 & 6 & 2 & 4 & 1 & 4 & 4 & 2 & 4 & 2 & 2 & 1 & 2 & $1 / 2$ & 2 & 1 & 1 & 1 & 1 & $1 / 2$ \\
\hline R45 & 1 & 1 & 1 & 6 & 2 & 4 & 1 & 4 & 4 & 2 & 4 & 2 & 2 & 1 & 2 & $1 / 2$ & 2 & 1 & 1 & 1 & 1 & $1 / 2$ \\
\hline
\end{tabular}


Table A6. Cont.

\begin{tabular}{|c|c|c|c|c|c|c|c|c|c|c|c|c|c|c|c|c|c|c|c|c|c|c|}
\hline & R43 & R44 & R45 & R46 & R47 & R48 & R49 & R50 & R51 & R52 & R53 & R54 & R55 & R56 & R57 & R58 & R59 & R60 & R61 & R62 & R63 & R64 \\
\hline R46 & $1 / 6$ & $1 / 6$ & $1 / 6$ & 1 & $1 / 4$ & $1 / 2$ & $1 / 6$ & $1 / 2$ & $1 / 2$ & $1 / 4$ & $1 / 2$ & $1 / 4$ & $1 / 4$ & $1 / 6$ & $1 / 4$ & $1 / 8$ & $1 / 4$ & $1 / 6$ & $1 / 6$ & $1 / 6$ & $1 / 6$ & $1 / 8$ \\
\hline R47 & $1 / 2$ & $1 / 2$ & $1 / 2$ & 4 & 1 & 2 & $1 / 2$ & 2 & 2 & 1 & 2 & 1 & 1 & $1 / 2$ & 1 & $1 / 4$ & 1 & $1 / 2$ & $1 / 2$ & $1 / 2$ & $1 / 2$ & $1 / 2$ \\
\hline R48 & $1 / 4$ & $1 / 4$ & $1 / 4$ & 2 & $1 / 2$ & 1 & $1 / 4$ & 1 & 1 & $1 / 2$ & 1 & $1 / 2$ & $1 / 2$ & $1 / 4$ & $1 / 2$ & $1 / 6$ & $1 / 2$ & $1 / 4$ & $1 / 4$ & $1 / 4$ & $1 / 4$ & $1 / 6$ \\
\hline R49 & 1 & 1 & 1 & 6 & 2 & 4 & 1 & 4 & 4 & 2 & 4 & 2 & 2 & 1 & 2 & $1 / 2$ & 2 & 1 & 1 & 1 & 1 & $1 / 2$ \\
\hline R50 & $1 / 4$ & $1 / 4$ & $1 / 4$ & 2 & $1 / 2$ & 1 & $1 / 4$ & 1 & 1 & $1 / 2$ & 1 & $1 / 2$ & $1 / 2$ & $1 / 4$ & $1 / 2$ & $1 / 6$ & $1 / 2$ & $1 / 4$ & $1 / 4$ & $1 / 4$ & $1 / 4$ & $1 / 6$ \\
\hline R51 & $1 / 4$ & $1 / 4$ & $1 / 4$ & 2 & $1 / 2$ & 1 & $1 / 4$ & 1 & 1 & $1 / 2$ & 1 & $1 / 2$ & $1 / 2$ & $1 / 4$ & $1 / 2$ & $1 / 6$ & $1 / 2$ & $1 / 4$ & $1 / 4$ & $1 / 4$ & $1 / 4$ & $1 / 6$ \\
\hline R52 & $1 / 2$ & $1 / 2$ & $1 / 2$ & 4 & 1 & 2 & $1 / 2$ & 2 & 2 & 1 & 2 & 1 & 1 & $1 / 2$ & 1 & $1 / 4$ & 1 & $1 / 2$ & $1 / 2$ & $1 / 2$ & $1 / 2$ & $1 / 2$ \\
\hline R53 & $1 / 4$ & $1 / 4$ & $1 / 4$ & 2 & $1 / 2$ & 1 & $1 / 4$ & 1 & 1 & $1 / 2$ & 1 & $1 / 2$ & $1 / 2$ & $1 / 4$ & $1 / 2$ & $1 / 6$ & $1 / 2$ & $1 / 4$ & $1 / 4$ & $1 / 4$ & $1 / 4$ & $1 / 6$ \\
\hline R54 & $1 / 2$ & $1 / 2$ & $1 / 2$ & 4 & 1 & 2 & $1 / 2$ & 2 & 2 & 1 & 2 & 1 & 1 & $1 / 2$ & 1 & $1 / 4$ & 1 & $1 / 2$ & $1 / 2$ & $1 / 2$ & $1 / 2$ & $1 / 2$ \\
\hline R55 & $1 / 2$ & $1 / 2$ & $1 / 2$ & 4 & 1 & 2 & $1 / 2$ & 2 & 2 & 1 & 2 & 1 & 1 & $1 / 2$ & 1 & $1 / 4$ & 1 & $1 / 2$ & $1 / 2$ & $1 / 2$ & $1 / 2$ & $1 / 2$ \\
\hline R56 & 1 & 1 & 1 & 6 & 2 & 4 & 1 & 4 & 4 & 2 & 4 & 2 & 2 & 1 & 2 & $1 / 2$ & 2 & 1 & 1 & 1 & 1 & $1 / 2$ \\
\hline R57 & $1 / 2$ & $1 / 2$ & $1 / 2$ & 4 & 1 & 2 & $1 / 2$ & 2 & 2 & 1 & 2 & 1 & 1 & $1 / 2$ & 1 & $1 / 4$ & 1 & $1 / 2$ & $1 / 2$ & $1 / 2$ & $1 / 2$ & $1 / 2$ \\
\hline R58 & 2 & 2 & 2 & 8 & 4 & 6 & 2 & 6 & 6 & 4 & 6 & 4 & 4 & 2 & 4 & 1 & 4 & 2 & 2 & 2 & 2 & 1 \\
\hline R59 & $1 / 2$ & $1 / 2$ & $1 / 2$ & 4 & 1 & 2 & $1 / 2$ & 2 & 2 & 1 & 2 & 1 & 1 & $1 / 2$ & 1 & $1 / 4$ & 1 & $1 / 2$ & $1 / 2$ & $1 / 2$ & $1 / 2$ & $1 / 2$ \\
\hline R60 & 1 & 1 & 1 & 6 & 2 & 4 & 1 & 4 & 4 & 2 & 4 & 2 & 2 & 1 & 2 & $1 / 2$ & 2 & 1 & 1 & 1 & 1 & $1 / 2$ \\
\hline R61 & 1 & 1 & 1 & 6 & 2 & 4 & 1 & 4 & 4 & 2 & 4 & 2 & 2 & 1 & 2 & $1 / 2$ & 2 & 1 & 1 & 1 & 1 & $1 / 2$ \\
\hline R62 & 1 & 1 & 1 & 6 & 2 & 4 & 1 & 4 & 4 & 2 & 4 & 2 & 2 & 1 & 2 & $1 / 2$ & 2 & 1 & 1 & 1 & 1 & $1 / 2$ \\
\hline R63 & 1 & 1 & 1 & 6 & 2 & 4 & 1 & 4 & 4 & 2 & 4 & 2 & 2 & 1 & 2 & $1 / 2$ & 2 & 1 & 1 & 1 & 1 & $1 / 2$ \\
\hline R64 & 2 & 2 & 2 & 8 & 4 & 6 & 2 & 6 & 6 & 4 & 6 & 4 & 4 & 2 & 4 & 1 & 4 & 2 & 2 & 2 & 2 & 1 \\
\hline
\end{tabular}

Table A7. Pairwise comparison matrix between risks according to risks' detectability, Part 1.

\begin{tabular}{|c|c|c|c|c|c|c|c|c|c|c|c|c|c|c|c|c|c|c|c|c|c|}
\hline & R1 & R2 & R3 & R4 & R5 & R6 & R7 & R8 & R9 & R10 & R11 & R12 & R13 & R14 & R15 & R16 & R17 & R18 & R19 & R20 & R21 \\
\hline R1 & 1 & 1 & 1 & 1 & 2 & 1 & 1 & 1 & $1 / 4$ & 1 & $1 / 2$ & 1 & 1 & $1 / 4$ & 2 & $1 / 2$ & $1 / 2$ & $1 / 2$ & 2 & 1 & 2 \\
\hline R2 & 1 & 1 & 1 & 1 & 2 & 1 & 1 & 1 & $1 / 4$ & 1 & $1 / 2$ & 1 & 1 & $1 / 4$ & 2 & $1 / 2$ & $1 / 2$ & $1 / 2$ & 2 & 1 & 2 \\
\hline R3 & 1 & 1 & 1 & 1 & 2 & 1 & 1 & 1 & $1 / 4$ & 1 & $1 / 2$ & 1 & 1 & $1 / 4$ & 2 & $1 / 2$ & $1 / 2$ & $1 / 2$ & 2 & 1 & 2 \\
\hline R4 & 1 & 1 & 1 & 1 & 2 & 1 & 1 & 1 & $1 / 4$ & 1 & $1 / 2$ & 1 & 1 & $1 / 4$ & 2 & $1 / 2$ & $1 / 2$ & $1 / 2$ & 2 & 1 & 2 \\
\hline R5 & $1 / 2$ & $1 / 2$ & $1 / 2$ & $1 / 2$ & 1 & $1 / 2$ & $1 / 2$ & $1 / 2$ & $1 / 6$ & $1 / 2$ & $1 / 4$ & $1 / 2$ & $1 / 2$ & $1 / 6$ & 1 & $1 / 4$ & $1 / 4$ & $1 / 4$ & 1 & $1 / 2$ & 1 \\
\hline R6 & 1 & 1 & 1 & 1 & 2 & 1 & 1 & 1 & $1 / 4$ & 1 & $1 / 2$ & 1 & 1 & $1 / 4$ & 2 & $1 / 2$ & $1 / 2$ & $1 / 2$ & 2 & 1 & 2 \\
\hline R7 & 1 & 1 & 1 & 1 & 2 & 1 & 1 & 1 & $1 / 4$ & 1 & $1 / 2$ & 1 & 1 & $1 / 4$ & 2 & $1 / 2$ & $1 / 2$ & $1 / 2$ & 2 & 1 & 2 \\
\hline R8 & 1 & 1 & 1 & 1 & 2 & 1 & 1 & 1 & $1 / 4$ & 1 & $1 / 2$ & 1 & 1 & $1 / 4$ & 2 & $1 / 2$ & $1 / 2$ & $1 / 2$ & 2 & 1 & 2 \\
\hline R9 & 4 & 4 & 4 & 4 & 6 & 4 & 4 & 4 & 1 & 4 & 2 & 4 & 4 & 1 & 6 & 2 & 2 & 2 & 6 & 4 & 6 \\
\hline R10 & 1 & 1 & 1 & 1 & 2 & 1 & 1 & 1 & $1 / 4$ & 1 & $1 / 2$ & 1 & 1 & $1 / 4$ & 2 & $1 / 2$ & $1 / 2$ & $1 / 2$ & 2 & 1 & 2 \\
\hline R11 & 2 & 2 & 2 & 2 & 4 & 2 & 2 & 2 & $1 / 2$ & 2 & 1 & 2 & 2 & $1 / 2$ & 4 & 1 & 1 & 1 & 4 & 2 & 4 \\
\hline R12 & 1 & 1 & 1 & 1 & 2 & 1 & 1 & 1 & $1 / 4$ & 1 & $1 / 2$ & 1 & 1 & $1 / 4$ & 2 & $1 / 2$ & $1 / 2$ & $1 / 2$ & 2 & 1 & 2 \\
\hline R13 & 1 & 1 & 1 & 1 & 2 & 1 & 1 & 1 & $1 / 4$ & 1 & $1 / 2$ & 1 & 1 & $1 / 4$ & 2 & $1 / 2$ & $1 / 2$ & $1 / 2$ & 2 & 1 & 2 \\
\hline R14 & 4 & 4 & 4 & 4 & 6 & 4 & 4 & 4 & 1 & 4 & 2 & 4 & 4 & 1 & 6 & 2 & 2 & 2 & 6 & 4 & 6 \\
\hline R15 & $1 / 2$ & $1 / 2$ & $1 / 2$ & $1 / 2$ & 1 & $1 / 2$ & $1 / 2$ & $1 / 2$ & $1 / 6$ & $1 / 2$ & $1 / 4$ & $1 / 2$ & $1 / 2$ & $1 / 6$ & 1 & $1 / 4$ & $1 / 4$ & $1 / 4$ & 1 & $1 / 2$ & 1 \\
\hline R16 & 2 & 2 & 2 & 2 & 4 & 2 & 2 & 2 & $1 / 2$ & 2 & 1 & 2 & 2 & $1 / 2$ & 4 & 1 & 1 & 1 & 4 & 2 & 4 \\
\hline R17 & 2 & 2 & 2 & 2 & 4 & 2 & 2 & 2 & $1 / 2$ & 2 & 1 & 2 & 2 & $1 / 2$ & 4 & 1 & 1 & 1 & 4 & 2 & 4 \\
\hline R18 & 2 & 2 & 2 & 2 & 4 & 2 & 2 & 2 & $1 / 2$ & 2 & 1 & 2 & 2 & $1 / 2$ & 4 & 1 & 1 & 1 & 4 & 2 & 4 \\
\hline R19 & $1 / 2$ & $1 / 2$ & $1 / 2$ & $1 / 2$ & 1 & $1 / 2$ & $1 / 2$ & $1 / 2$ & $1 / 6$ & $1 / 2$ & $1 / 4$ & $1 / 2$ & $1 / 2$ & $1 / 6$ & 1 & $1 / 4$ & $1 / 4$ & $1 / 4$ & 1 & $1 / 2$ & 1 \\
\hline R20 & 1 & 1 & 1 & 1 & 2 & 1 & 1 & 1 & $1 / 4$ & 1 & $1 / 2$ & 1 & 1 & $1 / 4$ & 2 & $1 / 2$ & $1 / 2$ & $1 / 2$ & 2 & 1 & 2 \\
\hline R21 & $1 / 2$ & $1 / 2$ & $1 / 2$ & $1 / 2$ & 1 & $1 / 2$ & $1 / 2$ & $1 / 2$ & $1 / 6$ & $1 / 2$ & $1 / 4$ & $1 / 2$ & $1 / 2$ & $1 / 6$ & 1 & $1 / 4$ & $1 / 4$ & $1 / 4$ & 1 & $1 / 2$ & 1 \\
\hline R22 & 1 & 1 & 1 & 1 & 2 & 1 & 1 & 1 & $1 / 4$ & 1 & $1 / 2$ & 1 & 1 & $1 / 4$ & 2 & $1 / 2$ & $1 / 2$ & $1 / 2$ & 2 & 1 & 2 \\
\hline R23 & $1 / 2$ & $1 / 2$ & $1 / 2$ & $1 / 2$ & 1 & $1 / 2$ & $1 / 2$ & $1 / 2$ & $1 / 6$ & $1 / 2$ & $1 / 4$ & $1 / 2$ & $1 / 2$ & $1 / 6$ & 1 & $1 / 4$ & $1 / 4$ & $1 / 4$ & 1 & $1 / 2$ & 1 \\
\hline R24 & $1 / 2$ & $1 / 2$ & $1 / 2$ & $1 / 2$ & 1 & $1 / 2$ & $1 / 2$ & $1 / 2$ & $1 / 6$ & $1 / 2$ & $1 / 4$ & $1 / 2$ & $1 / 2$ & $1 / 6$ & 1 & $1 / 4$ & $1 / 4$ & $1 / 4$ & 1 & $1 / 2$ & 1 \\
\hline R25 & 1 & 1 & 1 & 1 & 2 & 1 & 1 & 1 & $1 / 4$ & 1 & $1 / 2$ & 1 & 1 & $1 / 4$ & 2 & $1 / 2$ & $1 / 2$ & $1 / 2$ & 2 & 1 & 2 \\
\hline R26 & $1 / 2$ & $1 / 2$ & $1 / 2$ & $1 / 2$ & 1 & $1 / 2$ & $1 / 2$ & $1 / 2$ & $1 / 6$ & $1 / 2$ & $1 / 4$ & $1 / 2$ & $1 / 2$ & $1 / 6$ & 1 & $1 / 4$ & $1 / 4$ & $1 / 4$ & 1 & $1 / 2$ & 1 \\
\hline R27 & $1 / 2$ & $1 / 2$ & $1 / 2$ & $1 / 2$ & 1 & $1 / 2$ & $1 / 2$ & $1 / 2$ & $1 / 6$ & $1 / 2$ & $1 / 4$ & $1 / 2$ & $1 / 2$ & $1 / 6$ & 1 & $1 / 4$ & $1 / 4$ & $1 / 4$ & 1 & $1 / 2$ & 1 \\
\hline R28 & $1 / 2$ & $1 / 2$ & $1 / 2$ & $1 / 2$ & 1 & $1 / 2$ & $1 / 2$ & $1 / 2$ & $1 / 6$ & $1 / 2$ & $1 / 4$ & $1 / 2$ & $1 / 2$ & $1 / 6$ & 1 & $1 / 4$ & $1 / 4$ & $1 / 4$ & 1 & $1 / 2$ & 1 \\
\hline R29 & $1 / 2$ & $1 / 2$ & $1 / 2$ & $1 / 2$ & 1 & $1 / 2$ & $1 / 2$ & $1 / 2$ & $1 / 6$ & $1 / 2$ & $1 / 4$ & $1 / 2$ & $1 / 2$ & $1 / 6$ & 1 & $1 / 4$ & $1 / 4$ & $1 / 4$ & 1 & $1 / 2$ & 1 \\
\hline R30 & $1 / 2$ & $1 / 2$ & $1 / 2$ & $1 / 2$ & 1 & $1 / 2$ & $1 / 2$ & $1 / 2$ & $1 / 6$ & $1 / 2$ & $1 / 4$ & $1 / 2$ & $1 / 2$ & $1 / 6$ & 1 & $1 / 4$ & $1 / 4$ & $1 / 4$ & 1 & $1 / 2$ & 1 \\
\hline
\end{tabular}


Table A7. Cont.

\begin{tabular}{|c|c|c|c|c|c|c|c|c|c|c|c|c|c|c|c|c|c|c|c|c|c|}
\hline & R1 & R2 & R3 & R4 & R5 & R6 & R7 & R8 & R9 & R10 & R11 & R12 & R13 & R14 & R15 & R16 & R17 & R18 & R19 & R20 & R21 \\
\hline R31 & $1 / 2$ & $1 / 2$ & $1 / 2$ & $1 / 2$ & 1 & $1 / 2$ & $1 / 2$ & $1 / 2$ & $1 / 6$ & $1 / 2$ & $1 / 4$ & $1 / 2$ & $1 / 2$ & $1 / 6$ & 1 & $1 / 4$ & $1 / 4$ & $1 / 4$ & 1 & $1 / 2$ & 1 \\
\hline R32 & $1 / 2$ & $1 / 2$ & $1 / 2$ & $1 / 2$ & 1 & $1 / 2$ & $1 / 2$ & $1 / 2$ & $1 / 6$ & $1 / 2$ & $1 / 4$ & $1 / 2$ & $1 / 2$ & $1 / 6$ & 1 & $1 / 4$ & $1 / 4$ & $1 / 4$ & 1 & $1 / 2$ & 1 \\
\hline R33 & 1 & 1 & 1 & 1 & 2 & 1 & 1 & 1 & $1 / 4$ & 1 & $1 / 2$ & 1 & 1 & $1 / 4$ & 2 & $1 / 2$ & $1 / 2$ & $1 / 2$ & 2 & 1 & 2 \\
\hline R34 & $1 / 2$ & $1 / 2$ & $1 / 2$ & $1 / 2$ & 1 & $1 / 2$ & $1 / 2$ & $1 / 2$ & $1 / 6$ & $1 / 2$ & $1 / 4$ & $1 / 2$ & $1 / 2$ & $1 / 6$ & 1 & $1 / 4$ & $1 / 4$ & $1 / 4$ & 1 & $1 / 2$ & 1 \\
\hline R35 & $1 / 2$ & $1 / 2$ & $1 / 2$ & $1 / 2$ & 1 & $1 / 2$ & $1 / 2$ & $1 / 2$ & $1 / 6$ & $1 / 2$ & $1 / 4$ & $1 / 2$ & $1 / 2$ & $1 / 6$ & 1 & $1 / 4$ & $1 / 4$ & $1 / 4$ & 1 & $1 / 2$ & 1 \\
\hline R36 & $1 / 2$ & $1 / 2$ & $1 / 2$ & $1 / 2$ & 1 & $1 / 2$ & $1 / 2$ & $1 / 2$ & $1 / 6$ & $1 / 2$ & $1 / 4$ & $1 / 2$ & $1 / 2$ & $1 / 6$ & 1 & $1 / 4$ & $1 / 4$ & $1 / 4$ & 1 & $1 / 2$ & 1 \\
\hline R37 & 1 & 1 & 1 & 1 & 2 & 1 & 1 & 1 & $1 / 4$ & 1 & $1 / 2$ & 1 & 1 & $1 / 4$ & 2 & $1 / 2$ & $1 / 2$ & $1 / 2$ & 2 & 1 & 2 \\
\hline R38 & 1 & 1 & 1 & 1 & 2 & 1 & 1 & 1 & $1 / 4$ & 1 & $1 / 2$ & 1 & 1 & $1 / 4$ & 2 & $1 / 2$ & $1 / 2$ & $1 / 2$ & 2 & 1 & 2 \\
\hline R39 & 1 & 1 & 1 & 1 & 2 & 1 & 1 & 1 & $1 / 4$ & 1 & $1 / 2$ & 1 & 1 & $1 / 4$ & 2 & $1 / 2$ & $1 / 2$ & $1 / 2$ & 2 & 1 & 2 \\
\hline R40 & 1 & 1 & 1 & 1 & 2 & 1 & 1 & 1 & $1 / 4$ & 1 & $1 / 2$ & 1 & 1 & $1 / 4$ & 2 & $1 / 2$ & $1 / 2$ & $1 / 2$ & 2 & 1 & 2 \\
\hline R41 & 1 & 1 & 1 & 1 & 2 & 1 & 1 & 1 & $1 / 4$ & 1 & $1 / 2$ & 1 & 1 & $1 / 4$ & 2 & $1 / 2$ & $1 / 2$ & $1 / 2$ & 2 & 1 & 2 \\
\hline R42 & 1 & 1 & 1 & 1 & 2 & 1 & 1 & 1 & $1 / 4$ & 1 & $1 / 2$ & 1 & 1 & $1 / 4$ & 2 & $1 / 2$ & $1 / 2$ & $1 / 2$ & 2 & 1 & 2 \\
\hline R43 & 2 & 2 & 2 & 2 & 4 & 2 & 2 & 2 & $1 / 2$ & 2 & 1 & 2 & 2 & $1 / 2$ & 4 & 1 & 1 & 1 & 4 & 2 & 4 \\
\hline R44 & 4 & 4 & 4 & 4 & 6 & 4 & 4 & 4 & 1 & 4 & 2 & 4 & 4 & 1 & 6 & 2 & 2 & 2 & 6 & 4 & 6 \\
\hline R45 & 4 & 4 & 4 & 4 & 6 & 4 & 4 & 4 & 1 & 4 & 2 & 4 & 4 & 1 & 6 & 2 & 2 & 2 & 6 & 4 & 6 \\
\hline R46 & 1 & 1 & 1 & 1 & 2 & 1 & 1 & 1 & $1 / 4$ & 1 & $1 / 2$ & 1 & 1 & $1 / 4$ & 2 & $1 / 2$ & $1 / 2$ & $1 / 2$ & 2 & 1 & 2 \\
\hline R47 & $1 / 2$ & $1 / 2$ & $1 / 2$ & $1 / 2$ & 1 & $1 / 2$ & $1 / 2$ & $1 / 2$ & $1 / 6$ & $1 / 2$ & $1 / 4$ & $1 / 2$ & $1 / 2$ & $1 / 6$ & 1 & $1 / 4$ & $1 / 4$ & $1 / 4$ & 1 & $1 / 2$ & 1 \\
\hline R48 & 2 & 2 & 2 & 2 & 4 & 2 & 2 & 2 & $1 / 2$ & 2 & 1 & 2 & 2 & $1 / 2$ & 4 & 1 & 1 & 1 & 4 & 2 & 4 \\
\hline R49 & 2 & 2 & 2 & 2 & 4 & 2 & 2 & 2 & $1 / 2$ & 2 & 1 & 2 & 2 & $1 / 2$ & 4 & 1 & 1 & 1 & 4 & 2 & 4 \\
\hline R50 & 1 & 1 & 1 & 1 & 2 & 1 & 1 & 1 & $1 / 4$ & 1 & $1 / 2$ & 1 & 1 & $1 / 4$ & 2 & $1 / 2$ & $1 / 2$ & $1 / 2$ & 2 & 1 & 2 \\
\hline R51 & 2 & 2 & 2 & 2 & 4 & 2 & 2 & 2 & $1 / 2$ & 2 & 1 & 2 & 2 & $1 / 2$ & 4 & 1 & 1 & 1 & 4 & 2 & 4 \\
\hline R52 & 1 & 1 & 1 & 1 & 2 & 1 & 1 & 1 & $1 / 4$ & 1 & $1 / 2$ & 1 & 1 & $1 / 4$ & 2 & $1 / 2$ & $1 / 2$ & $1 / 2$ & 2 & 1 & 2 \\
\hline R53 & 1 & 1 & 1 & 1 & 2 & 1 & 1 & 1 & $1 / 4$ & 1 & $1 / 2$ & 1 & 1 & $1 / 4$ & 2 & $1 / 2$ & $1 / 2$ & $1 / 2$ & 2 & 1 & 2 \\
\hline R54 & 1 & 1 & 1 & 1 & 2 & 1 & 1 & 1 & $1 / 4$ & 1 & $1 / 2$ & 1 & 1 & $1 / 4$ & 2 & $1 / 2$ & $1 / 2$ & $1 / 2$ & 2 & 1 & 2 \\
\hline R55 & 1 & 1 & 1 & 1 & 2 & 1 & 1 & 1 & $1 / 4$ & 1 & $1 / 2$ & 1 & 1 & $1 / 4$ & 2 & $1 / 2$ & $1 / 2$ & $1 / 2$ & 2 & 1 & 2 \\
\hline R56 & 2 & 2 & 2 & 2 & 4 & 2 & 2 & 2 & $1 / 2$ & 2 & 1 & 2 & 2 & $1 / 2$ & 4 & 1 & 1 & 1 & 4 & 2 & 4 \\
\hline R57 & 2 & 2 & 2 & 2 & 4 & 2 & 2 & 2 & $1 / 2$ & 2 & 1 & 2 & 2 & $1 / 2$ & 4 & 1 & 1 & 1 & 4 & 2 & 4 \\
\hline R58 & $1 / 2$ & $1 / 2$ & $1 / 2$ & $1 / 2$ & 1 & $1 / 2$ & $1 / 2$ & $1 / 2$ & $1 / 6$ & $1 / 2$ & $1 / 4$ & $1 / 2$ & $1 / 2$ & $1 / 6$ & 1 & $1 / 4$ & $1 / 4$ & $1 / 4$ & 1 & $1 / 2$ & 1 \\
\hline R59 & 2 & 2 & 2 & 2 & 4 & 2 & 2 & 2 & $1 / 2$ & 2 & 1 & 2 & 2 & $1 / 2$ & 4 & 1 & 1 & 1 & 4 & 2 & 4 \\
\hline R60 & 1 & 1 & 1 & 1 & 2 & 1 & 1 & 1 & $1 / 4$ & 1 & $1 / 2$ & 1 & 1 & $1 / 4$ & 2 & $1 / 2$ & $1 / 2$ & $1 / 2$ & 2 & 1 & 2 \\
\hline R61 & 2 & 2 & 2 & 2 & 4 & 2 & 2 & 2 & $1 / 2$ & 2 & 1 & 2 & 2 & $1 / 2$ & 4 & 1 & 1 & 1 & 4 & 2 & 4 \\
\hline R62 & 1 & 1 & 1 & 1 & 2 & 1 & 1 & 1 & $1 / 4$ & 1 & $1 / 2$ & 1 & 1 & $1 / 4$ & 2 & $1 / 2$ & $1 / 2$ & $1 / 2$ & 2 & 1 & 2 \\
\hline R63 & 2 & 2 & 2 & 2 & 4 & 2 & 2 & 2 & $1 / 2$ & 2 & 1 & 2 & 2 & $1 / 2$ & 4 & 1 & 1 & 1 & 4 & 2 & 4 \\
\hline R64 & $1 / 2$ & $1 / 2$ & $1 / 2$ & $1 / 2$ & 1 & $1 / 2$ & $1 / 2$ & $1 / 2$ & $1 / 6$ & $1 / 2$ & $1 / 4$ & $1 / 2$ & $1 / 2$ & $1 / 6$ & 1 & $1 / 4$ & $1 / 4$ & $1 / 4$ & 1 & $1 / 2$ & 1 \\
\hline
\end{tabular}

Table A8. Pairwise comparison matrix between risks according to risks' detectability, Part 2.

\begin{tabular}{|c|c|c|c|c|c|c|c|c|c|c|c|c|c|c|c|c|c|c|c|c|c|}
\hline & R22 & R23 & R24 & R25 & R26 & R27 & R28 & R29 & R30 & R31 & R32 & R33 & R34 & R35 & R36 & R37 & R38 & R39 & R40 & R41 & R42 \\
\hline R1 & 1 & 2 & 2 & 1 & 2 & 2 & 2 & 2 & 2 & 2 & 2 & 1 & 2 & 2 & 2 & 1 & 1 & 1 & 1 & 1 & 1 \\
\hline R2 & 1 & 2 & 2 & 1 & 2 & 2 & 2 & 2 & 2 & 2 & 2 & 1 & 2 & 2 & 2 & 1 & 1 & 1 & 1 & 1 & 1 \\
\hline R3 & 1 & 2 & 2 & 1 & 2 & 2 & 2 & 2 & 2 & 2 & 2 & 1 & 2 & 2 & 2 & 1 & 1 & 1 & 1 & 1 & 1 \\
\hline $\mathbf{R} 4$ & 1 & 2 & 2 & 1 & 2 & 2 & 2 & 2 & 2 & 2 & 2 & 1 & 2 & 2 & 2 & 1 & 1 & 1 & 1 & 1 & 1 \\
\hline R5 & $1 / 2$ & 1 & 1 & $1 / 2$ & 1 & 1 & 1 & 1 & 1 & 1 & 1 & $1 / 2$ & 1 & 1 & 1 & $1 / 2$ & $1 / 2$ & $1 / 2$ & $1 / 2$ & $1 / 2$ & $1 / 2$ \\
\hline R6 & 1 & 2 & 2 & 1 & 2 & 2 & 2 & 2 & 2 & 2 & 2 & 1 & 2 & 2 & 2 & 1 & 1 & 1 & 1 & 1 & 1 \\
\hline R7 & 1 & 2 & 2 & 1 & 2 & 2 & 2 & 2 & 2 & 2 & 2 & 1 & 2 & 2 & 2 & 1 & 1 & 1 & 1 & 1 & 1 \\
\hline R8 & 1 & 2 & 2 & 1 & 2 & 2 & 2 & 2 & 2 & 2 & 2 & 1 & 2 & 2 & 2 & 1 & 1 & 1 & 1 & 1 & 1 \\
\hline R9 & 4 & 6 & 6 & 4 & 6 & 6 & 6 & 6 & 6 & 6 & 6 & 4 & 6 & 6 & 6 & 4 & 4 & 4 & 4 & 4 & 4 \\
\hline R10 & 1 & 2 & 2 & 1 & 2 & 2 & 2 & 2 & 2 & 2 & 2 & 1 & 2 & 2 & 2 & 1 & 1 & 1 & 1 & 1 & 1 \\
\hline R11 & 2 & 4 & 4 & 2 & 4 & 4 & 4 & 4 & 4 & 4 & 4 & 2 & 4 & 4 & 4 & 2 & 2 & 2 & 2 & 2 & 2 \\
\hline R12 & 1 & 2 & 2 & 1 & 2 & 2 & 2 & 2 & 2 & 2 & 2 & 1 & 2 & 2 & 2 & 1 & 1 & 1 & 1 & 1 & 1 \\
\hline R13 & 1 & 2 & 2 & 1 & 2 & 2 & 2 & 2 & 2 & 2 & 2 & 1 & 2 & 2 & 2 & 1 & 1 & 1 & 1 & 1 & 1 \\
\hline R14 & 4 & 6 & 6 & 4 & 6 & 6 & 6 & 6 & 6 & 6 & 6 & 4 & 6 & 6 & 6 & 4 & 4 & 4 & 4 & 4 & 4 \\
\hline R15 & $1 / 2$ & 1 & 1 & $1 / 2$ & 1 & 1 & 1 & 1 & 1 & 1 & 1 & $1 / 2$ & 1 & 1 & 1 & $1 / 2$ & $1 / 2$ & $1 / 2$ & $1 / 2$ & $1 / 2$ & $1 / 2$ \\
\hline
\end{tabular}


Table A8. Cont.

\begin{tabular}{|c|c|c|c|c|c|c|c|c|c|c|c|c|c|c|c|c|c|c|c|c|c|}
\hline & R22 & R23 & R24 & R25 & R26 & R27 & R28 & R29 & R30 & R31 & R32 & R33 & R34 & R35 & R36 & R37 & R38 & R39 & R40 & R41 & R42 \\
\hline R16 & 2 & 4 & 4 & 2 & 4 & 4 & 4 & 4 & 4 & 4 & 4 & 2 & 4 & 4 & 4 & 2 & 2 & 2 & 2 & 2 & 2 \\
\hline R17 & 2 & 4 & 4 & 2 & 4 & 4 & 4 & 4 & 4 & 4 & 4 & 2 & 4 & 4 & 4 & 2 & 2 & 2 & 2 & 2 & 2 \\
\hline R18 & 2 & 4 & 4 & 2 & 4 & 4 & 4 & 4 & 4 & 4 & 4 & 2 & 4 & 4 & 4 & 2 & 2 & 2 & 2 & 2 & 2 \\
\hline R19 & $1 / 2$ & 1 & 1 & $1 / 2$ & 1 & 1 & 1 & 1 & 1 & 1 & 1 & $1 / 2$ & 1 & 1 & 1 & $1 / 2$ & $1 / 2$ & $1 / 2$ & $1 / 2$ & $1 / 2$ & $1 / 2$ \\
\hline R20 & 1 & 2 & 2 & 1 & 2 & 2 & 2 & 2 & 2 & 2 & 2 & 1 & 2 & 2 & 2 & 1 & 1 & 1 & 1 & 1 & 1 \\
\hline R21 & $1 / 2$ & 1 & 1 & $1 / 2$ & 1 & 1 & 1 & 1 & 1 & 1 & 1 & $1 / 2$ & 1 & 1 & 1 & $1 / 2$ & $1 / 2$ & $1 / 2$ & $1 / 2$ & $1 / 2$ & $1 / 2$ \\
\hline R22 & 1 & 2 & 2 & 1 & 2 & 2 & 2 & 2 & 2 & 2 & 2 & 1 & 2 & 2 & 2 & 1 & 1 & 1 & 1 & 1 & 1 \\
\hline R23 & $1 / 2$ & 1 & 1 & $1 / 2$ & 1 & 1 & 1 & 1 & 1 & 1 & 1 & $1 / 2$ & 1 & 1 & 1 & $1 / 2$ & $1 / 2$ & $1 / 2$ & $1 / 2$ & $1 / 2$ & $1 / 2$ \\
\hline R24 & $1 / 2$ & 1 & 1 & $1 / 2$ & 1 & 1 & 1 & 1 & 1 & 1 & 1 & $1 / 2$ & 1 & 1 & 1 & $1 / 2$ & $1 / 2$ & $1 / 2$ & $1 / 2$ & $1 / 2$ & $1 / 2$ \\
\hline R25 & 1 & 2 & 2 & 1 & 2 & 2 & 2 & 2 & 2 & 2 & 2 & 1 & 2 & 2 & 2 & 1 & 1 & 1 & 1 & 1 & 1 \\
\hline R26 & $1 / 2$ & 1 & 1 & $1 / 2$ & 1 & 1 & 1 & 1 & 1 & 1 & 1 & $1 / 2$ & 1 & 1 & 1 & $1 / 2$ & $1 / 2$ & $1 / 2$ & $1 / 2$ & $1 / 2$ & $1 / 2$ \\
\hline R27 & $1 / 2$ & 1 & 1 & $1 / 2$ & 1 & 1 & 1 & 1 & 1 & 1 & 1 & $1 / 2$ & 1 & 1 & 1 & $1 / 2$ & $1 / 2$ & $1 / 2$ & $1 / 2$ & $1 / 2$ & $1 / 2$ \\
\hline R28 & $1 / 2$ & 1 & 1 & $1 / 2$ & 1 & 1 & 1 & 1 & 1 & 1 & 1 & $1 / 2$ & 1 & 1 & 1 & $1 / 2$ & $1 / 2$ & $1 / 2$ & $1 / 2$ & $1 / 2$ & $1 / 2$ \\
\hline R29 & $1 / 2$ & 1 & 1 & $1 / 2$ & 1 & 1 & 1 & 1 & 1 & 1 & 1 & $1 / 2$ & 1 & 1 & 1 & $1 / 2$ & $1 / 2$ & $1 / 2$ & $1 / 2$ & $1 / 2$ & $1 / 2$ \\
\hline R30 & $1 / 2$ & 1 & 1 & $1 / 2$ & 1 & 1 & 1 & 1 & 1 & 1 & 1 & $1 / 2$ & 1 & 1 & 1 & $1 / 2$ & $1 / 2$ & $1 / 2$ & $1 / 2$ & $1 / 2$ & $1 / 2$ \\
\hline R31 & $1 / 2$ & 1 & 1 & $1 / 2$ & 1 & 1 & 1 & 1 & 1 & 1 & 1 & $1 / 2$ & 1 & 1 & 1 & $1 / 2$ & $1 / 2$ & $1 / 2$ & $1 / 2$ & $1 / 2$ & $1 / 2$ \\
\hline R32 & $1 / 2$ & 1 & 1 & $1 / 2$ & 1 & 1 & 1 & 1 & 1 & 1 & 1 & $1 / 2$ & 1 & 1 & 1 & $1 / 2$ & $1 / 2$ & $1 / 2$ & $1 / 2$ & $1 / 2$ & $1 / 2$ \\
\hline R33 & 1 & 2 & 2 & 1 & 2 & 2 & 2 & 2 & 2 & 2 & 2 & 1 & 2 & 2 & 2 & 1 & 1 & 1 & 1 & 1 & 1 \\
\hline R34 & $1 / 2$ & 1 & 1 & $1 / 2$ & 1 & 1 & 1 & 1 & 1 & 1 & 1 & $1 / 2$ & 1 & 1 & 1 & $1 / 2$ & $1 / 2$ & $1 / 2$ & $1 / 2$ & $1 / 2$ & $1 / 2$ \\
\hline R35 & $1 / 2$ & 1 & 1 & $1 / 2$ & 1 & 1 & 1 & 1 & 1 & 1 & 1 & $1 / 2$ & 1 & 1 & 1 & $1 / 2$ & $1 / 2$ & $1 / 2$ & $1 / 2$ & $1 / 2$ & $1 / 2$ \\
\hline R36 & $1 / 2$ & 1 & 1 & $1 / 2$ & 1 & 1 & 1 & 1 & 1 & 1 & 1 & $1 / 2$ & 1 & 1 & 1 & $1 / 2$ & $1 / 2$ & $1 / 2$ & $1 / 2$ & $1 / 2$ & $1 / 2$ \\
\hline R37 & 1 & 2 & 2 & 1 & 2 & 2 & 2 & 2 & 2 & 2 & 2 & 1 & 2 & 2 & 2 & 1 & 1 & 1 & 1 & 1 & 1 \\
\hline R38 & 1 & 2 & 2 & 1 & 2 & 2 & 2 & 2 & 2 & 2 & 2 & 1 & 2 & 2 & 2 & 1 & 1 & 1 & 1 & 1 & 1 \\
\hline R39 & 1 & 2 & 2 & 1 & 2 & 2 & 2 & 2 & 2 & 2 & 2 & 1 & 2 & 2 & 2 & 1 & 1 & 1 & 1 & 1 & 1 \\
\hline R40 & 1 & 2 & 2 & 1 & 2 & 2 & 2 & 2 & 2 & 2 & 2 & 1 & 2 & 2 & 2 & 1 & 1 & 1 & 1 & 1 & 1 \\
\hline R41 & 1 & 2 & 2 & 1 & 2 & 2 & 2 & 2 & 2 & 2 & 2 & 1 & 2 & 2 & 2 & 1 & 1 & 1 & 1 & 1 & 1 \\
\hline R42 & 1 & 2 & 2 & 1 & 2 & 2 & 2 & 2 & 2 & 2 & 2 & 1 & 2 & 2 & 2 & 1 & 1 & 1 & 1 & 1 & 1 \\
\hline R43 & 2 & 4 & 4 & 2 & 4 & 4 & 4 & 4 & 4 & 4 & 4 & 2 & 4 & 4 & 4 & 2 & 2 & 2 & 2 & 2 & 2 \\
\hline R44 & 4 & 6 & 6 & 4 & 6 & 6 & 6 & 6 & 6 & 6 & 6 & 4 & 6 & 6 & 6 & 4 & 4 & 4 & 4 & 4 & 4 \\
\hline R45 & 4 & 6 & 6 & 4 & 6 & 6 & 6 & 6 & 6 & 6 & 6 & 4 & 6 & 6 & 6 & 4 & 4 & 4 & 4 & 4 & 4 \\
\hline R46 & 1 & 2 & 2 & 1 & 2 & 2 & 2 & 2 & 2 & 2 & 2 & 1 & 2 & 2 & 2 & 1 & 1 & 1 & 1 & 1 & 1 \\
\hline R47 & $1 / 2$ & 1 & 1 & $1 / 2$ & 1 & 1 & 1 & 1 & 1 & 1 & 1 & $1 / 2$ & 1 & 1 & 1 & $1 / 2$ & $1 / 2$ & $1 / 2$ & $1 / 2$ & $1 / 2$ & $1 / 2$ \\
\hline R48 & 2 & 4 & 4 & 2 & 4 & 4 & 4 & 4 & 4 & 4 & 4 & 2 & 4 & 4 & 4 & 2 & 2 & 2 & 2 & 2 & 2 \\
\hline R49 & 2 & 4 & 4 & 2 & 4 & 4 & 4 & 4 & 4 & 4 & 4 & 2 & 4 & 4 & 4 & 2 & 2 & 2 & 2 & 2 & 2 \\
\hline R50 & 1 & 2 & 2 & 1 & 2 & 2 & 2 & 2 & 2 & 2 & 2 & 1 & 2 & 2 & 2 & 1 & 1 & 1 & 1 & 1 & 1 \\
\hline R51 & 2 & 4 & 4 & 2 & 4 & 4 & 4 & 4 & 4 & 4 & 4 & 2 & 4 & 4 & 4 & 2 & 2 & 2 & 2 & 2 & 2 \\
\hline R52 & 1 & 2 & 2 & 1 & 2 & 2 & 2 & 2 & 2 & 2 & 2 & 1 & 2 & 2 & 2 & 1 & 1 & 1 & 1 & 1 & 1 \\
\hline R53 & 1 & 2 & 2 & 1 & 2 & 2 & 2 & 2 & 2 & 2 & 2 & 1 & 2 & 2 & 2 & 1 & 1 & 1 & 1 & 1 & 1 \\
\hline R54 & 1 & 2 & 2 & 1 & 2 & 2 & 2 & 2 & 2 & 2 & 2 & 1 & 2 & 2 & 2 & 1 & 1 & 1 & 1 & 1 & 1 \\
\hline R55 & 1 & 2 & 2 & 1 & 2 & 2 & 2 & 2 & 2 & 2 & 2 & 1 & 2 & 2 & 2 & 1 & 1 & 1 & 1 & 1 & 1 \\
\hline R56 & 2 & 4 & 4 & 2 & 4 & 4 & 4 & 4 & 4 & 4 & 4 & 2 & 4 & 4 & 4 & 2 & 2 & 2 & 2 & 2 & 2 \\
\hline R57 & 2 & 4 & 4 & 2 & 4 & 4 & 4 & 4 & 4 & 4 & 4 & 2 & 4 & 4 & 4 & 2 & 2 & 2 & 2 & 2 & 2 \\
\hline R58 & $1 / 2$ & 1 & 1 & $1 / 2$ & 1 & 1 & 1 & 1 & 1 & 1 & 1 & $1 / 2$ & 1 & 1 & 1 & $1 / 2$ & $1 / 2$ & $1 / 2$ & $1 / 2$ & $1 / 2$ & $1 / 2$ \\
\hline R59 & 2 & 4 & 4 & 2 & 4 & 4 & 4 & 4 & 4 & 4 & 4 & 2 & 4 & 4 & 4 & 2 & 2 & 2 & 2 & 2 & 2 \\
\hline R60 & 1 & 2 & 2 & 1 & 2 & 2 & 2 & 2 & 2 & 2 & 2 & 1 & 2 & 2 & 2 & 1 & 1 & 1 & 1 & 1 & 1 \\
\hline R61 & 2 & 4 & 4 & 2 & 4 & 4 & 4 & 4 & 4 & 4 & 4 & 2 & 4 & 4 & 4 & 2 & 2 & 2 & 2 & 2 & 2 \\
\hline R62 & 1 & 2 & 2 & 1 & 2 & 2 & 2 & 2 & 2 & 2 & 2 & 1 & 2 & 2 & 2 & 1 & 1 & 1 & 1 & 1 & 1 \\
\hline R63 & 2 & 4 & 4 & 2 & 4 & 4 & 4 & 4 & 4 & 4 & 4 & 2 & 4 & 4 & 4 & 2 & 2 & 2 & 2 & 2 & 2 \\
\hline R64 & $1 / 2$ & 1 & 1 & $1 / 2$ & 1 & 1 & 1 & 1 & 1 & 1 & 1 & $1 / 2$ & 1 & 1 & 1 & $1 / 2$ & $1 / 2$ & $1 / 2$ & $1 / 2$ & $1 / 2$ & $1 / 2$ \\
\hline
\end{tabular}

Table A9. Pairwise comparison matrix between risks according to risks' detectability, Part 3.

\begin{tabular}{|c|c|c|c|c|c|c|c|c|c|c|c|c|c|c|c|c|c|c|c|c|c|c|}
\hline & R43 & R44 & R45 & R46 & R47 & R48 & R49 & R50 & R51 & R52 & R53 & R54 & R55 & R56 & R57 & R58 & R59 & R60 & R61 & R62 & R63 & R64 \\
\hline R1 & $1 / 2$ & $1 / 4$ & $1 / 4$ & 1 & 2 & $1 / 2$ & $1 / 2$ & 1 & $1 / 2$ & 1 & 1 & 1 & 1 & $1 / 2$ & $1 / 2$ & 2 & $1 / 2$ & 1 & $1 / 2$ & 1 & $1 / 2$ & 2 \\
\hline R2 & $1 / 2$ & $1 / 4$ & $1 / 4$ & 1 & 2 & $1 / 2$ & $1 / 2$ & 1 & $1 / 2$ & 1 & 1 & 1 & 1 & $1 / 2$ & $1 / 2$ & 2 & $1 / 2$ & 1 & $1 / 2$ & 1 & $1 / 2$ & 2 \\
\hline R3 & $1 / 2$ & $1 / 4$ & $1 / 4$ & 1 & 2 & $1 / 2$ & $1 / 2$ & 1 & $1 / 2$ & 1 & 1 & 1 & 1 & $1 / 2$ & $1 / 2$ & 2 & $1 / 2$ & 1 & $1 / 2$ & 1 & $1 / 2$ & 2 \\
\hline
\end{tabular}


Table A9. Cont.

\begin{tabular}{|c|c|c|c|c|c|c|c|c|c|c|c|c|c|c|c|c|c|c|c|c|c|c|}
\hline & R43 & R44 & R45 & R46 & R47 & R48 & R49 & R50 & R51 & R52 & R53 & R54 & R55 & R56 & R57 & R58 & R59 & R60 & R61 & R62 & R63 & R64 \\
\hline R4 & $1 / 2$ & $1 / 4$ & $1 / 4$ & 1 & 2 & $1 / 2$ & $1 / 2$ & 1 & $1 / 2$ & 1 & 1 & 1 & 1 & $1 / 2$ & $1 / 2$ & 2 & $1 / 2$ & 1 & $1 / 2$ & 1 & $1 / 2$ & 2 \\
\hline R5 & $1 / 4$ & $1 / 6$ & $1 / 6$ & $1 / 2$ & 1 & $1 / 4$ & $1 / 4$ & $1 / 2$ & $1 / 4$ & $1 / 2$ & $1 / 2$ & $1 / 2$ & $1 / 2$ & $1 / 4$ & $1 / 4$ & 1 & $1 / 4$ & $1 / 2$ & $1 / 4$ & $1 / 2$ & $1 / 4$ & 1 \\
\hline R6 & $1 / 2$ & $1 / 4$ & $1 / 4$ & 1 & 2 & $1 / 2$ & $1 / 2$ & 1 & $1 / 2$ & 1 & 1 & 1 & 1 & $1 / 2$ & $1 / 2$ & 2 & $1 / 2$ & 1 & $1 / 2$ & 1 & $1 / 2$ & 2 \\
\hline R7 & $1 / 2$ & $1 / 4$ & $1 / 4$ & 1 & 2 & $1 / 2$ & $1 / 2$ & 1 & $1 / 2$ & 1 & 1 & 1 & 1 & $1 / 2$ & $1 / 2$ & 2 & $1 / 2$ & 1 & $1 / 2$ & 1 & $1 / 2$ & 2 \\
\hline R8 & $1 / 2$ & $1 / 4$ & $1 / 4$ & 1 & 2 & $1 / 2$ & $1 / 2$ & 1 & $1 / 2$ & 1 & 1 & 1 & 1 & $1 / 2$ & $1 / 2$ & 2 & $1 / 2$ & 1 & $1 / 2$ & 1 & $1 / 2$ & 2 \\
\hline R9 & 2 & 1 & 1 & 4 & 6 & 2 & 2 & 4 & 2 & 4 & 4 & 4 & 4 & 2 & 2 & 6 & 2 & 4 & 2 & 4 & 2 & 6 \\
\hline R10 & $1 / 2$ & $1 / 4$ & $1 / 4$ & 1 & 2 & $1 / 2$ & $1 / 2$ & 1 & $1 / 2$ & 1 & 1 & 1 & 1 & $1 / 2$ & $1 / 2$ & 2 & $1 / 2$ & 1 & $1 / 2$ & 1 & $1 / 2$ & 2 \\
\hline R11 & 1 & $1 / 2$ & $1 / 2$ & 2 & 4 & 1 & 1 & 2 & 1 & 2 & 2 & 2 & 2 & 1 & 1 & 4 & 1 & 2 & 1 & 2 & 1 & 4 \\
\hline R12 & $1 / 2$ & $1 / 4$ & $1 / 4$ & 1 & 2 & $1 / 2$ & $1 / 2$ & 1 & $1 / 2$ & 1 & 1 & 1 & 1 & $1 / 2$ & $1 / 2$ & 2 & $1 / 2$ & 1 & $1 / 2$ & 1 & $1 / 2$ & 2 \\
\hline R13 & $1 / 2$ & $1 / 4$ & $1 / 4$ & 1 & 2 & $1 / 2$ & $1 / 2$ & 1 & $1 / 2$ & 1 & 1 & 1 & 1 & $1 / 2$ & $1 / 2$ & 2 & $1 / 2$ & 1 & $1 / 2$ & 1 & $1 / 2$ & 2 \\
\hline R14 & 2 & 1 & 1 & 4 & 6 & 2 & 2 & 4 & 2 & 4 & 4 & 4 & 4 & 2 & 2 & 6 & 2 & 4 & 2 & 4 & 2 & 6 \\
\hline R15 & $1 / 4$ & $1 / 6$ & $1 / 6$ & $1 / 2$ & 1 & $1 / 4$ & $1 / 4$ & $1 / 2$ & $1 / 4$ & $1 / 2$ & $1 / 2$ & $1 / 2$ & $1 / 2$ & $1 / 4$ & $1 / 4$ & 1 & $1 / 4$ & $1 / 2$ & $1 / 4$ & $1 / 2$ & $1 / 4$ & 1 \\
\hline R16 & 1 & $1 / 2$ & $1 / 2$ & 2 & 4 & 1 & 1 & 2 & 1 & 2 & 2 & 2 & 2 & 1 & 1 & 4 & 1 & 2 & 1 & 2 & 1 & 4 \\
\hline R17 & 1 & $1 / 2$ & $1 / 2$ & 2 & 4 & 1 & 1 & 2 & 1 & 2 & 2 & 2 & 2 & 1 & 1 & 4 & 1 & 2 & 1 & 2 & 1 & 4 \\
\hline R18 & 1 & $1 / 2$ & $1 / 2$ & 2 & 4 & 1 & 1 & 2 & 1 & 2 & 2 & 2 & 2 & 1 & 1 & 4 & 1 & 2 & 1 & 2 & 1 & 4 \\
\hline R19 & $1 / 4$ & $1 / 6$ & $1 / 6$ & $1 / 2$ & 1 & $1 / 4$ & $1 / 4$ & $1 / 2$ & $1 / 4$ & $1 / 2$ & $1 / 2$ & $1 / 2$ & $1 / 2$ & $1 / 4$ & $1 / 4$ & 1 & $1 / 4$ & $1 / 2$ & $1 / 4$ & $1 / 2$ & $1 / 4$ & 1 \\
\hline R20 & $1 / 2$ & $1 / 4$ & $1 / 4$ & 1 & 2 & $1 / 2$ & $1 / 2$ & 1 & $1 / 2$ & 1 & 1 & 1 & 1 & $1 / 2$ & $1 / 2$ & 2 & $1 / 2$ & 1 & $1 / 2$ & 1 & $1 / 2$ & 2 \\
\hline R21 & $1 / 4$ & $1 / 6$ & $1 / 6$ & $1 / 2$ & 1 & $1 / 4$ & $1 / 4$ & $1 / 2$ & $1 / 4$ & $1 / 2$ & $1 / 2$ & $1 / 2$ & $1 / 2$ & $1 / 4$ & $1 / 4$ & 1 & $1 / 4$ & $1 / 2$ & $1 / 4$ & $1 / 2$ & $1 / 4$ & 1 \\
\hline R22 & $1 / 2$ & $1 / 4$ & $1 / 4$ & 1 & 2 & $1 / 2$ & $1 / 2$ & 1 & $1 / 2$ & 1 & 1 & 1 & 1 & $1 / 2$ & $1 / 2$ & 2 & $1 / 2$ & 1 & $1 / 2$ & 1 & $1 / 2$ & 2 \\
\hline R23 & $1 / 4$ & $1 / 6$ & $1 / 6$ & $1 / 2$ & 1 & $1 / 4$ & $1 / 4$ & $1 / 2$ & $1 / 4$ & $1 / 2$ & $1 / 2$ & $1 / 2$ & $1 / 2$ & $1 / 4$ & $1 / 4$ & 1 & $1 / 4$ & $1 / 2$ & $1 / 4$ & $1 / 2$ & $1 / 4$ & 1 \\
\hline R24 & $1 / 4$ & $1 / 6$ & $1 / 6$ & $1 / 2$ & 1 & $1 / 4$ & $1 / 4$ & $1 / 2$ & $1 / 4$ & $1 / 2$ & $1 / 2$ & $1 / 2$ & $1 / 2$ & $1 / 4$ & $1 / 4$ & 1 & $1 / 4$ & $1 / 2$ & $1 / 4$ & $1 / 2$ & $1 / 4$ & 1 \\
\hline R25 & $1 / 2$ & $1 / 4$ & $1 / 4$ & 1 & 2 & $1 / 2$ & $1 / 2$ & 1 & $1 / 2$ & 1 & 1 & 1 & 1 & $1 / 2$ & $1 / 2$ & 2 & $1 / 2$ & 1 & $1 / 2$ & 1 & $1 / 2$ & 2 \\
\hline R26 & $1 / 4$ & $1 / 6$ & $1 / 6$ & $1 / 2$ & 1 & $1 / 4$ & $1 / 4$ & $1 / 2$ & $1 / 4$ & $1 / 2$ & $1 / 2$ & $1 / 2$ & $1 / 2$ & $1 / 4$ & $1 / 4$ & 1 & $1 / 4$ & $1 / 2$ & $1 / 4$ & $1 / 2$ & $1 / 4$ & 1 \\
\hline R27 & $1 / 4$ & $1 / 6$ & $1 / 6$ & $1 / 2$ & 1 & $1 / 4$ & $1 / 4$ & $1 / 2$ & $1 / 4$ & $1 / 2$ & $1 / 2$ & $1 / 2$ & $1 / 2$ & $1 / 4$ & $1 / 4$ & 1 & $1 / 4$ & $1 / 2$ & $1 / 4$ & $1 / 2$ & $1 / 4$ & 1 \\
\hline R28 & $1 / 4$ & $1 / 6$ & $1 / 6$ & $1 / 2$ & 1 & $1 / 4$ & $1 / 4$ & $1 / 2$ & $1 / 4$ & $1 / 2$ & $1 / 2$ & $1 / 2$ & $1 / 2$ & $1 / 4$ & $1 / 4$ & 1 & $1 / 4$ & $1 / 2$ & $1 / 4$ & $1 / 2$ & $1 / 4$ & 1 \\
\hline R29 & $1 / 4$ & $1 / 6$ & $1 / 6$ & $1 / 2$ & 1 & $1 / 4$ & $1 / 4$ & $1 / 2$ & $1 / 4$ & $1 / 2$ & $1 / 2$ & $1 / 2$ & $1 / 2$ & $1 / 4$ & $1 / 4$ & 1 & $1 / 4$ & $1 / 2$ & $1 / 4$ & $1 / 2$ & $1 / 4$ & 1 \\
\hline R30 & $1 / 4$ & $1 / 6$ & $1 / 6$ & $1 / 2$ & 1 & $1 / 4$ & $1 / 4$ & $1 / 2$ & $1 / 4$ & $1 / 2$ & $1 / 2$ & $1 / 2$ & $1 / 2$ & $1 / 4$ & $1 / 4$ & 1 & $1 / 4$ & $1 / 2$ & $1 / 4$ & $1 / 2$ & $1 / 4$ & 1 \\
\hline R31 & $1 / 4$ & $1 / 6$ & $1 / 6$ & $1 / 2$ & 1 & $1 / 4$ & $1 / 4$ & $1 / 2$ & $1 / 4$ & $1 / 2$ & $1 / 2$ & $1 / 2$ & $1 / 2$ & $1 / 4$ & $1 / 4$ & 1 & $1 / 4$ & $1 / 2$ & $1 / 4$ & $1 / 2$ & $1 / 4$ & 1 \\
\hline R32 & $1 / 4$ & $1 / 6$ & $1 / 6$ & $1 / 2$ & 1 & $1 / 4$ & $1 / 4$ & $1 / 2$ & $1 / 4$ & $1 / 2$ & $1 / 2$ & $1 / 2$ & $1 / 2$ & $1 / 4$ & $1 / 4$ & 1 & $1 / 4$ & $1 / 2$ & $1 / 4$ & $1 / 2$ & $1 / 4$ & 1 \\
\hline R33 & $1 / 2$ & $1 / 4$ & $1 / 4$ & 1 & 2 & $1 / 2$ & $1 / 2$ & 1 & $1 / 2$ & 1 & 1 & 1 & 1 & $1 / 2$ & $1 / 2$ & 2 & $1 / 2$ & 1 & $1 / 2$ & 1 & $1 / 2$ & 2 \\
\hline R34 & $1 / 4$ & $1 / 6$ & $1 / 6$ & $1 / 2$ & 1 & $1 / 4$ & $1 / 4$ & $1 / 2$ & $1 / 4$ & $1 / 2$ & $1 / 2$ & $1 / 2$ & $1 / 2$ & $1 / 4$ & $1 / 4$ & 1 & $1 / 4$ & $1 / 2$ & $1 / 4$ & $1 / 2$ & $1 / 4$ & 1 \\
\hline R35 & $1 / 4$ & $1 / 6$ & $1 / 6$ & $1 / 2$ & 1 & $1 / 4$ & $1 / 4$ & $1 / 2$ & $1 / 4$ & $1 / 2$ & $1 / 2$ & $1 / 2$ & $1 / 2$ & $1 / 4$ & $1 / 4$ & 1 & $1 / 4$ & $1 / 2$ & $1 / 4$ & $1 / 2$ & $1 / 4$ & 1 \\
\hline R36 & $1 / 4$ & $1 / 6$ & $1 / 6$ & $1 / 2$ & 1 & $1 / 4$ & $1 / 4$ & $1 / 2$ & $1 / 4$ & $1 / 2$ & $1 / 2$ & $1 / 2$ & $1 / 2$ & $1 / 4$ & $1 / 4$ & 1 & $1 / 4$ & $1 / 2$ & $1 / 4$ & $1 / 2$ & $1 / 4$ & 1 \\
\hline R37 & $1 / 2$ & $1 / 4$ & $1 / 4$ & 1 & 2 & $1 / 2$ & $1 / 2$ & 1 & $1 / 2$ & 1 & 1 & 1 & 1 & $1 / 2$ & $1 / 2$ & 2 & $1 / 2$ & 1 & $1 / 2$ & 1 & $1 / 2$ & 2 \\
\hline R38 & $1 / 2$ & $1 / 4$ & $1 / 4$ & 1 & 2 & $1 / 2$ & $1 / 2$ & 1 & $1 / 2$ & 1 & 1 & 1 & 1 & $1 / 2$ & $1 / 2$ & 2 & $1 / 2$ & 1 & $1 / 2$ & 1 & $1 / 2$ & 2 \\
\hline R39 & $1 / 2$ & $1 / 4$ & $1 / 4$ & 1 & 2 & $1 / 2$ & $1 / 2$ & 1 & $1 / 2$ & 1 & 1 & 1 & 1 & $1 / 2$ & $1 / 2$ & 2 & $1 / 2$ & 1 & $1 / 2$ & 1 & $1 / 2$ & 2 \\
\hline R40 & $1 / 2$ & $1 / 4$ & $1 / 4$ & 1 & 2 & $1 / 2$ & $1 / 2$ & 1 & $1 / 2$ & 1 & 1 & 1 & 1 & $1 / 2$ & $1 / 2$ & 2 & $1 / 2$ & 1 & $1 / 2$ & 1 & $1 / 2$ & 2 \\
\hline R41 & $1 / 2$ & $1 / 4$ & $1 / 4$ & 1 & 2 & $1 / 2$ & $1 / 2$ & 1 & $1 / 2$ & 1 & 1 & 1 & 1 & $1 / 2$ & $1 / 2$ & 2 & $1 / 2$ & 1 & $1 / 2$ & 1 & $1 / 2$ & 2 \\
\hline R42 & $1 / 2$ & $1 / 4$ & $1 / 4$ & 1 & 2 & $1 / 2$ & $1 / 2$ & 1 & $1 / 2$ & 1 & 1 & 1 & 1 & $1 / 2$ & $1 / 2$ & 2 & $1 / 2$ & 1 & $1 / 2$ & 1 & $1 / 2$ & 2 \\
\hline R43 & 1 & $1 / 2$ & $1 / 2$ & 2 & 4 & 1 & 1 & 2 & 1 & 2 & 2 & 2 & 2 & 1 & 1 & 4 & 1 & 2 & 1 & 2 & 1 & 4 \\
\hline R44 & 2 & 1 & 1 & 4 & 6 & 2 & 2 & 4 & 2 & 4 & 4 & 4 & 4 & 2 & 2 & 6 & 2 & 4 & 2 & 4 & 2 & 6 \\
\hline R45 & 2 & 1 & 1 & 4 & 6 & 2 & 2 & 4 & 2 & 4 & 4 & 4 & 4 & 2 & 2 & 6 & 2 & 4 & 2 & 4 & 2 & 6 \\
\hline R46 & $1 / 2$ & $1 / 4$ & $1 / 4$ & 1 & 2 & $1 / 2$ & $1 / 2$ & 1 & $1 / 2$ & 1 & 1 & 1 & 1 & $1 / 2$ & $1 / 2$ & 2 & $1 / 2$ & 1 & $1 / 2$ & 1 & $1 / 2$ & 2 \\
\hline R47 & $1 / 4$ & $1 / 6$ & $1 / 6$ & $1 / 2$ & 1 & $1 / 4$ & $1 / 4$ & $1 / 2$ & $1 / 4$ & $1 / 2$ & $1 / 2$ & $1 / 2$ & $1 / 2$ & $1 / 4$ & $1 / 4$ & 1 & $1 / 4$ & $1 / 2$ & $1 / 4$ & $1 / 2$ & $1 / 4$ & 1 \\
\hline R48 & 1 & $1 / 2$ & $1 / 2$ & 2 & 4 & 1 & 1 & 2 & 1 & 2 & 2 & 2 & 2 & 1 & 1 & 4 & 1 & 2 & 1 & 2 & 1 & 4 \\
\hline R49 & 1 & $1 / 2$ & $1 / 2$ & 2 & 4 & 1 & 1 & 2 & 1 & 2 & 2 & 2 & 2 & 1 & 1 & 4 & 1 & 2 & 1 & 2 & 1 & 4 \\
\hline R50 & $1 / 2$ & $1 / 4$ & $1 / 4$ & 1 & 2 & $1 / 2$ & $1 / 2$ & 1 & $1 / 2$ & 1 & 1 & 1 & 1 & $1 / 2$ & $1 / 2$ & 2 & $1 / 2$ & 1 & $1 / 2$ & 1 & $1 / 2$ & 2 \\
\hline R51 & 1 & $1 / 2$ & $1 / 2$ & 2 & 4 & 1 & 1 & 2 & 1 & 2 & 2 & 2 & 2 & 1 & 1 & 4 & 1 & 2 & 1 & 2 & 1 & 4 \\
\hline R52 & $1 / 2$ & $1 / 4$ & $1 / 4$ & 1 & 2 & $1 / 2$ & $1 / 2$ & 1 & $1 / 2$ & 1 & 1 & 1 & 1 & $1 / 2$ & $1 / 2$ & 2 & $1 / 2$ & 1 & $1 / 2$ & 1 & $1 / 2$ & 2 \\
\hline R53 & $1 / 2$ & $1 / 4$ & $1 / 4$ & 1 & 2 & $1 / 2$ & $1 / 2$ & 1 & $1 / 2$ & 1 & 1 & 1 & 1 & $1 / 2$ & $1 / 2$ & 2 & $1 / 2$ & 1 & $1 / 2$ & 1 & $1 / 2$ & 2 \\
\hline R54 & $1 / 2$ & $1 / 4$ & $1 / 4$ & 1 & 2 & $1 / 2$ & $1 / 2$ & 1 & $1 / 2$ & 1 & 1 & 1 & 1 & $1 / 2$ & $1 / 2$ & 2 & $1 / 2$ & 1 & $1 / 2$ & 1 & $1 / 2$ & 2 \\
\hline R55 & $1 / 2$ & $1 / 4$ & $1 / 4$ & 1 & 2 & $1 / 2$ & $1 / 2$ & 1 & $1 / 2$ & 1 & 1 & 1 & 1 & $1 / 2$ & $1 / 2$ & 2 & $1 / 2$ & 1 & $1 / 2$ & 1 & $1 / 2$ & 2 \\
\hline R56 & 1 & $1 / 2$ & $1 / 2$ & 2 & 4 & 1 & 1 & 2 & 1 & 2 & 2 & 2 & 2 & 1 & 1 & 4 & 1 & 2 & 1 & 2 & 1 & 4 \\
\hline R57 & 1 & $1 / 2$ & $1 / 2$ & 2 & 4 & 1 & 1 & 2 & 1 & 2 & 2 & 2 & 2 & 1 & 1 & 4 & 1 & 2 & 1 & 2 & 1 & 4 \\
\hline R58 & $1 / 4$ & $1 / 6$ & $1 / 6$ & $1 / 2$ & 1 & $1 / 4$ & $1 / 4$ & $1 / 2$ & $1 / 4$ & $1 / 2$ & $1 / 2$ & $1 / 2$ & $1 / 2$ & $1 / 4$ & $1 / 4$ & 1 & $1 / 4$ & $1 / 2$ & $1 / 4$ & $1 / 2$ & $1 / 4$ & 1 \\
\hline
\end{tabular}


Table A9. Cont.

$\begin{array}{llllllllllllllllllllll}\text { R43 } & \text { R44 } & \text { R45 } & \text { R46 } & \text { R47 } & \text { R48 } & \text { R49 } & \text { R50 } & \text { R51 } & \text { R52 } & \text { R53 } & \text { R54 } & \text { R55 } & \text { R56 } & \text { R57 } & \text { R58 } & \text { R59 } & \text { R60 } & \text { R61 } & \text { R62 } & \text { R63 } & \text { R64 }\end{array}$

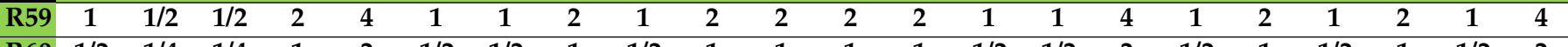

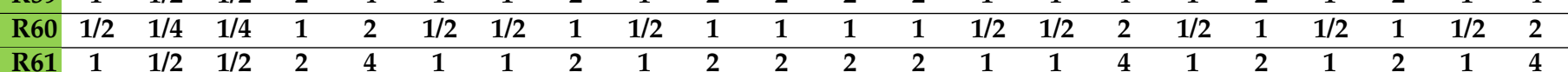
$\begin{array}{lllllllllllllllllllllll}\operatorname{R} 62 & 1 / 2 & 1 / 4 & 1 / 4 & 1 & 2 & 1 / 2 & 1 / 2 & 1 & 1 / 2 & 1 & 1 & 1 & 1 & 1 / 2 & 1 / 2 & 2 & 1 / 2 & 1 & 1 / 2 & 1 & 1 / 2 & 2\end{array}$

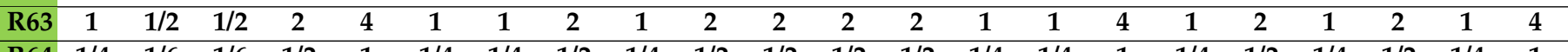

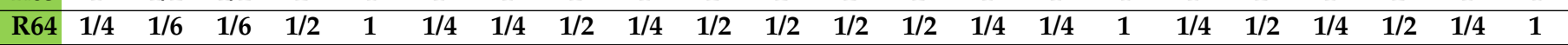

Table A10. Pairwise comparison matrix between risks according to organization's policy, Part 1.

\begin{tabular}{|c|c|c|c|c|c|c|c|c|c|c|c|c|c|c|c|c|c|c|c|c|c|}
\hline & R1 & R2 & R3 & R4 & R5 & R6 & R7 & R8 & R9 & R10 & R11 & R12 & R13 & R14 & R15 & R16 & R17 & R18 & R19 & R20 & R21 \\
\hline R1 & 1 & 1 & 1 & 1 & 1 & 1 & 1 & 1 & 1 & $1 / 2$ & $1 / 2$ & 1 & 1 & 1 & 1 & 1 & 1 & 1 & 1 & 1 & 1 \\
\hline R2 & 1 & 1 & 1 & 1 & 1 & 1 & 1 & 1 & 1 & $1 / 2$ & $1 / 2$ & 1 & 1 & 1 & 1 & 1 & 1 & 1 & 1 & 1 & 1 \\
\hline R3 & 1 & 1 & 1 & 1 & 1 & 1 & 1 & 1 & 1 & $1 / 2$ & $1 / 2$ & 1 & 1 & 1 & 1 & 1 & 1 & 1 & 1 & 1 & 1 \\
\hline R4 & 1 & 1 & 1 & 1 & 1 & 1 & 1 & 1 & 1 & $1 / 2$ & $1 / 2$ & 1 & 1 & 1 & 1 & 1 & 1 & 1 & 1 & 1 & 1 \\
\hline R5 & 1 & 1 & 1 & 1 & 1 & 1 & 1 & 1 & 1 & $1 / 2$ & $1 / 2$ & 1 & 1 & 1 & 1 & 1 & 1 & 1 & 1 & 1 & 1 \\
\hline R6 & 1 & 1 & 1 & 1 & 1 & 1 & 1 & 1 & 1 & $1 / 2$ & $1 / 2$ & 1 & 1 & 1 & 1 & 1 & 1 & 1 & 1 & 1 & 1 \\
\hline R7 & 1 & 1 & 1 & 1 & 1 & 1 & 1 & 1 & 1 & $1 / 2$ & $1 / 2$ & 1 & 1 & 1 & 1 & 1 & 1 & 1 & 1 & 1 & 1 \\
\hline R8 & 1 & 1 & 1 & 1 & 1 & 1 & 1 & 1 & 1 & $1 / 2$ & $1 / 2$ & 1 & 1 & 1 & 1 & 1 & 1 & 1 & 1 & 1 & 1 \\
\hline R9 & 1 & 1 & 1 & 1 & 1 & 1 & 1 & 1 & 1 & $1 / 2$ & $1 / 2$ & 1 & 1 & 1 & 1 & 1 & 1 & 1 & 1 & 1 & 1 \\
\hline R10 & 2 & 2 & 2 & 2 & 2 & 2 & 2 & 2 & 2 & 1 & 1 & 2 & 2 & 2 & 2 & 2 & 2 & 2 & 2 & 2 & 2 \\
\hline R11 & 2 & 2 & 2 & 2 & 2 & 2 & 2 & 2 & 2 & 1 & 1 & 2 & 2 & 2 & 2 & 2 & 2 & 2 & 2 & 2 & 2 \\
\hline R12 & 1 & 1 & 1 & 1 & 1 & 1 & 1 & 1 & 1 & $1 / 2$ & $1 / 2$ & 1 & 1 & 1 & 1 & 1 & 1 & 1 & 1 & 1 & 1 \\
\hline R13 & 1 & 1 & 1 & 1 & 1 & 1 & 1 & 1 & 1 & $1 / 2$ & $1 / 2$ & 1 & 1 & 1 & 1 & 1 & 1 & 1 & 1 & 1 & 1 \\
\hline R14 & 1 & 1 & 1 & 1 & 1 & 1 & 1 & 1 & 1 & $1 / 2$ & $1 / 2$ & 1 & 1 & 1 & 1 & 1 & 1 & 1 & 1 & 1 & 1 \\
\hline R15 & 1 & 1 & 1 & 1 & 1 & 1 & 1 & 1 & 1 & $1 / 2$ & $1 / 2$ & 1 & 1 & 1 & 1 & 1 & 1 & 1 & 1 & 1 & 1 \\
\hline R16 & 1 & 1 & 1 & 1 & 1 & 1 & 1 & 1 & 1 & $1 / 2$ & $1 / 2$ & 1 & 1 & 1 & 1 & 1 & 1 & 1 & 1 & 1 & 1 \\
\hline R17 & 1 & 1 & 1 & 1 & 1 & 1 & 1 & 1 & 1 & $1 / 2$ & $1 / 2$ & 1 & 1 & 1 & 1 & 1 & 1 & 1 & 1 & 1 & 1 \\
\hline R18 & 1 & 1 & 1 & 1 & 1 & 1 & 1 & 1 & 1 & $1 / 2$ & $1 / 2$ & 1 & 1 & 1 & 1 & 1 & 1 & 1 & 1 & 1 & 1 \\
\hline R19 & 1 & 1 & 1 & 1 & 1 & 1 & 1 & 1 & 1 & $1 / 2$ & $1 / 2$ & 1 & 1 & 1 & 1 & 1 & 1 & 1 & 1 & 1 & 1 \\
\hline R20 & 1 & 1 & 1 & 1 & 1 & 1 & 1 & 1 & 1 & $1 / 2$ & $1 / 2$ & 1 & 1 & 1 & 1 & 1 & 1 & 1 & 1 & 1 & 1 \\
\hline R21 & 1 & 1 & 1 & 1 & 1 & 1 & 1 & 1 & 1 & $1 / 2$ & $1 / 2$ & 1 & 1 & 1 & 1 & 1 & 1 & 1 & 1 & 1 & $\mathbf{1}$ \\
\hline R22 & 1 & 1 & 1 & 1 & 1 & 1 & 1 & 1 & 1 & $1 / 2$ & $1 / 2$ & 1 & 1 & 1 & 1 & 1 & 1 & 1 & 1 & 1 & 1 \\
\hline R23 & 1 & 1 & 1 & 1 & 1 & 1 & 1 & 1 & 1 & $1 / 2$ & $1 / 2$ & 1 & 1 & 1 & 1 & 1 & 1 & 1 & 1 & 1 & 1 \\
\hline R24 & 1 & 1 & 1 & 1 & 1 & 1 & 1 & 1 & 1 & $1 / 2$ & $1 / 2$ & 1 & 1 & 1 & 1 & 1 & 1 & 1 & 1 & 1 & 1 \\
\hline R25 & 1 & 1 & 1 & 1 & 1 & 1 & 1 & 1 & 1 & $1 / 2$ & $1 / 2$ & 1 & 1 & 1 & 1 & 1 & 1 & 1 & 1 & 1 & 1 \\
\hline R26 & $1 / 2$ & $1 / 2$ & $1 / 2$ & $1 / 2$ & $1 / 2$ & $1 / 2$ & $1 / 2$ & $1 / 2$ & $1 / 2$ & $1 / 4$ & $1 / 4$ & $1 / 2$ & $1 / 2$ & $1 / 2$ & $1 / 2$ & $1 / 2$ & $1 / 2$ & $1 / 2$ & $1 / 2$ & $1 / 2$ & $1 / 2$ \\
\hline R27 & $1 / 2$ & $1 / 2$ & $1 / 2$ & $1 / 2$ & $1 / 2$ & $1 / 2$ & $1 / 2$ & $1 / 2$ & $1 / 2$ & $1 / 4$ & $1 / 4$ & $1 / 2$ & $1 / 2$ & $1 / 2$ & $1 / 2$ & $1 / 2$ & $1 / 2$ & $1 / 2$ & $1 / 2$ & $1 / 2$ & $1 / 2$ \\
\hline R28 & $1 / 2$ & $1 / 2$ & $1 / 2$ & $1 / 2$ & $1 / 2$ & $1 / 2$ & $1 / 2$ & $1 / 2$ & $1 / 2$ & $1 / 4$ & $1 / 4$ & $1 / 2$ & $1 / 2$ & $1 / 2$ & $1 / 2$ & $1 / 2$ & $1 / 2$ & $1 / 2$ & $1 / 2$ & $1 / 2$ & $1 / 2$ \\
\hline R29 & $1 / 2$ & $1 / 2$ & $1 / 2$ & $1 / 2$ & $1 / 2$ & $1 / 2$ & $1 / 2$ & $1 / 2$ & $1 / 2$ & $1 / 4$ & $1 / 4$ & $1 / 2$ & $1 / 2$ & $1 / 2$ & $1 / 2$ & $1 / 2$ & $1 / 2$ & $1 / 2$ & $1 / 2$ & $1 / 2$ & $1 / 2$ \\
\hline R30 & $1 / 2$ & $1 / 2$ & $1 / 2$ & $1 / 2$ & $1 / 2$ & $1 / 2$ & $1 / 2$ & $1 / 2$ & $1 / 2$ & $1 / 4$ & $1 / 4$ & $1 / 2$ & $1 / 2$ & $1 / 2$ & $1 / 2$ & $1 / 2$ & $1 / 2$ & $1 / 2$ & $1 / 2$ & $1 / 2$ & $1 / 2$ \\
\hline R31 & $1 / 2$ & $1 / 2$ & $1 / 2$ & $1 / 2$ & $1 / 2$ & $1 / 2$ & $1 / 2$ & $1 / 2$ & $1 / 2$ & $1 / 4$ & $1 / 4$ & $1 / 2$ & $1 / 2$ & $1 / 2$ & $1 / 2$ & $1 / 2$ & $1 / 2$ & $1 / 2$ & $1 / 2$ & $1 / 2$ & $1 / 2$ \\
\hline R32 & $1 / 2$ & $1 / 2$ & $1 / 2$ & $1 / 2$ & $1 / 2$ & $1 / 2$ & $1 / 2$ & $1 / 2$ & $1 / 2$ & $1 / 4$ & $1 / 4$ & $1 / 2$ & $1 / 2$ & $1 / 2$ & $1 / 2$ & $1 / 2$ & $1 / 2$ & $1 / 2$ & $1 / 2$ & $1 / 2$ & $1 / 2$ \\
\hline R33 & $1 / 2$ & $1 / 2$ & $1 / 2$ & $1 / 2$ & $1 / 2$ & $1 / 2$ & $1 / 2$ & $1 / 2$ & $1 / 2$ & $1 / 4$ & $1 / 4$ & $1 / 2$ & $1 / 2$ & $1 / 2$ & $1 / 2$ & $1 / 2$ & $1 / 2$ & $1 / 2$ & $1 / 2$ & $1 / 2$ & $1 / 2$ \\
\hline R34 & $1 / 2$ & $1 / 2$ & $1 / 2$ & $1 / 2$ & $1 / 2$ & $1 / 2$ & $1 / 2$ & $1 / 2$ & $1 / 2$ & $1 / 4$ & $1 / 4$ & $1 / 2$ & $1 / 2$ & $1 / 2$ & $1 / 2$ & $1 / 2$ & $1 / 2$ & $1 / 2$ & $1 / 2$ & $1 / 2$ & $1 / 2$ \\
\hline R35 & $1 / 2$ & $1 / 2$ & $1 / 2$ & $1 / 2$ & $1 / 2$ & $1 / 2$ & $1 / 2$ & $1 / 2$ & $1 / 2$ & $1 / 4$ & $1 / 4$ & $1 / 2$ & $1 / 2$ & $1 / 2$ & $1 / 2$ & $1 / 2$ & $1 / 2$ & $1 / 2$ & $1 / 2$ & $1 / 2$ & $1 / 2$ \\
\hline R36 & $1 / 2$ & $1 / 2$ & $1 / 2$ & $1 / 2$ & $1 / 2$ & $1 / 2$ & $1 / 2$ & $1 / 2$ & $1 / 2$ & $1 / 4$ & $1 / 4$ & $1 / 2$ & $1 / 2$ & $1 / 2$ & $1 / 2$ & $1 / 2$ & $1 / 2$ & $1 / 2$ & $1 / 2$ & $1 / 2$ & $1 / 2$ \\
\hline R37 & 4 & 4 & 4 & 4 & 4 & 4 & 4 & 4 & 4 & 2 & 2 & 4 & 4 & 4 & 4 & 4 & 4 & 4 & 4 & 4 & 4 \\
\hline R38 & 4 & 4 & 4 & 4 & 4 & 4 & 4 & 4 & 4 & 2 & 2 & 4 & 4 & 4 & 4 & 4 & 4 & 4 & 4 & 4 & 4 \\
\hline R39 & 4 & 4 & 4 & 4 & 4 & 4 & 4 & 4 & 4 & 2 & 2 & 4 & 4 & 4 & 4 & 4 & 4 & 4 & 4 & 4 & 4 \\
\hline R40 & 4 & 4 & 4 & 4 & 4 & 4 & 4 & 4 & 4 & 2 & 2 & 4 & 4 & 4 & 4 & 4 & 4 & 4 & 4 & 4 & 4 \\
\hline R41 & 4 & 4 & 4 & 4 & 4 & 4 & 4 & 4 & 4 & 2 & 2 & 4 & 4 & 4 & 4 & 4 & 4 & 4 & 4 & 4 & 4 \\
\hline R42 & 4 & 4 & 4 & 4 & 4 & 4 & 4 & 4 & 4 & 2 & 2 & 4 & 4 & 4 & 4 & 4 & 4 & 4 & 4 & 4 & 4 \\
\hline
\end{tabular}


Table A10. Cont.

\begin{tabular}{|c|c|c|c|c|c|c|c|c|c|c|c|c|c|c|c|c|c|c|c|c|c|}
\hline & R1 & R2 & R3 & R4 & R5 & R6 & R7 & R8 & R9 & R10 & R11 & R12 & R13 & R14 & R15 & R16 & R17 & R18 & R19 & R20 & R21 \\
\hline R43 & 4 & 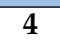 & 4 & 4 & 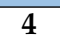 & 4 & 4 & 4 & 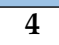 & 2 & 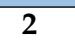 & 4 & 4 & 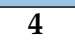 & 4 & 4 & 4 & 4 & 4 & 4 & 4 \\
\hline R44 & $1 / 2$ & $1 / 2$ & $1 / 2$ & $1 / 2$ & $1 / 2$ & $1 / 2$ & $1 / 2$ & $1 / 2$ & $1 / 2$ & $1 / 4$ & $1 / 4$ & $1 / 2$ & $1 / 2$ & $1 / 2$ & $1 / 2$ & $1 / 2$ & $1 / 2$ & $1 / 2$ & $1 / 2$ & $1 / 2$ & $1 / 2$ \\
\hline R45 & $1 / 2$ & $1 / 2$ & $1 / 2$ & $1 / 2$ & $1 / 2$ & $1 / 2$ & $1 / 2$ & $1 / 2$ & $1 / 2$ & $1 / 4$ & $1 / 4$ & $1 / 2$ & $1 / 2$ & $1 / 2$ & $1 / 2$ & $1 / 2$ & $1 / 2$ & $1 / 2$ & $1 / 2$ & $1 / 2$ & $1 / 2$ \\
\hline R46 & $1 / 2$ & $1 / 2$ & $1 / 2$ & $1 / 2$ & $1 / 2$ & $1 / 2$ & $1 / 2$ & $1 / 2$ & $1 / 2$ & $1 / 4$ & $1 / 4$ & $1 / 2$ & $1 / 2$ & $1 / 2$ & $1 / 2$ & $1 / 2$ & $1 / 2$ & $1 / 2$ & $1 / 2$ & $1 / 2$ & $1 / 2$ \\
\hline R47 & $1 / 2$ & $1 / 2$ & $1 / 2$ & $1 / 2$ & $1 / 2$ & $1 / 2$ & $1 / 2$ & $1 / 2$ & $1 / 2$ & $1 / 4$ & $1 / 4$ & $1 / 2$ & $1 / 2$ & $1 / 2$ & $1 / 2$ & $1 / 2$ & $1 / 2$ & $1 / 2$ & $1 / 2$ & $1 / 2$ & $1 / 2$ \\
\hline R48 & $1 / 2$ & $1 / 2$ & $1 / 2$ & $1 / 2$ & $1 / 2$ & $1 / 2$ & $1 / 2$ & $1 / 2$ & $1 / 2$ & $1 / 4$ & $1 / 4$ & $1 / 2$ & $1 / 2$ & $1 / 2$ & $1 / 2$ & $1 / 2$ & $1 / 2$ & $1 / 2$ & $1 / 2$ & $1 / 2$ & $1 / 2$ \\
\hline R49 & $1 / 2$ & $1 / 2$ & $1 / 2$ & $1 / 2$ & $1 / 2$ & $1 / 2$ & $1 / 2$ & $1 / 2$ & $1 / 2$ & $1 / 4$ & $1 / 4$ & $1 / 2$ & $1 / 2$ & $1 / 2$ & $1 / 2$ & $1 / 2$ & $1 / 2$ & $1 / 2$ & $1 / 2$ & $1 / 2$ & $1 / 2$ \\
\hline R50 & $1 / 2$ & $1 / 2$ & $1 / 2$ & $1 / 2$ & $1 / 2$ & $1 / 2$ & $1 / 2$ & $1 / 2$ & $1 / 2$ & $1 / 4$ & $1 / 4$ & $1 / 2$ & $1 / 2$ & $1 / 2$ & $1 / 2$ & $1 / 2$ & $1 / 2$ & $1 / 2$ & $1 / 2$ & $1 / 2$ & $1 / 2$ \\
\hline R51 & $1 / 2$ & $1 / 2$ & $1 / 2$ & $1 / 2$ & $1 / 2$ & $1 / 2$ & $1 / 2$ & $1 / 2$ & $1 / 2$ & $1 / 4$ & $1 / 4$ & $1 / 2$ & $1 / 2$ & $1 / 2$ & $1 / 2$ & $1 / 2$ & $1 / 2$ & $1 / 2$ & $1 / 2$ & $1 / 2$ & $1 / 2$ \\
\hline R52 & $1 / 2$ & $1 / 2$ & $1 / 2$ & $1 / 2$ & $1 / 2$ & $1 / 2$ & $1 / 2$ & $1 / 2$ & $1 / 2$ & $1 / 4$ & $1 / 4$ & $1 / 2$ & $1 / 2$ & $1 / 2$ & $1 / 2$ & $1 / 2$ & $1 / 2$ & $1 / 2$ & $1 / 2$ & $1 / 2$ & $1 / 2$ \\
\hline R53 & $1 / 4$ & $1 / 4$ & $1 / 4$ & $1 / 4$ & $1 / 4$ & $1 / 4$ & $1 / 4$ & $1 / 4$ & $1 / 4$ & $1 / 6$ & $1 / 6$ & $1 / 4$ & $1 / 4$ & $1 / 4$ & $1 / 4$ & $1 / 4$ & $1 / 4$ & $1 / 4$ & $1 / 4$ & $1 / 4$ & $1 / 4$ \\
\hline R54 & $1 / 4$ & $1 / 4$ & $1 / 4$ & $1 / 4$ & $1 / 4$ & $1 / 4$ & $1 / 4$ & $1 / 4$ & $1 / 4$ & $1 / 6$ & $1 / 6$ & $1 / 4$ & $1 / 4$ & $1 / 4$ & $1 / 4$ & $1 / 4$ & $1 / 4$ & $1 / 4$ & $1 / 4$ & $1 / 4$ & $1 / 4$ \\
\hline R55 & $1 / 4$ & $1 / 4$ & $1 / 4$ & $1 / 4$ & $1 / 4$ & $1 / 4$ & $1 / 4$ & $1 / 4$ & $1 / 4$ & $1 / 6$ & $1 / 6$ & $1 / 4$ & $1 / 4$ & $1 / 4$ & $1 / 4$ & $1 / 4$ & $1 / 4$ & $1 / 4$ & $1 / 4$ & $1 / 4$ & $1 / 4$ \\
\hline R56 & $1 / 4$ & $1 / 4$ & $1 / 4$ & $1 / 4$ & $1 / 4$ & $1 / 4$ & $1 / 4$ & $1 / 4$ & $1 / 4$ & $1 / 6$ & $1 / 6$ & $1 / 4$ & $1 / 4$ & $1 / 4$ & $1 / 4$ & $1 / 4$ & $1 / 4$ & $1 / 4$ & $1 / 4$ & $1 / 4$ & $1 / 4$ \\
\hline R57 & $1 / 4$ & $1 / 4$ & $1 / 4$ & $1 / 4$ & $1 / 4$ & $1 / 4$ & $1 / 4$ & $1 / 4$ & $1 / 4$ & $1 / 6$ & $1 / 6$ & $1 / 4$ & $1 / 4$ & $1 / 4$ & $1 / 4$ & $1 / 4$ & $1 / 4$ & $1 / 4$ & $1 / 4$ & $1 / 4$ & $1 / 4$ \\
\hline R58 & $1 / 4$ & $1 / 4$ & $1 / 4$ & $1 / 4$ & $1 / 4$ & $1 / 4$ & $1 / 4$ & $1 / 4$ & $1 / 4$ & $1 / 6$ & $1 / 6$ & $1 / 4$ & $1 / 4$ & $1 / 4$ & $1 / 4$ & $1 / 4$ & $1 / 4$ & $1 / 4$ & $1 / 4$ & $1 / 4$ & $1 / 4$ \\
\hline R59 & $1 / 4$ & $1 / 4$ & $1 / 4$ & $1 / 4$ & $1 / 4$ & $1 / 4$ & $1 / 4$ & $1 / 4$ & $1 / 4$ & $1 / 6$ & $1 / 6$ & $1 / 4$ & $1 / 4$ & $1 / 4$ & $1 / 4$ & $1 / 4$ & $1 / 4$ & $1 / 4$ & $1 / 4$ & $1 / 4$ & $1 / 4$ \\
\hline R60 & $1 / 4$ & $1 / 4$ & $1 / 4$ & $1 / 4$ & $1 / 4$ & $1 / 4$ & $1 / 4$ & $1 / 4$ & $1 / 4$ & $1 / 6$ & $1 / 6$ & $1 / 4$ & $1 / 4$ & $1 / 4$ & $1 / 4$ & $1 / 4$ & $1 / 4$ & $1 / 4$ & $1 / 4$ & $1 / 4$ & $1 / 4$ \\
\hline R61 & $1 / 4$ & $1 / 4$ & $1 / 4$ & $1 / 4$ & $1 / 4$ & $1 / 4$ & $1 / 4$ & $1 / 4$ & $1 / 4$ & $1 / 6$ & $1 / 6$ & $1 / 4$ & $1 / 4$ & $1 / 4$ & $1 / 4$ & $1 / 4$ & $1 / 4$ & $1 / 4$ & $1 / 4$ & $1 / 4$ & $1 / 4$ \\
\hline R62 & $1 / 4$ & $1 / 4$ & $1 / 4$ & $1 / 4$ & $1 / 4$ & $1 / 4$ & $1 / 4$ & $1 / 4$ & $1 / 4$ & $1 / 6$ & $1 / 6$ & $1 / 4$ & $1 / 4$ & $1 / 4$ & $1 / 4$ & $1 / 4$ & $1 / 4$ & $1 / 4$ & $1 / 4$ & $1 / 4$ & $1 / 4$ \\
\hline R63 & $1 / 4$ & $1 / 4$ & $1 / 4$ & $1 / 4$ & $1 / 4$ & $1 / 4$ & $1 / 4$ & $1 / 4$ & $1 / 4$ & $1 / 6$ & $1 / 6$ & $1 / 4$ & $1 / 4$ & $1 / 4$ & $1 / 4$ & $1 / 4$ & $1 / 4$ & $1 / 4$ & $1 / 4$ & $1 / 4$ & $1 / 4$ \\
\hline R64 & $1 / 4$ & $1 / 4$ & $1 / 4$ & $1 / 4$ & $1 / 4$ & $1 / 4$ & $1 / 4$ & $1 / 4$ & $1 / 4$ & $1 / 6$ & $1 / 6$ & $1 / 4$ & $1 / 4$ & $1 / 4$ & $1 / 4$ & $1 / 4$ & $1 / 4$ & $1 / 4$ & $1 / 4$ & $1 / 4$ & $1 / 4$ \\
\hline
\end{tabular}

Table A11. Pairwise comparison matrix between risks according to organization's policy, Part 2.

\begin{tabular}{|c|c|c|c|c|c|c|c|c|c|c|c|c|c|c|c|c|c|c|c|c|c|}
\hline & R22 & R23 & R24 & R25 & R26 & R27 & R28 & R29 & R30 & R31 & R32 & R33 & R34 & R35 & R36 & R37 & R38 & R39 & R40 & R41 & R42 \\
\hline R1 & 1 & 1 & 1 & 1 & 2 & 2 & 2 & 2 & 2 & 2 & 2 & 2 & 2 & 2 & 2 & $1 / 4$ & $1 / 4$ & $1 / 4$ & $1 / 4$ & $1 / 4$ & $1 / 4$ \\
\hline R2 & 1 & 1 & 1 & 1 & 2 & 2 & 2 & 2 & 2 & 2 & 2 & 2 & 2 & 2 & 2 & $1 / 4$ & $1 / 4$ & $1 / 4$ & $1 / 4$ & $1 / 4$ & $1 / 4$ \\
\hline R3 & 1 & 1 & 1 & 1 & 2 & 2 & 2 & 2 & 2 & 2 & 2 & 2 & 2 & 2 & 2 & $1 / 4$ & $1 / 4$ & $1 / 4$ & $1 / 4$ & $1 / 4$ & $1 / 4$ \\
\hline R4 & 1 & 1 & 1 & 1 & 2 & 2 & 2 & 2 & 2 & 2 & 2 & 2 & 2 & 2 & 2 & $1 / 4$ & $1 / 4$ & $1 / 4$ & $1 / 4$ & $1 / 4$ & $1 / 4$ \\
\hline R5 & 1 & 1 & 1 & 1 & 2 & 2 & 2 & 2 & 2 & 2 & 2 & 2 & 2 & 2 & 2 & $1 / 4$ & $1 / 4$ & $1 / 4$ & $1 / 4$ & $1 / 4$ & $1 / 4$ \\
\hline R6 & 1 & 1 & 1 & 1 & 2 & 2 & 2 & 2 & 2 & 2 & 2 & 2 & 2 & 2 & 2 & $1 / 4$ & $1 / 4$ & $1 / 4$ & $1 / 4$ & $1 / 4$ & $1 / 4$ \\
\hline R7 & 1 & 1 & 1 & 1 & 2 & 2 & 2 & 2 & 2 & 2 & 2 & 2 & 2 & 2 & 2 & $1 / 4$ & $1 / 4$ & $1 / 4$ & $1 / 4$ & $1 / 4$ & $1 / 4$ \\
\hline R8 & 1 & 1 & 1 & 1 & 2 & 2 & 2 & 2 & 2 & 2 & 2 & 2 & 2 & 2 & 2 & $1 / 4$ & $1 / 4$ & $1 / 4$ & $1 / 4$ & $1 / 4$ & $1 / 4$ \\
\hline R9 & 1 & 1 & 1 & 1 & 2 & 2 & 2 & 2 & 2 & 2 & 2 & 2 & 2 & 2 & 2 & $1 / 4$ & $1 / 4$ & $1 / 4$ & $1 / 4$ & $1 / 4$ & $1 / 4$ \\
\hline R10 & 4 & 4 & 4 & 4 & 4 & 4 & 4 & 4 & 4 & 4 & 4 & 4 & 4 & 4 & 4 & $1 / 2$ & $1 / 2$ & $1 / 2$ & $1 / 2$ & $1 / 2$ & $1 / 2$ \\
\hline R11 & 4 & 4 & 4 & 4 & 4 & 4 & 4 & 4 & 4 & 4 & 4 & 4 & 4 & 4 & 4 & $1 / 2$ & $1 / 2$ & $1 / 2$ & $1 / 2$ & $1 / 2$ & $1 / 2$ \\
\hline R12 & 1 & 1 & 1 & 1 & 2 & 2 & 2 & 2 & 2 & 2 & 2 & 2 & 2 & 2 & 2 & $1 / 4$ & $1 / 4$ & $1 / 4$ & $1 / 4$ & $1 / 4$ & $1 / 4$ \\
\hline R13 & 1 & 1 & 1 & 1 & 2 & 2 & 2 & 2 & 2 & 2 & 2 & 2 & 2 & 2 & 2 & $1 / 4$ & $1 / 4$ & $1 / 4$ & $1 / 4$ & $1 / 4$ & $1 / 4$ \\
\hline R14 & 1 & 1 & 1 & 1 & 2 & 2 & 2 & 2 & 2 & 2 & 2 & 2 & 2 & 2 & 2 & $1 / 4$ & $1 / 4$ & $1 / 4$ & $1 / 4$ & $1 / 4$ & $1 / 4$ \\
\hline R15 & 1 & 1 & 1 & 1 & 2 & 2 & 2 & 2 & 2 & 2 & 2 & 2 & 2 & 2 & 2 & $1 / 4$ & $1 / 4$ & $1 / 4$ & $1 / 4$ & $1 / 4$ & $1 / 4$ \\
\hline R16 & 1 & 1 & 1 & 1 & 2 & 2 & 2 & 2 & 2 & 2 & 2 & 2 & 2 & 2 & 2 & $1 / 4$ & $1 / 4$ & $1 / 4$ & $1 / 4$ & $1 / 4$ & $1 / 4$ \\
\hline R17 & 1 & 1 & 1 & 1 & 2 & 2 & 2 & 2 & 2 & 2 & 2 & 2 & 2 & 2 & 2 & $1 / 4$ & $1 / 4$ & $1 / 4$ & $1 / 4$ & $1 / 4$ & $1 / 4$ \\
\hline R18 & 1 & 1 & 1 & 1 & 2 & 2 & 2 & 2 & 2 & 2 & 2 & 2 & 2 & 2 & 2 & $1 / 4$ & $1 / 4$ & $1 / 4$ & $1 / 4$ & $1 / 4$ & $1 / 4$ \\
\hline R19 & 1 & 1 & 1 & 1 & 2 & 2 & 2 & 2 & 2 & 2 & 2 & 2 & 2 & 2 & 2 & $1 / 4$ & $1 / 4$ & $1 / 4$ & $1 / 4$ & $1 / 4$ & $1 / 4$ \\
\hline R20 & 1 & 1 & 1 & 1 & 2 & 2 & 2 & 2 & 2 & 2 & 2 & 2 & 2 & 2 & 2 & $1 / 4$ & $1 / 4$ & $1 / 4$ & $1 / 4$ & $1 / 4$ & $1 / 4$ \\
\hline R21 & 1 & 1 & 1 & 1 & 2 & 2 & 2 & 2 & 2 & 2 & 2 & 2 & 2 & 2 & 2 & $1 / 4$ & $1 / 4$ & $1 / 4$ & $1 / 4$ & $1 / 4$ & $1 / 4$ \\
\hline R22 & 1 & 1 & 1 & 1 & 2 & 2 & 2 & 2 & 2 & 2 & 2 & 2 & 2 & 2 & 2 & $1 / 4$ & $1 / 4$ & $1 / 4$ & $1 / 4$ & $1 / 4$ & $1 / 4$ \\
\hline R23 & 1 & 1 & 1 & 1 & 2 & 2 & 2 & 2 & 2 & 2 & 2 & 2 & 2 & 2 & 2 & $1 / 4$ & $1 / 4$ & $1 / 4$ & $1 / 4$ & $1 / 4$ & $1 / 4$ \\
\hline R24 & 1 & 1 & 1 & 1 & 2 & 2 & 2 & 2 & 2 & 2 & 2 & 2 & 2 & 2 & 2 & $1 / 4$ & $1 / 4$ & $1 / 4$ & $1 / 4$ & $1 / 4$ & $1 / 4$ \\
\hline R25 & 1 & 1 & 1 & 1 & 2 & 2 & 2 & 2 & 2 & 2 & 2 & 2 & 2 & 2 & 2 & $1 / 4$ & $1 / 4$ & $1 / 4$ & $1 / 4$ & $1 / 4$ & $1 / 4$ \\
\hline R26 & $1 / 2$ & $1 / 2$ & $1 / 2$ & $1 / 2$ & 1 & 1 & 1 & 1 & 1 & 1 & 1 & 1 & 1 & 1 & 1 & $1 / 6$ & $1 / 6$ & $1 / 6$ & $1 / 6$ & $1 / 6$ & $1 / 6$ \\
\hline R27 & $1 / 2$ & $1 / 2$ & $1 / 2$ & $1 / 2$ & 1 & 1 & 1 & 1 & 1 & 1 & 1 & 1 & 1 & 1 & 1 & $1 / 6$ & $1 / 6$ & $1 / 6$ & $1 / 6$ & $1 / 6$ & $1 / 6$ \\
\hline R28 & $1 / 2$ & $1 / 2$ & $1 / 2$ & $1 / 2$ & 1 & 1 & 1 & 1 & 1 & 1 & 1 & 1 & 1 & 1 & 1 & $1 / 6$ & $1 / 6$ & $1 / 6$ & $1 / 6$ & $1 / 6$ & $1 / 6$ \\
\hline
\end{tabular}


Table A11. Cont.

\begin{tabular}{|c|c|c|c|c|c|c|c|c|c|c|c|c|c|c|c|c|c|c|c|c|c|}
\hline & R22 & R23 & R24 & R25 & R26 & R27 & R28 & R29 & R30 & R31 & R32 & R33 & R34 & R35 & R36 & R37 & R38 & R39 & R40 & R41 & R42 \\
\hline R29 & $1 / 2$ & $1 / 2$ & $1 / 2$ & $1 / 2$ & 1 & 1 & 1 & 1 & 1 & 1 & 1 & 1 & 1 & 1 & 1 & $1 / 6$ & $1 / 6$ & $1 / 6$ & $1 / 6$ & $1 / 6$ & $1 / 6$ \\
\hline R30 & $1 / 2$ & $1 / 2$ & $1 / 2$ & $1 / 2$ & 1 & 1 & 1 & 1 & 1 & 1 & 1 & 1 & 1 & 1 & 1 & $1 / 6$ & $1 / 6$ & $1 / 6$ & $1 / 6$ & $1 / 6$ & $1 / 6$ \\
\hline R31 & $1 / 2$ & $1 / 2$ & $1 / 2$ & $1 / 2$ & 1 & 1 & 1 & 1 & 1 & 1 & 1 & 1 & 1 & 1 & 1 & $1 / 6$ & $1 / 6$ & $1 / 6$ & $1 / 6$ & $1 / 6$ & $1 / 6$ \\
\hline R32 & $1 / 2$ & $1 / 2$ & $1 / 2$ & $1 / 2$ & 1 & 1 & 1 & 1 & 1 & 1 & 1 & 1 & 1 & 1 & 1 & $1 / 6$ & $1 / 6$ & $1 / 6$ & $1 / 6$ & $1 / 6$ & $1 / 6$ \\
\hline R33 & $1 / 2$ & $1 / 2$ & $1 / 2$ & $1 / 2$ & 1 & 1 & 1 & 1 & 1 & 1 & 1 & 1 & 1 & 1 & 1 & $1 / 6$ & $1 / 6$ & $1 / 6$ & $1 / 6$ & $1 / 6$ & $1 / 6$ \\
\hline R34 & $1 / 2$ & $1 / 2$ & $1 / 2$ & $1 / 2$ & 1 & 1 & 1 & 1 & 1 & 1 & 1 & 1 & 1 & 1 & 1 & $1 / 6$ & $1 / 6$ & $1 / 6$ & $1 / 6$ & $1 / 6$ & $1 / 6$ \\
\hline R35 & $1 / 2$ & $1 / 2$ & $1 / 2$ & $1 / 2$ & 1 & 1 & 1 & 1 & 1 & 1 & 1 & 1 & 1 & 1 & 1 & $1 / 6$ & $1 / 6$ & $1 / 6$ & $1 / 6$ & $1 / 6$ & $1 / 6$ \\
\hline R36 & $1 / 2$ & $1 / 2$ & $1 / 2$ & $1 / 2$ & 1 & 1 & 1 & 1 & 1 & 1 & 1 & 1 & 1 & 1 & 1 & $1 / 6$ & $1 / 6$ & $1 / 6$ & $1 / 6$ & $1 / 6$ & $1 / 6$ \\
\hline R37 & 4 & 4 & 4 & 4 & 6 & 6 & 6 & 6 & 6 & 6 & 6 & 6 & 6 & 6 & 6 & 1 & 1 & 1 & 1 & 1 & 1 \\
\hline R38 & 4 & 4 & 4 & 4 & 6 & 6 & 6 & 6 & 6 & 6 & 6 & 6 & 6 & 6 & 6 & 1 & 1 & 1 & 1 & 1 & 1 \\
\hline R39 & 4 & 4 & 4 & 4 & 6 & 6 & 6 & 6 & 6 & 6 & 6 & 6 & 6 & 6 & 6 & 1 & 1 & 1 & 1 & 1 & 1 \\
\hline R40 & 4 & 4 & 4 & 4 & 6 & 6 & 6 & 6 & 6 & 6 & 6 & 6 & 6 & 6 & 6 & 1 & 1 & 1 & 1 & 1 & 1 \\
\hline R41 & 4 & 4 & 4 & 4 & 6 & 6 & 6 & 6 & 6 & 6 & 6 & 6 & 6 & 6 & 6 & 1 & 1 & 1 & 1 & 1 & 1 \\
\hline R42 & 4 & 4 & 4 & 4 & 6 & 6 & 6 & 6 & 6 & 6 & 6 & 6 & 6 & 6 & 6 & 1 & 1 & 1 & 1 & 1 & 1 \\
\hline R43 & 4 & 4 & 4 & 4 & 6 & 6 & 6 & 6 & 6 & 6 & 6 & 6 & 6 & 6 & 6 & 1 & 1 & 1 & 1 & 1 & 1 \\
\hline R44 & $1 / 2$ & $1 / 2$ & $1 / 2$ & $1 / 2$ & 1 & 1 & 1 & 1 & 1 & 1 & 1 & 1 & 1 & 1 & 1 & $1 / 6$ & $1 / 6$ & $1 / 6$ & $1 / 6$ & $1 / 6$ & $1 / 6$ \\
\hline R45 & $1 / 2$ & $1 / 2$ & $1 / 2$ & $1 / 2$ & 1 & 1 & 1 & 1 & 1 & 1 & 1 & 1 & 1 & 1 & 1 & $1 / 6$ & $1 / 6$ & $1 / 6$ & $1 / 6$ & $1 / 6$ & $1 / 6$ \\
\hline R46 & $1 / 2$ & $1 / 2$ & $1 / 2$ & $1 / 2$ & 1 & 1 & 1 & 1 & 1 & 1 & 1 & 1 & 1 & 1 & 1 & $1 / 6$ & $1 / 6$ & $1 / 6$ & $1 / 6$ & $1 / 6$ & $1 / 6$ \\
\hline R47 & $1 / 2$ & $1 / 2$ & $1 / 2$ & $1 / 2$ & 1 & 1 & 1 & 1 & 1 & 1 & 1 & 1 & 1 & 1 & 1 & $1 / 6$ & $1 / 6$ & $1 / 6$ & $1 / 6$ & $1 / 6$ & $1 / 6$ \\
\hline R48 & $1 / 2$ & $1 / 2$ & $1 / 2$ & $1 / 2$ & 1 & 1 & 1 & 1 & 1 & 1 & 1 & 1 & 1 & 1 & 1 & $1 / 6$ & $1 / 6$ & $1 / 6$ & $1 / 6$ & $1 / 6$ & $1 / 6$ \\
\hline R49 & $1 / 2$ & $1 / 2$ & $1 / 2$ & $1 / 2$ & 1 & 1 & 1 & 1 & 1 & 1 & 1 & 1 & 1 & 1 & 1 & $1 / 6$ & $1 / 6$ & $1 / 6$ & $1 / 6$ & $1 / 6$ & $1 / 6$ \\
\hline R50 & $1 / 2$ & $1 / 2$ & $1 / 2$ & $1 / 2$ & 1 & 1 & 1 & 1 & 1 & 1 & 1 & 1 & 1 & 1 & 1 & $1 / 6$ & $1 / 6$ & $1 / 6$ & $1 / 6$ & $1 / 6$ & $1 / 6$ \\
\hline R51 & $1 / 2$ & $1 / 2$ & $1 / 2$ & $1 / 2$ & 1 & 1 & 1 & 1 & 1 & 1 & 1 & 1 & 1 & 1 & 1 & $1 / 6$ & $1 / 6$ & $1 / 6$ & $1 / 6$ & $1 / 6$ & $1 / 6$ \\
\hline R52 & $1 / 2$ & $1 / 2$ & $1 / 2$ & $1 / 2$ & 1 & 1 & 1 & 1 & 1 & 1 & 1 & 1 & 1 & 1 & 1 & $1 / 6$ & $1 / 6$ & $1 / 6$ & $1 / 6$ & $1 / 6$ & $1 / 6$ \\
\hline R53 & $1 / 4$ & $1 / 4$ & $1 / 4$ & $1 / 4$ & $1 / 2$ & $1 / 2$ & $1 / 2$ & $1 / 2$ & $1 / 2$ & $1 / 2$ & $1 / 2$ & $1 / 2$ & $1 / 2$ & $1 / 2$ & $1 / 2$ & $1 / 8$ & $1 / 8$ & $1 / 8$ & $1 / 8$ & $1 / 8$ & $1 / 8$ \\
\hline R54 & $1 / 4$ & $1 / 4$ & $1 / 4$ & $1 / 4$ & $1 / 2$ & $1 / 2$ & $1 / 2$ & $1 / 2$ & $1 / 2$ & $1 / 2$ & $1 / 2$ & $1 / 2$ & $1 / 2$ & $1 / 2$ & $1 / 2$ & $1 / 8$ & $1 / 8$ & $1 / 8$ & $1 / 8$ & $1 / 8$ & $1 / 8$ \\
\hline R55 & $1 / 4$ & $1 / 4$ & $1 / 4$ & $1 / 4$ & $1 / 2$ & $1 / 2$ & $1 / 2$ & $1 / 2$ & $1 / 2$ & $1 / 2$ & $1 / 2$ & $1 / 2$ & $1 / 2$ & $1 / 2$ & $1 / 2$ & $1 / 8$ & $1 / 8$ & $1 / 8$ & $1 / 8$ & $1 / 8$ & $1 / 8$ \\
\hline R56 & $1 / 4$ & $1 / 4$ & $1 / 4$ & $1 / 4$ & $1 / 2$ & $1 / 2$ & $1 / 2$ & $1 / 2$ & $1 / 2$ & $1 / 2$ & $1 / 2$ & $1 / 2$ & $1 / 2$ & $1 / 2$ & $1 / 2$ & $1 / 8$ & $1 / 8$ & $1 / 8$ & $1 / 8$ & $1 / 8$ & $1 / 8$ \\
\hline R57 & $1 / 4$ & $1 / 4$ & $1 / 4$ & $1 / 4$ & $1 / 2$ & $1 / 2$ & $1 / 2$ & $1 / 2$ & $1 / 2$ & $1 / 2$ & $1 / 2$ & $1 / 2$ & $1 / 2$ & $1 / 2$ & $1 / 2$ & $1 / 8$ & $1 / 8$ & $1 / 8$ & $1 / 8$ & $1 / 8$ & $1 / 8$ \\
\hline R58 & $1 / 4$ & $1 / 4$ & $1 / 4$ & $1 / 4$ & $1 / 2$ & $1 / 2$ & $1 / 2$ & $1 / 2$ & $1 / 2$ & $1 / 2$ & $1 / 2$ & $1 / 2$ & $1 / 2$ & $1 / 2$ & $1 / 2$ & $1 / 8$ & $1 / 8$ & $1 / 8$ & $1 / 8$ & $1 / 8$ & $1 / 8$ \\
\hline R59 & $1 / 4$ & $1 / 4$ & $1 / 4$ & $1 / 4$ & $1 / 2$ & $1 / 2$ & $1 / 2$ & $1 / 2$ & $1 / 2$ & $1 / 2$ & $1 / 2$ & $1 / 2$ & $1 / 2$ & $1 / 2$ & $1 / 2$ & $1 / 8$ & $1 / 8$ & $1 / 8$ & $1 / 8$ & $1 / 8$ & $1 / 8$ \\
\hline R60 & $1 / 4$ & $1 / 4$ & $1 / 4$ & $1 / 4$ & $1 / 2$ & $1 / 2$ & $1 / 2$ & $1 / 2$ & $1 / 2$ & $1 / 2$ & $1 / 2$ & $1 / 2$ & $1 / 2$ & $1 / 2$ & $1 / 2$ & $1 / 8$ & $1 / 8$ & $1 / 8$ & $1 / 8$ & $1 / 8$ & $1 / 8$ \\
\hline R61 & $1 / 4$ & $1 / 4$ & $1 / 4$ & $1 / 4$ & $1 / 2$ & $1 / 2$ & $1 / 2$ & $1 / 2$ & $1 / 2$ & $1 / 2$ & $1 / 2$ & $1 / 2$ & $1 / 2$ & $1 / 2$ & $1 / 2$ & $1 / 8$ & $1 / 8$ & $1 / 8$ & $1 / 8$ & $1 / 8$ & $1 / 8$ \\
\hline R62 & $1 / 4$ & $1 / 4$ & $1 / 4$ & $1 / 4$ & $1 / 2$ & $1 / 2$ & $1 / 2$ & $1 / 2$ & $1 / 2$ & $1 / 2$ & $1 / 2$ & $1 / 2$ & $1 / 2$ & $1 / 2$ & $1 / 2$ & $1 / 8$ & $1 / 8$ & $1 / 8$ & $1 / 8$ & $1 / 8$ & $1 / 8$ \\
\hline R63 & $1 / 4$ & $1 / 4$ & $1 / 4$ & $1 / 4$ & $1 / 2$ & $1 / 2$ & $1 / 2$ & $1 / 2$ & $1 / 2$ & $1 / 2$ & $1 / 2$ & $1 / 2$ & $1 / 2$ & $1 / 2$ & $1 / 2$ & $1 / 8$ & $1 / 8$ & $1 / 8$ & $1 / 8$ & $1 / 8$ & $1 / 8$ \\
\hline R64 & $1 / 4$ & $1 / 4$ & $1 / 4$ & $1 / 4$ & $1 / 2$ & $1 / 2$ & $1 / 2$ & $1 / 2$ & $1 / 2$ & $1 / 2$ & $1 / 2$ & $1 / 2$ & $1 / 2$ & $1 / 2$ & $1 / 2$ & $1 / 8$ & $1 / 8$ & $1 / 8$ & $1 / 8$ & $1 / 8$ & $1 / 8$ \\
\hline
\end{tabular}

Table A12. Pairwise comparison matrix between risks according to organization's policy, Part 3.

$\begin{array}{lllllllllllllllllllllll}\text { R43 } & \text { R44 } & \text { R45 } & \text { R46 } & \text { R47 } & \text { R48 } & \text { R49 } & \text { R50 } & \text { R51 } & \text { R52 } & \text { R53 } & \text { R54 } & \text { R55 } & \text { R56 } & \text { R57 } & \text { R58 } & \text { R59 } & \text { R60 } & \text { R61 } & \text { R62 } & \text { R63 } & \text { R64 }\end{array}$ $\begin{array}{lllllllllllllllllllllll}\text { R1 } & 1 / 4 & 2 & 2 & 2 & 2 & 2 & 2 & 2 & 2 & 2 & 4 & 4 & 4 & 4 & 4 & 4 & 4 & 4 & 4 & 4 & 4 & 4 \\ \text { R2 } & 1 / 4 & 2 & 2 & 2 & 2 & 2 & 2 & 2 & 2 & 2 & 4 & 4 & 4 & 4 & 4 & 4 & 4 & 4 & 4 & 4 & 4 & 4\end{array}$

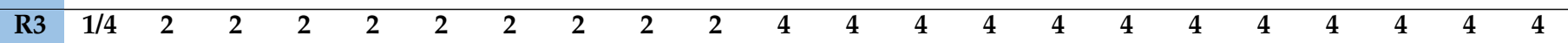

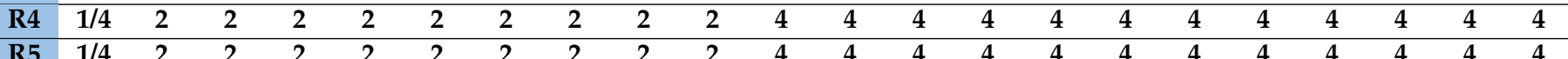

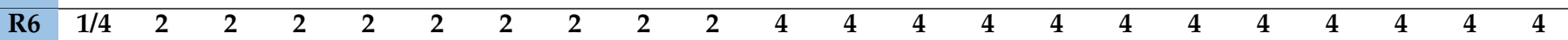

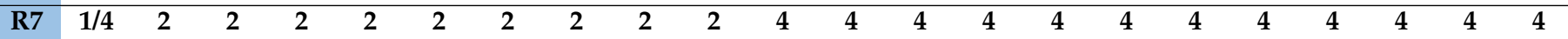

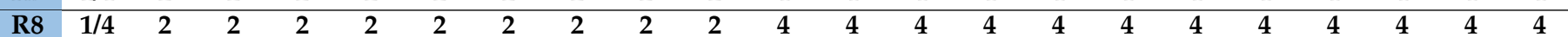

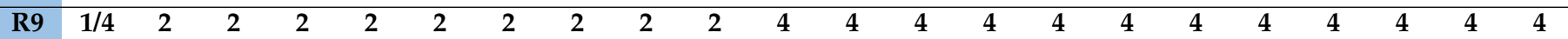

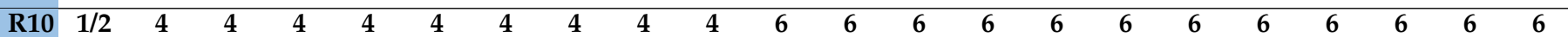
\begin{tabular}{lllllllllllllllllllllll} 
R11 & $1 / 2$ & 4 & 4 & 4 & 4 & 4 & 4 & 4 & 4 & 4 & 6 & 6 & 6 & 6 & 6 & 6 & 6 & 6 & 6 & 6 & 6 & 6 \\
\hline R12 & $1 / 4$ & 2 & 2 & 2 & 2 & 2 & 2 & 2 & 2 & 2 & 4 & 4 & 4 & 4 & 4 & 4 & 4 & 4 & 4 & 4 & 4 & 4
\end{tabular}

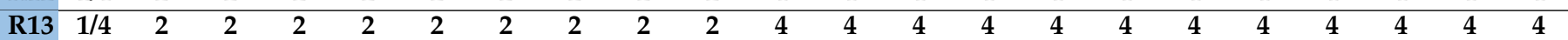

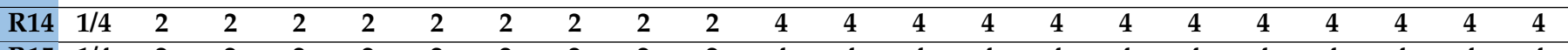
$\begin{array}{lllllllllllllllllllllll}\text { R15 } & 1 / 4 & 2 & 2 & 2 & 2 & 2 & 2 & 2 & 2 & 2 & 4 & 4 & 4 & 4 & 4 & 4 & 4 & 4 & 4 & 4 & 4 & 4\end{array}$ 
Table A12. Cont.

\begin{tabular}{|c|c|c|c|c|c|c|c|c|c|c|c|c|c|c|c|c|c|c|c|c|c|c|}
\hline & R43 & R44 & R45 & R46 & R47 & R48 & R49 & R50 & R51 & R52 & R53 & R54 & R55 & R56 & R57 & R58 & R59 & R60 & R61 & R62 & R63 & R64 \\
\hline R16 & $1 / 4$ & 2 & 2 & 2 & 2 & 2 & 2 & 2 & 2 & 2 & 4 & 4 & 4 & 4 & 4 & 4 & 4 & 4 & 4 & 4 & 4 & 4 \\
\hline R17 & $1 / 4$ & 2 & 2 & 2 & 2 & 2 & 2 & 2 & 2 & 2 & 4 & 4 & 4 & 4 & 4 & 4 & 4 & 4 & 4 & 4 & 4 & 4 \\
\hline R18 & $1 / 4$ & 2 & 2 & 2 & 2 & 2 & 2 & 2 & 2 & 2 & 4 & 4 & 4 & 4 & 4 & 4 & 4 & 4 & 4 & 4 & 4 & 4 \\
\hline R19 & $1 / 4$ & 2 & 2 & 2 & 2 & 2 & 2 & 2 & 2 & 2 & 4 & 4 & 4 & 4 & 4 & 4 & 4 & 4 & 4 & 4 & 4 & 4 \\
\hline R20 & $1 / 4$ & 2 & 2 & 2 & 2 & 2 & 2 & 2 & 2 & 2 & 4 & 4 & 4 & 4 & 4 & 4 & 4 & 4 & 4 & 4 & 4 & 4 \\
\hline R21 & $1 / 4$ & 2 & 2 & 2 & 2 & 2 & 2 & 2 & 2 & 2 & 4 & 4 & 4 & 4 & 4 & 4 & 4 & 4 & 4 & 4 & 4 & 4 \\
\hline R22 & $1 / 4$ & 2 & 2 & 2 & 2 & 2 & 2 & 2 & 2 & 2 & 4 & 4 & 4 & 4 & 4 & 4 & 4 & 4 & 4 & 4 & 4 & 4 \\
\hline R23 & $1 / 4$ & 2 & 2 & 2 & 2 & 2 & 2 & 2 & 2 & 2 & 4 & 4 & 4 & 4 & 4 & 4 & 4 & 4 & 4 & 4 & 4 & 4 \\
\hline R24 & $1 / 4$ & 2 & 2 & 2 & 2 & 2 & 2 & 2 & 2 & 2 & 4 & 4 & 4 & 4 & 4 & 4 & 4 & 4 & 4 & 4 & 4 & 4 \\
\hline R25 & $1 / 4$ & 2 & 2 & 2 & 2 & 2 & 2 & 2 & 2 & 2 & 4 & 4 & 4 & 4 & 4 & 4 & 4 & 4 & 4 & 4 & 4 & 4 \\
\hline R26 & $1 / 6$ & 1 & 1 & 1 & 1 & 1 & 1 & 1 & 1 & 1 & 1 & 1 & 2 & 2 & 2 & 2 & 2 & 2 & 2 & 2 & 2 & 2 \\
\hline R27 & $1 / 6$ & 1 & 1 & 1 & 1 & 1 & 1 & 1 & 1 & 1 & 1 & 1 & 2 & 2 & 2 & 2 & 2 & 2 & 2 & 2 & 2 & 2 \\
\hline R28 & $1 / 6$ & 1 & 1 & 1 & 1 & 1 & 1 & 1 & 1 & 1 & 1 & 1 & 2 & 2 & 2 & 2 & 2 & 2 & 2 & 2 & 2 & 2 \\
\hline R29 & $1 / 6$ & 1 & 1 & 1 & 1 & 1 & 1 & 1 & 1 & 1 & 1 & 1 & 2 & 2 & 2 & 2 & 2 & 2 & 2 & 2 & 2 & 2 \\
\hline R30 & $1 / 6$ & 1 & 1 & 1 & 1 & 1 & 1 & 1 & 1 & 1 & 1 & 1 & 2 & 2 & 2 & 2 & 2 & 2 & 2 & 2 & 2 & 2 \\
\hline R31 & $1 / 6$ & 1 & 1 & 1 & 1 & 1 & 1 & 1 & 1 & 1 & 1 & 1 & 2 & 2 & 2 & 2 & 2 & 2 & 2 & 2 & 2 & 2 \\
\hline R32 & $1 / 6$ & 1 & 1 & 1 & 1 & $\mathbf{1}$ & 1 & 1 & 1 & 1 & 1 & 1 & 2 & 2 & 2 & 2 & 2 & 2 & 2 & 2 & 2 & 2 \\
\hline R33 & $1 / 6$ & 1 & 1 & 1 & 1 & 1 & 1 & 1 & 1 & 1 & 1 & 1 & 2 & 2 & 2 & 2 & 2 & 2 & 2 & 2 & 2 & 2 \\
\hline R34 & $1 / 6$ & 1 & 1 & 1 & 1 & 1 & 1 & 1 & 1 & 1 & 1 & 1 & 2 & 2 & 2 & 2 & 2 & 2 & 2 & 2 & 2 & 2 \\
\hline R35 & $1 / 6$ & 1 & 1 & 1 & 1 & 1 & 1 & 1 & 1 & 1 & 1 & 1 & 2 & 2 & 2 & 2 & 2 & 2 & 2 & 2 & 2 & 2 \\
\hline R36 & $1 / 6$ & 1 & 1 & 1 & 1 & 1 & 1 & 1 & 1 & 1 & 1 & 1 & 2 & 2 & 2 & 2 & 2 & 2 & 2 & 2 & 2 & 2 \\
\hline R37 & 1 & 6 & 6 & 6 & 6 & 6 & 6 & 6 & 6 & 6 & 8 & 8 & 8 & 8 & 8 & 8 & 8 & 8 & 8 & 8 & 8 & 8 \\
\hline R38 & 1 & 6 & 6 & 6 & 6 & 6 & 6 & 6 & 6 & 6 & 8 & 8 & 8 & 8 & 8 & 8 & 8 & 8 & 8 & 8 & 8 & 8 \\
\hline R39 & 1 & 6 & 6 & 6 & 6 & 6 & 6 & 6 & 6 & 6 & 8 & 8 & 8 & 8 & 8 & 8 & 8 & 8 & 8 & 8 & 8 & 8 \\
\hline R40 & 1 & 6 & 6 & 6 & 6 & 6 & 6 & 6 & 6 & 6 & 8 & 8 & 8 & 8 & 8 & 8 & 8 & 8 & 8 & 8 & 8 & 8 \\
\hline R41 & 1 & 6 & 6 & 6 & 6 & 6 & 6 & 6 & 6 & 6 & 8 & 8 & 8 & 8 & 8 & 8 & 8 & 8 & 8 & 8 & 8 & 8 \\
\hline R42 & 1 & 6 & 6 & 6 & 6 & 6 & 6 & 6 & 6 & 6 & 8 & 8 & 8 & 8 & 8 & 8 & 8 & 8 & 8 & 8 & 8 & 8 \\
\hline R43 & 1 & 6 & 6 & 6 & 6 & 6 & 6 & 6 & 6 & 6 & 8 & 8 & 8 & 8 & 8 & 8 & 8 & 8 & 8 & 8 & 8 & 8 \\
\hline R44 & $1 / 6$ & 1 & 1 & 1 & 1 & 1 & 1 & 1 & 1 & 1 & 1 & 1 & 2 & 2 & 2 & 2 & 2 & 2 & 2 & 2 & 2 & 2 \\
\hline R45 & $1 / 6$ & 1 & 1 & 1 & 1 & 1 & 1 & 1 & 1 & 1 & 1 & 1 & 2 & 2 & 2 & 2 & 2 & 2 & 2 & 2 & 2 & 2 \\
\hline R46 & $1 / 6$ & 1 & 1 & 1 & 1 & 1 & 1 & 1 & 1 & 1 & 1 & 1 & 2 & 2 & 2 & 2 & 2 & 2 & 2 & 2 & 2 & 2 \\
\hline R47 & $1 / 6$ & 1 & 1 & 1 & 1 & 1 & 1 & 1 & 1 & 1 & 1 & 1 & 2 & 2 & 2 & 2 & 2 & 2 & 2 & 2 & 2 & 2 \\
\hline R48 & $1 / 6$ & 1 & 1 & 1 & 1 & 1 & 1 & 1 & 1 & 1 & 1 & 1 & 2 & 2 & 2 & 2 & 2 & 2 & 2 & 2 & 2 & 2 \\
\hline R49 & $1 / 6$ & 1 & 1 & 1 & 1 & 1 & 1 & 1 & 1 & 1 & 1 & 1 & 2 & 2 & 2 & 2 & 2 & 2 & 2 & 2 & 2 & 2 \\
\hline R50 & $1 / 6$ & 1 & 1 & 1 & 1 & 1 & 1 & 1 & 1 & 1 & 1 & 1 & 2 & 2 & 2 & 2 & 2 & 2 & 2 & 2 & 2 & 2 \\
\hline R51 & $1 / 6$ & 1 & 1 & 1 & 1 & 1 & 1 & 1 & 1 & 1 & 1 & 1 & 2 & 2 & 2 & 2 & 2 & 2 & 2 & 2 & 2 & 2 \\
\hline R52 & $1 / 6$ & 1 & 1 & 1 & 1 & 1 & 1 & 1 & 1 & 1 & 1 & 1 & 2 & 2 & 2 & 2 & 2 & 2 & 2 & 2 & 2 & 2 \\
\hline R53 & $1 / 8$ & $1 / 2$ & $1 / 2$ & $1 / 2$ & $1 / 2$ & $1 / 2$ & $1 / 2$ & $1 / 2$ & $1 / 2$ & $1 / 2$ & 1 & 1 & 1 & 1 & 1 & 1 & 1 & 1 & 1 & 1 & 1 & 1 \\
\hline R54 & $1 / 8$ & $1 / 2$ & $1 / 2$ & $1 / 2$ & $1 / 2$ & $1 / 2$ & $1 / 2$ & $1 / 2$ & $1 / 2$ & $1 / 2$ & 1 & 1 & 1 & 1 & 1 & 1 & 1 & 1 & 1 & 1 & 1 & 1 \\
\hline R55 & $1 / 8$ & $1 / 2$ & $1 / 2$ & $1 / 2$ & $1 / 2$ & $1 / 2$ & $1 / 2$ & $1 / 2$ & $1 / 2$ & $1 / 2$ & 1 & 1 & 1 & 1 & 1 & 1 & 1 & 1 & 1 & 1 & 1 & 1 \\
\hline R56 & $1 / 8$ & $1 / 2$ & $1 / 2$ & $1 / 2$ & $1 / 2$ & $1 / 2$ & $1 / 2$ & $1 / 2$ & $1 / 2$ & $1 / 2$ & 1 & 1 & 1 & 1 & 1 & 1 & 1 & 1 & 1 & 1 & 1 & 1 \\
\hline R57 & $1 / 8$ & $1 / 2$ & $1 / 2$ & $1 / 2$ & $1 / 2$ & $1 / 2$ & $1 / 2$ & $1 / 2$ & $1 / 2$ & $1 / 2$ & 1 & 1 & 1 & 1 & 1 & 1 & 1 & 1 & 1 & 1 & 1 & 1 \\
\hline R58 & $1 / 8$ & $1 / 2$ & $1 / 2$ & $1 / 2$ & $1 / 2$ & $1 / 2$ & $1 / 2$ & $1 / 2$ & $1 / 2$ & $1 / 2$ & 1 & 1 & 1 & 1 & 1 & 1 & 1 & 1 & 1 & 1 & 1 & 1 \\
\hline R59 & $1 / 8$ & $1 / 2$ & $1 / 2$ & $1 / 2$ & $1 / 2$ & $1 / 2$ & $1 / 2$ & $1 / 2$ & $1 / 2$ & $1 / 2$ & 1 & 1 & 1 & 1 & 1 & 1 & 1 & 1 & 1 & 1 & 1 & 1 \\
\hline R60 & $1 / 8$ & $1 / 2$ & $1 / 2$ & $1 / 2$ & $1 / 2$ & $1 / 2$ & $1 / 2$ & $1 / 2$ & $1 / 2$ & $1 / 2$ & 1 & 1 & 1 & $\mathbf{1}$ & $\mathbf{1}$ & 1 & 1 & 1 & 1 & 1 & 1 & 1 \\
\hline R61 & $1 / 8$ & $1 / 2$ & $1 / 2$ & $1 / 2$ & $1 / 2$ & $1 / 2$ & $1 / 2$ & $1 / 2$ & $1 / 2$ & $1 / 2$ & 1 & 1 & 1 & 1 & 1 & 1 & 1 & 1 & 1 & 1 & 1 & 1 \\
\hline R62 & $1 / 8$ & $1 / 2$ & $1 / 2$ & $1 / 2$ & $1 / 2$ & $1 / 2$ & $1 / 2$ & $1 / 2$ & $1 / 2$ & $1 / 2$ & 1 & 1 & 1 & 1 & $\mathbf{1}$ & 1 & 1 & 1 & 1 & 1 & 1 & 1 \\
\hline R63 & $1 / 8$ & $1 / 2$ & $1 / 2$ & $1 / 2$ & $1 / 2$ & $1 / 2$ & $1 / 2$ & $1 / 2$ & $1 / 2$ & $1 / 2$ & 1 & 1 & 1 & 1 & 1 & 1 & 1 & 1 & 1 & 1 & 1 & 1 \\
\hline R64 & $1 / 8$ & $1 / 2$ & $1 / 2$ & $1 / 2$ & $1 / 2$ & $1 / 2$ & $1 / 2$ & $1 / 2$ & $1 / 2$ & $1 / 2$ & 1 & 1 & 1 & 1 & 1 & 1 & 1 & 1 & 1 & 1 & 1 & 1 \\
\hline
\end{tabular}




\section{Appendix B}

Table A13. $W_{C 1}, W_{C 2}, W_{C 3}$ and $W_{C 4}$.

\begin{tabular}{|c|c|c|c|c|}
\hline \multirow{2}{*}{ Risk Associated with Vector's Line } & \multicolumn{4}{|c|}{ Weight Vectors } \\
\hline & $\mathbf{W}_{\mathrm{C} 1}$ & $\mathrm{~W}_{\mathrm{C} 2}$ & $\mathbf{W}_{\mathrm{C} 3}$ & $\mathrm{~W}_{\mathrm{C} 4}$ \\
\hline $\mathrm{R} 1$ & 0.026907974 & 0.006560894 & 0.012746344 & 0.015880281 \\
\hline $\mathrm{R} 2$ & 0.006760961 & 0.006560894 & 0.012746344 & 0.015880281 \\
\hline $\mathrm{R} 3$ & 0.006760961 & 0.013141076 & 0.012746344 & 0.015880281 \\
\hline $\mathrm{R} 4$ & 0.013453987 & 0.006560894 & 0.012746344 & 0.015880281 \\
\hline R5 & 0.006760961 & 0.003701471 & 0.00649918 & 0.015880281 \\
\hline R6 & 0.013453987 & 0.013141076 & 0.012746344 & 0.015880281 \\
\hline R7 & 0.013453987 & 0.025234707 & 0.012746344 & 0.015880281 \\
\hline $\mathrm{R} 8$ & 0.013453987 & 0.013141076 & 0.012746344 & 0.015880281 \\
\hline R9 & 0.013453987 & 0.013141076 & 0.047053256 & 0.015880281 \\
\hline R10 & 0.026907974 & 0.013141076 & 0.012746344 & 0.031697096 \\
\hline R11 & 0.013453987 & 0.013141076 & 0.025492687 & 0.031697096 \\
\hline R12 & 0.026907974 & 0.013141076 & 0.012746344 & 0.015880281 \\
\hline R13 & 0.013453987 & 0.013141076 & 0.012746344 & 0.015880281 \\
\hline R14 & 0.013453987 & 0.025234707 & 0.047053256 & 0.015880281 \\
\hline R15 & 0.006760961 & 0.006560894 & 0.00649918 & 0.015880281 \\
\hline R16 & 0.013453987 & 0.006560894 & 0.025492687 & 0.015880281 \\
\hline R17 & 0.013453987 & 0.025234707 & 0.025492687 & 0.015880281 \\
\hline R18 & 0.026907974 & 0.045256153 & 0.025492687 & 0.015880281 \\
\hline R19 & 0.013453987 & 0.003701471 & 0.00649918 & 0.015880281 \\
\hline R20 & 0.013453987 & 0.003701471 & 0.012746344 & 0.015880281 \\
\hline $\mathrm{R} 21$ & 0.026907974 & 0.003701471 & 0.00649918 & 0.015880281 \\
\hline R22 & 0.013453987 & 0.006560894 & 0.012746344 & 0.015880281 \\
\hline $\mathrm{R} 23$ & 0.026907974 & 0.006560894 & 0.00649918 & 0.015880281 \\
\hline $\mathrm{R} 24$ & 0.026907974 & 0.006560894 & 0.00649918 & 0.015880281 \\
\hline $\mathrm{R} 25$ & 0.026907974 & 0.006560894 & 0.012746344 & 0.015880281 \\
\hline R26 & 0.013453987 & 0.013141076 & 0.00649918 & 0.008022616 \\
\hline $\mathrm{R} 27$ & 0.026907974 & 0.025234707 & 0.00649918 & 0.008022616 \\
\hline R28 & 0.013453987 & 0.003701471 & 0.00649918 & 0.008022616 \\
\hline R29 & 0.026907974 & 0.006560894 & 0.00649918 & 0.008022616 \\
\hline R30 & 0.026907974 & 0.025234707 & 0.00649918 & 0.008022616 \\
\hline R31 & 0.013453987 & 0.013141076 & 0.00649918 & 0.008022616 \\
\hline R32 & 0.026907974 & 0.006560894 & 0.00649918 & 0.008022616 \\
\hline R33 & 0.026907974 & 0.025234707 & 0.012746344 & 0.008022616 \\
\hline R34 & 0.051052342 & 0.025234707 & 0.00649918 & 0.008022616 \\
\hline R35 & 0.026907974 & 0.013141076 & 0.00649918 & 0.008022616 \\
\hline R36 & 0.013453987 & 0.045256153 & 0.00649918 & 0.008022616 \\
\hline R37 & 0.013453987 & 0.013141076 & 0.012746344 & 0.051199864 \\
\hline R38 & 0.013453987 & 0.006560894 & 0.012746344 & 0.051199864 \\
\hline
\end{tabular}


Table A13. Cont.

\begin{tabular}{|c|c|c|c|c|}
\hline \multirow{2}{*}{ Risk Associated with Vector's Line } & \multicolumn{4}{|c|}{ Weight Vectors } \\
\hline & $\mathbf{W}_{\mathrm{C} 1}$ & $\mathrm{~W}_{\mathrm{C} 2}$ & $\mathbf{W}_{\mathrm{C} 3}$ & $\mathrm{~W}_{\mathrm{C} 4}$ \\
\hline R39 & 0.013453987 & 0.006560894 & 0.012746344 & 0.051199864 \\
\hline $\mathrm{R} 40$ & 0.013453987 & 0.006560894 & 0.012746344 & 0.051199864 \\
\hline $\mathrm{R} 41$ & 0.013453987 & 0.013141076 & 0.012746344 & 0.051199864 \\
\hline $\mathrm{R} 42$ & 0.006760961 & 0.025234707 & 0.012746344 & 0.051199864 \\
\hline $\mathrm{R} 43$ & 0.013453987 & 0.025234707 & 0.025492687 & 0.051199864 \\
\hline $\mathrm{R} 44$ & 0.013453987 & 0.025234707 & 0.047053256 & 0.008022616 \\
\hline $\mathrm{R} 45$ & 0.013453987 & 0.025234707 & 0.047053256 & 0.008022616 \\
\hline $\mathrm{R} 46$ & 0.006760961 & 0.003701471 & 0.012746344 & 0.008022616 \\
\hline $\mathrm{R} 47$ & 0.013453987 & 0.013141076 & 0.00649918 & 0.008022616 \\
\hline $\mathrm{R} 48$ & 0.013453987 & 0.006560894 & 0.025492687 & 0.008022616 \\
\hline R49 & 0.013453987 & 0.025234707 & 0.025492687 & 0.008022616 \\
\hline $\mathrm{R} 50$ & 0.013453987 & 0.006560894 & 0.012746344 & 0.008022616 \\
\hline R51 & 0.006760961 & 0.006560894 & 0.025492687 & 0.008022616 \\
\hline R52 & 0.006760961 & 0.013141076 & 0.012746344 & 0.008022616 \\
\hline $\mathrm{R} 53$ & 0.013453987 & 0.006560894 & 0.012746344 & 0.004375665 \\
\hline $\mathrm{R} 54$ & 0.013453987 & 0.013141076 & 0.012746344 & 0.004375665 \\
\hline R55 & 0.013453987 & 0.013141076 & 0.012746344 & 0.004375665 \\
\hline R56 & 0.013453987 & 0.025234707 & 0.025492687 & 0.004375665 \\
\hline $\mathrm{R} 57$ & 0.013453987 & 0.013141076 & 0.025492687 & 0.004375665 \\
\hline R58 & 0.013453987 & 0.045256153 & 0.00649918 & 0.004375665 \\
\hline R59 & 0.013453987 & 0.013141076 & 0.025492687 & 0.004375665 \\
\hline R60 & 0.006760961 & 0.025234707 & 0.012746344 & 0.004375665 \\
\hline R61 & 0.006760961 & 0.025234707 & 0.025492687 & 0.004375665 \\
\hline R62 & 0.006760961 & 0.025234707 & 0.012746344 & 0.004375665 \\
\hline R63 & 0.006760961 & 0.025234707 & 0.025492687 & 0.004375665 \\
\hline R64 & 0.006760961 & 0.045256153 & 0.00649918 & 0.004375665 \\
\hline
\end{tabular}

\section{References}

1. Khana, M.P.; Talibb, N.A.; Kowangc, T.O. The development of a sustainability framework via lean green six sigma practices in smes based upon rbv theory. Int. J. Innov. Creat. Chang. 2020, 12, 135-156.

2. Abualfaraa, W.; Salonitis, K.; Al-Ashaab, A.; Ala'Raj, M. Lean-green manufacturing practices and their link with sustainability: A critical review. Sustainability 2020, 12, 981. [CrossRef]

3. Jasti, N.V.K.; Sharma, A.; Kodali, R. Lean to green supply chain management: A case study. J. Environ. Res. Dev. 2012, 6, 890-899.

4. King, A.A.; Lenox, M.J. Lean and green? An empirical examination of the relationship between lean production and environemental performance. production and operations management. Prod. Oper. Manag. 2001, 10, 244-256. [CrossRef]

5. Cheung, W.M.; Leong, J.T.; Vichare, P. Incorporating lean thinking and life cycle assessment to reduce environmental impacts of plastic injection moulded products. J. Clean. Prod. 2017, 167, 759-775. [CrossRef]

6. United States Environmental Protection Agency. The Lean And Environment Toolkit; United States Environmental Protection Agency: Washington, DC, USA, 2007.

7. Wu, L.; Subramanian, N.; Abdulrahman, M.D.; Liu, C.; Lai, K.-H.; Pawar, K.S. The impact of integrated practices of lean, green, and social management systems on firm sustainability performance-Evidence from Chinese fashion auto-parts suppliers. Sustainability 2015, 7, 3838-3858. [CrossRef]

8. Meera, L.; Chitramani, P. Causal effect of between lean and green supply chain management practices on environmental performance of manufacturing firms. Int. J. Manag. Bus. Stud. 2016, 6, 29-35. 
9. Prasad, S.; Khanduja, D.; Sharma, S.K. An empirical study on applicability of lean and green practices in the foundry industry. J. Manuf. Technol. Manag. 2016, 27, 408-426. [CrossRef]

10. Rajive, D.; Kress, R.; Upretia, G. Does lean mean green? J. Clean. Prod. 2014, 85, 1-7.

11. Henao, R.; Sarache, W.; Gómez, I. Lean manufacturing and sustainable performance: Trends and future challenges. J. Clean. Prod. 2019, 208, 99-116. [CrossRef]

12. Sartal, A.; Senra, A.I.M.; Cruz-Machado, V. Are all lean principles equally eco-friendly? A panel data study. J. Clean. Prod. 2018, 177, 362-370. [CrossRef]

13. Saroha, R. Green logistics \& its significance in modern day systems. Int. Rev. Appl. Eng. Res. 2014, 4, 89-92.

14. Carvalho, H.; Govindan, K.; Azevedo, S.G.; Machado, V. Modelling green and lean supply chains: An eco-efficiency perspective. Resour. Conserv. Recycl. 2017, 120, 75-87. [CrossRef]

15. Venkat, K.; Wakeland, W. Is Lean necessarily green? In Proceedings of the 50th Annual Meeting of the ISSS, Sonoma, CA, USA, 9-14 July 2006.

16. Bergmiller, G.G.; McCright, P. Parallel models for lean and green operations. In Proceedings of the 2009 Industrial Engineering Research Conference, Xi'an, China, 26-27 December 2009.

17. Garza-Reyes, J.A. Green lean and the need for Six Sigma. Int. J. Lean Six Sigma 2015, 6, 226-248. [CrossRef]

18. Fercoq, A.; Lamouri, S.; Carbone, V.; Lelièvre, A.; Lemieux, A.-A. Combining lean and green in manufacturing: A model of waste management. IFAC Proc. Vol. 2013, 46, 117-122. [CrossRef]

19. Rosenbaum, S. Green-lean approach for assessing environmental and production waste in construction. In Proceedings of the 20th Annual Conference of the IGLC, San Diego, CA, USA, 18-20 July 2012.

20. Folinas, D.; Aidonis, D.; Triantafillou, D.; Malindretos, G. Exploring the Greening of the Food Supply Chain with Lean Thinking Techniques. Procedia Technol. 2013, 8, 416-424. [CrossRef]

21. Pampanelli, A.B.; Found, P.; Bernardes, A.M. A Lean \& Green Model for a production cell. J. Clean. Prod. 2014, 85, 19-30.

22. Risk Management_-Guidelines; The British Standards Institution: London, UK, 2018.

23. Yaakub, S.; Mustafa, H.K. Supply Chain Risk Management for the SME's. Acad. J. Interdiscip. Stud. MCSER Publ. 2015, 4, 151-158. [CrossRef]

24. Manuj, I.; Mentzer, J.T. Global supply chain risk management strategies. Int. J. Phys. Distrib. Logist. Manag. 2008, 38, 192-223. [CrossRef]

25. Natarajan, D. ISO 9001 Quality Management Systems, Management and Industrial Engineering; Springer International Publishing AG: New York, NY, USA, 2017.

26. Garvey, M.D.; Carnovale, S.; Yeniyurt, S. An analytical framework for supply network risk propagation: A bayesian network approach. Eur. J. Oper. Res. 2015, 242, 618-627. [CrossRef]

27. Zsidisin, G.; Panelli, A.; Upton, R. Purchasing organization involvement in risk assessments, contingency plans, and risk management: An exploratory study. Supply Chain Manag. Int. J. 2000, 5, 187-198. [CrossRef]

28. Zsidisin, G. A grounded definition of supply risk. J. Purch. Supply Manag. 2003, 9, 217-224. [CrossRef]

29. Manuj, I.; Mentzer, J.T. Global supply chain risk managemenT. J. Bus. Logist. 2008, 29, 133-155. [CrossRef]

30. Louis, M.; Pagell, M. Categorizing Supply Chain Risks: Review, Integrated Typology and Future Research. Integrated Typology and Future Research; Springer: Berlin/Heidelberg, Germany, 2019.

31. Shahbaz, M.S.; Rasi, R.Z.R.; Ahmad, F. A novel classification of supply chain risks: Scale development and validation. J. Ind. Eng. Manag. 2019, 12, 201-218. [CrossRef]

32. Xu, M.; Cui, Y.; Hu, M.; Xu, X.; Zhang, Z.; Liang, S.; Qu, S. Supply chain sustainability risk and assessment. J. Clean. Prod. 2019, 225, 857-867. [CrossRef]

33. DuHadway, S.; Carnovale, S.; Hazen, B. Understanding risk management for intentional supply chain disruptions: Risk detection, risk mitigation, and risk recovery. Ann. Oper. Res. 2019, 283, 179-198. [CrossRef]

34. Drew, J.; McCallum, B.; Roggenhofer, S. Objectif Lean; Eyrolles: Paris, France, 2004.

35. Karvonen, T.; Rodriguez, P.; Kuvaja, P.; Mikkonen, K.; Oivo, M. Adapting the lean enterprise self-assessment tool for the software development domain. In Proceedings of the 38th Euromicro Conference on Software Engineering and Advanced Applications, Washington, DC, USA, 5-8 September 2012; pp. 266-273.

36. Duarte, S.; Cruz-Machado, V. An Investigation of Lean and Green Supply Chain in the Industry 4.0. In Proceedings of the 2017 International Conference on Industrial Engineering and Operations Management (IEOM), Bristol, UK, $24-25$ July 2017.

37. US Environmental Protection Agency. Lean Manufacturing and the Environment: Research on Advanced Manufacturing Systems and the Environment and Recommendations for Leveraging Better Environmental Performance; US Environmental Protection Agency: Washington, DC, USA, 2003.

38. Breka, J.N.; Gaultier-Gaillard, S. La Supply Chain Verte Dans Les Entreprises Agroalimentaires Françaises: Freins Et Motivations Association de recherches et publications en management. Gestion 2000 2013, 30, 15-31. [CrossRef]

39. Carneiro, S.B.D.M.; Campos, I.B.; Lins, D.M.D.O.; Barros Neto, J.D.P. Lean And Green: A Relationship Matrix. In Proceedings of the 20th Annual Conference of the International Group for Lean Construction, San Diego, CA, USA, 18-20 July 2012.

40. Dube, A.; Gawande, R. Green Supply Chain Management-A literature review. Int. J. Comput. Appl. 2011, 8887, 975.

41. Al-Aomar, R.; Weriaka, D. A framework for a green and lean supply chain: A construction project application. In Proceedings of the 2012 International Conference on Industrial Engineering and Operations Management, Istanbul, Turkey, 3-6 July 2012. 
42. Patil, G.; Dolas, D. Green Supply Chain Management: A Review. Int. Res. J. Eng. Technol. 2015, 2, 1095-1099.

43. Fremy, O.; de Cheffontaines, C.; Chassende-Baroz, E.; Fontanille, O. Pratique du Lean, Réduire les Pertes en Conception, Production et Industrialisation; Préface de Yasuhiko Izumimoto: Paris, France, 2010.

44. Giannakisa, M.; Papadopoulosb, T. Supply chain in sustainability: A risk management approach. J. Prod. Econ. 2016, 171, 455-470. [CrossRef]

45. Brunelli, M. Introduction to the Analytic Hierarchy Process. Pract. Decis. Mak. 2015. [CrossRef]

46. Bhushan, N. Strategic Decision Making: Applying the Analytic Hierarchy Process; Springer: London, UK, 2004.

47. Alonso, J.A.; Lamata, T. Consistency in the Analytic Hierarchy Process: A New Approach. Int. J. Uncertain. 2006, 14, 445-459. [CrossRef]

48. Remy Hasan, P.M.; Bernard, A. L'intégration de l'approche TRIZ dans le processus d'utilisation du modèle générique de la situation de travail: Cas d'une ligne d'imprimerie. In Proceedings of the 4th International Industrial Engineering Conference, Aix-Marseille, France, 2-4 June 2001.

49. Cavallucci, D. TRIZ-The Theory of Inventive Problem Solving Current Research and Trends in French Academic Institutions; Springer International Publishing: New York, NY, USA, 2017.

50. Eltzer, T.; Guio, R.D. Constraint based modelling as a mean to link dialectical thinking and corporate data, Application to the Design of Experiments, in Trends in Computer Aided Innovation. In Proceedings of the Second IFIP Working Conference on Computer Aided Innovation, Michigan, MI, USA, 8-9 October 2007; pp. 145-155.

51. Moussa, F.Z.B.; De Guio, R.; Dubois, S.; Rasovska, I.; Benmoussa, R. Study of an innovative method based on complemntarity between ARIZ, lean management and discrete event simulation for solving warehousing problems. Comput. Ind. Eng. 2019, 132, 124-140. [CrossRef]

52. Dubois, S.; De Guio, R.; Rasovska, I. Different ways to identify generalized system of contradictions, a strategic meaning. Procedia Eng. 2011, 9, 119-125. [CrossRef]

53. Gadd, K. TRIZ for Engineers: Enabling Inventive Problem Solving; John Wiley \& Sons: Hoboken, NJ, USA, 2011.

54. Andersen, B.; Fagerhaug, T.N. ASQ Pocket Guide to Root Cause Analysis; American Society for Quality: Milwaukee, WI, USA, 2013.

55. Vorley, G. Mini Guide to Root Cause Analysis. Geoff Vorley MSc. MCQI, Mini Guide to Root Cause Analysis; Quality Management \& Training Limited: London, UK, 2008. 